\title{
OJIBWE DISCOURSE MARKERS
}

\author{
A DISSERTATION \\ SUBMITTED TO THE FACULTY OF THE GRADUATE SCHOOL \\ OF THE UNVERSITY OF MINNESOTA \\ BY
}

Brendan George Fairbanks

IN PARTIAL FULFILLMENT OF THE REQUIREMENTS

FOR THE DEGREE OF DOCTOR OF PHILOSOPHY

Jeanette Gundel, John D. Nichols

August, 2009 
(C) Brendan George Fairbanks 2009 


\section{Acknowledgements}

I am indebted to the elders of the Mille Lacs Band of Ojibwe without whom this work would not have been possible, and thankful for their patience as I bombarded them with my endless questions. Miigwech gidinininim: Biidaabanookwe (Marge Anderson), Okaadaak (Elfreda Sam), Naawigiizis (Jim Clark), Zhaawanigiizhigookwe (Millie Benjamin), Bebaamaashiikwe (Susan Shingobe), Biidwewidamookwe (Maggie Kegg), Mashkawigaabawiikwe (Virginia Davis), Gimiwan (Raining Boyd), Asinigaabawiikwe (Carol Nickoboine), Amikogaabaw (Larry Smallwood), Obizaan (Lee Staples), and Naawigiizis (Frank Mason). All these elders allowed me free access to their brains and their intuitions about the language data contained in this thesis. I would especially like to thank Marge Anderson for letting me text and call her anytime I wanted to ask her a million questions and to pick her brain! This was invaluable. I would also like to thank Lillian Rice (Ogimaakwe) also in helping me to understand many of the nuances existing with many of the discourse markers examined for this thesis.

I would also like to thank the members of my committee who provided me with much need feedback and support. Their counsel and mentoring has allowed me to be a much better researcher.

I would also like to acknowledge my father for his speeches growing up about the importance of getting an education, for my mom who always said I was smart, and for my grandma who has always inspired me by her love of education and hatred of alcohol, a liquid that has done so much destruction among my own people (the Kickapoos and Ojibwes) and among other tribes. To this day, I have never had a drink because of her. 
I also want to thank my friends and colleagues who have constantly encouraged my research in the Ojibwe language. I want to thank Laura Pederson, Tony Drews, Marisa Carr, Amber Ruel, Karen McCall, Loanna Lynn Stainbrook, and Patricia Shepard, who have all been my traveling partners to Mille Lacs over the years. They have all kept me company on our long trips up to Mille Lacs.

I also want to acknowledge monetary support for this thesis from the following institutions and organizations: The Kickapoo Tribe of Oklahoma, Wicoie Nandagikendan Urban Immersion Project, the Bush Foundation, Massachusetts Indian Association, The American Indian Graduate Center, Association on American Indian Affairs, and the Minnesota Indian Scholarship. I especially want to thank Margaret Boyer and Betty Jane Schaaf of the Wicoie Nandagikendan Urban Immersion Project where I have been employed as an Ojibwe immersion teacher for allowing me to come in a little later than I should have as a result of late night dissertation writing.

Last but not least, I would like to thank my wife Chelsea who endured lonely weekends and more than her share of the housework during the writing of this thesis. 
For the elders at Mille Lacs and for my son Mekethia. 


\begin{abstract}
In this thesis, I describe the functions of a variety of discourse markers in the Ojibwe language, a language belonging to the Algonquian family of languages of North America. Discourse markers have been defined by Schiffrin as "sequentially dependent elements which bracket units of talk" (Schiffrin 1987:31), and as elements which, among other things, are syntactically detachable from a sentence (i.e. independent of sentential structure), and commonly used in initial position (Schiffrin 1987:32, 328). This thesis shows that her initial characterization must be broadened in order to account for languages such as Ojibwe which show discourse markers occurring in both initial and second position, and for other languages which show discourse markers occurring in medial and final positions. Also, since many languages like Ojibwe and the Amazonian languages examined in this thesis make regular use of clitics and affixes as discourse markers, I show that not all discourse markers are 'detachable' from their containing sentences. Based upon this and other cross-linguistic evidence, I offer a definition of discourse markers which essentially refines Schiffrin's characterization.

This thesis ultimately reveals the exploitive nature of language (and ultimately of its speakers) in regards to discourse. While languages show that individual words, particles, lexicalized phrases, clitics, and affixes may be 'exploited' for their sentence-level functions for work at the discourse level, Ojibwe shows that entire inflectional systems may also be targets for discourse work. For example, Ojibwe exploits the sentence-level cohesive function of conjunct verbs in order to mark the eventline structure of a narrative. This accounts for the seemingly contradictive ability of conjunct verbs to serve as subordinate clauses at the sentence level, but as independent clauses at the discourse level. Such behavior, termed in this thesis as "discourse marking," shows that the use of morphological forms must also be included within a viable definition of discourse markers.
\end{abstract}




\section{Table of Contents}

Acknowledgements

Abstract

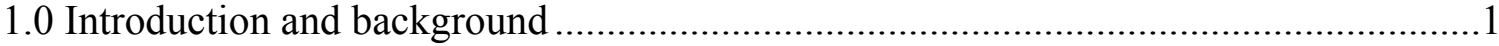

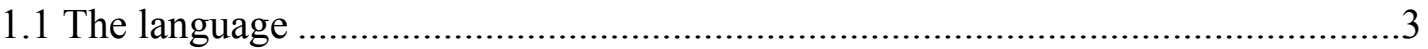

1.2 Why study Ojibwe discourse markers ..............................................................

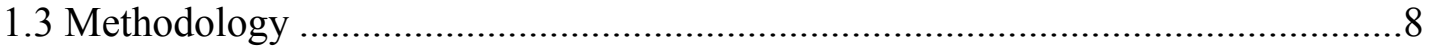

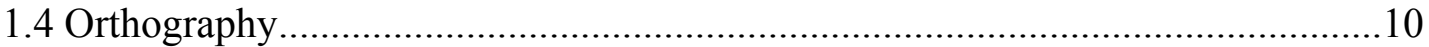

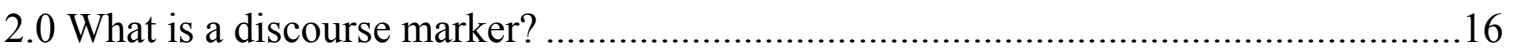

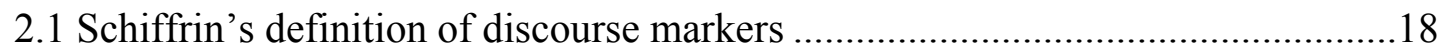

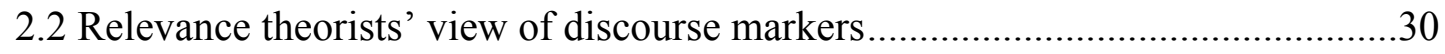

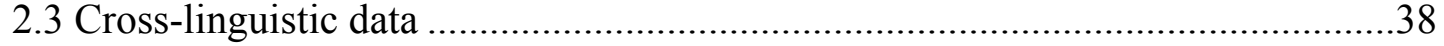

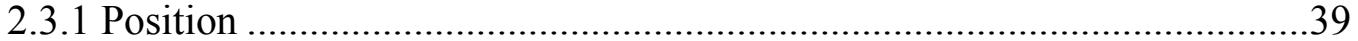

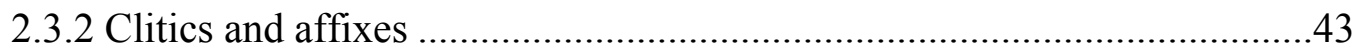

2.3.3 TAM (tense-aspect-mode) systems .....................................................46

2.3.4 Simultaneous textual and interpersonal functions of discourse markers ...48

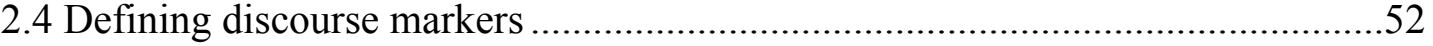

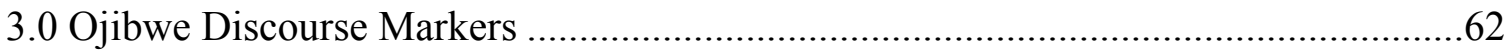

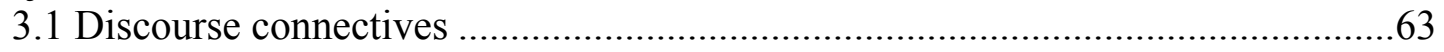

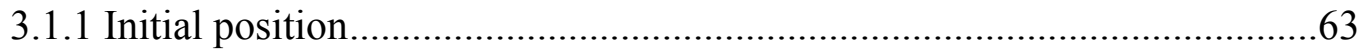

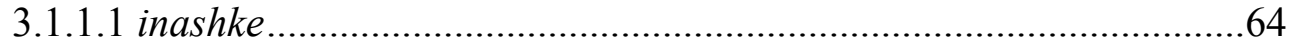

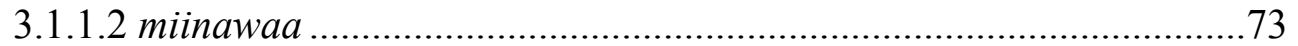

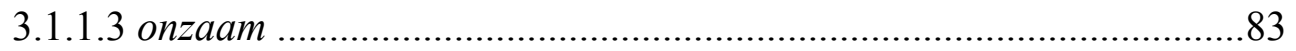

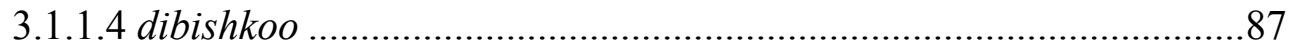

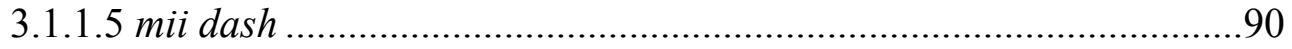

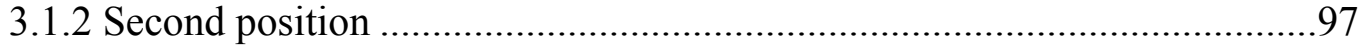

3.1.2.1 idash as a contrastive marker ......................................................98

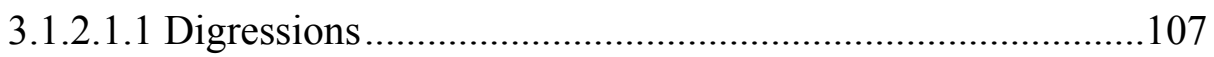

3.1.2.1.2 Backgrounding and foregrounding .................................111

3.1.2.1.3 idash in adjacency pairs .................................................114

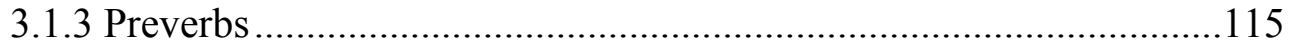

3.1.3.1 Relative preverb $i z h i$..................................................115

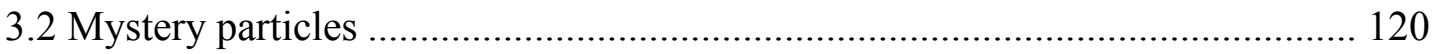

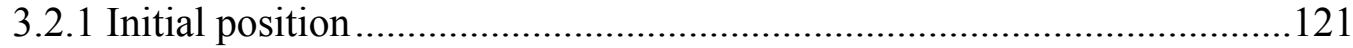

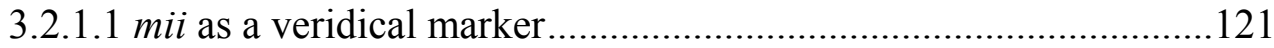

3.2.1.2 mii as a command softener ..................................................... 128



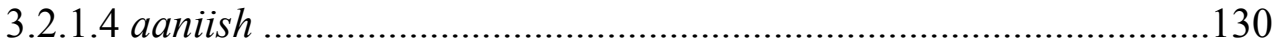

3.2.2 Second position mystery particles ................................................. 135 


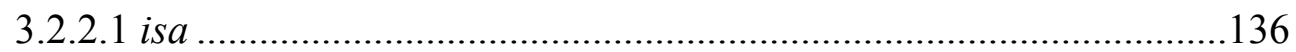

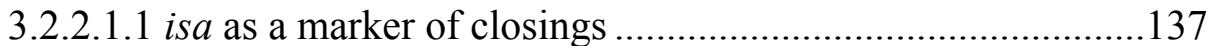

3.2.2.1.2 is $a$ as a marker of relinquishment .......................................139

3.2.2.1.3 is $a$ as a marker of conclusory gists ......................................140

3.2.2.1.4 is $a$ as a marker of resultant action..........................................143

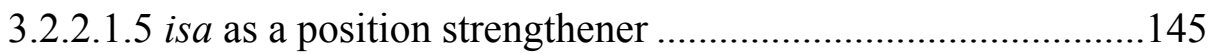

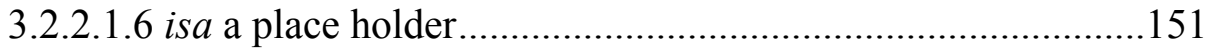

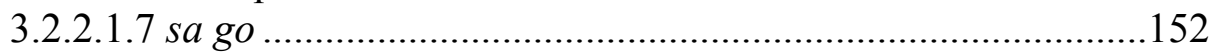

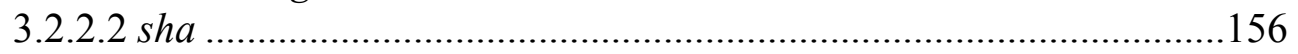

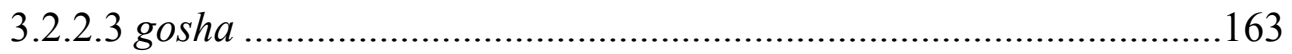

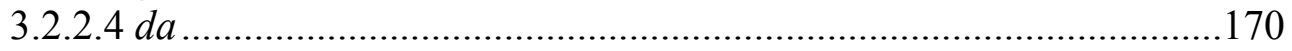

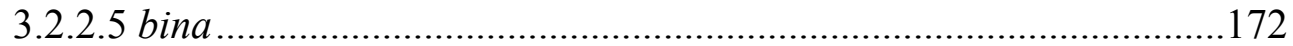

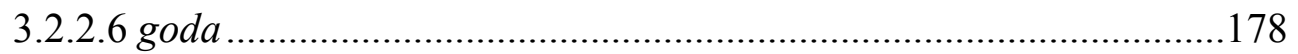

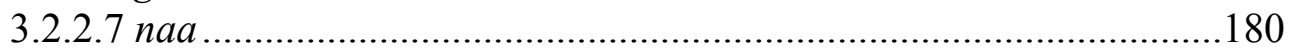

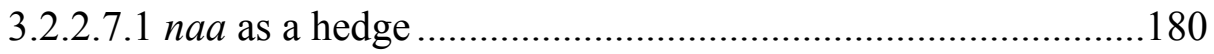

3.2.2.7.2 naa as an evidential marker ..............................................188

3.2.2.7.3 naa as a pleading particle.....................................................191

3.2.2.7.3.1 Second position discourse clusters with naa .............192

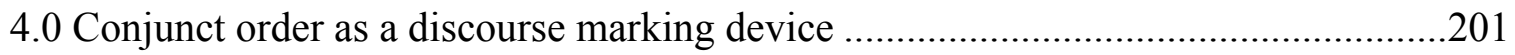

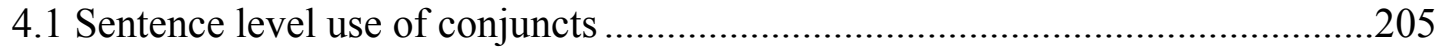

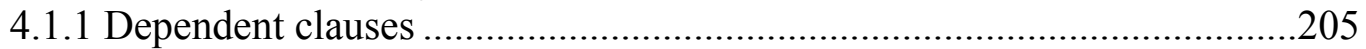

4.1.2 Temporal immediacy and the connective feature of the conjunct............208

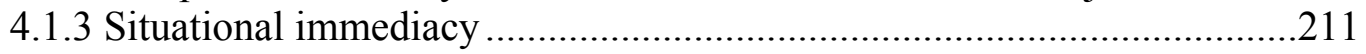

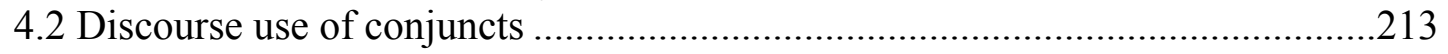

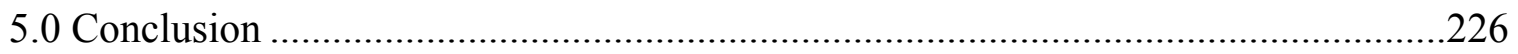

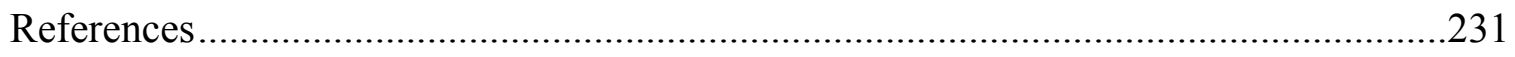




\subsection{Introduction and background}

In this thesis, I identify and describe DISCOURSE MARKERS as they occur in Ojibwe, a language belonging to the Algonquian family of languages. The particular dialect that I investigate is the one spoken by people living at the Mille Lacs Band of Ojibwe reservation located in east-central Minnesota. The topic of discourse markers in Ojibwe is largely unexplored, and many discourse markers in Ojibwe are either unknown or poorly understood. Also, discourse markers have not been the topic of debate nor discussion within the Algonquian literature, let alone within the growing cross-linguistic literature surrounding discourse markers. This thesis fills some of that void.

Ultimately, this thesis will show that there are two major functions of discourse markers: to add to the cohesiveness of a narrative ("discourse connectives"), and to contribute an interpersonal nuance to an utterance ("mystery particles"). ${ }^{1}$ Discourse connectives show a tendency to exploit grammatical features, lexical items, or even whole inflectional paradigms (all which have functions at the sentence level) in order to accomplish work at the discourse level. In a way, discourse connectives in Ojibwe live double lives, in that they are part-time sentence level elements (grammatical or lexical),

\footnotetext{
${ }^{1}$ To my knowledge, the term mystery particle was coined by Longacre (1976). He used this term to describe certain verbal and nominal affixes and sentential particles which "defy analysis even at a relatively advanced state of research" (Longacre 1976:468). He goes on to say that "the native speaker uses such affixes and particles with complete assurance but is unable to verbalize anything very concrete as to their meaning and function" (Longacre 1976:468). I am using mystery particle to describe the type of markers in Ojibwe which share this difficulty. In other words, they have no, or very little, referential meaning. While it is quite easy for speakers to come up with a definition of the discourse connective miinawaa 'and', speakers usually cannot do so for markers such as sha which have no meaning in and of itself, and which can only be defined by its use within a certain context. As it turns out, all the Ojibwe mystery particles that I describe in this thesis all happen to serve an interpersonal or pragmatic function. Many of the mystery particles described by Longacre for Amazonian languages, however, have a textual function rather than a interpersonal or pragmatic one, e.g. marking the backbone structure of a discourse. Therefore, my division between discourse connectives and mystery particles here is not meant to suggest that all mystery particles serve a pragmatic function in all languages. They just happen to in Ojibwe, and organizing them in this fashion is only a matter of convenience.
} 
and part-time discourse markers, doing work above the sentence level. Mystery particles, on the other hand, are full-time discourse markers as they are always working at a level above the sentence, indicating a variety of interpersonal functions, e.g. denial of propositions, justifications, reprimands, eliciting pity, correcting interlocutors, etc.

In more theoretical terms, this thesis contributes to the literature an account of the use of second position particles and preverbal elements as discourse markers, expanding the domain in which these elements are known to occur. This is significant as the literature to date has been virtually silent about the occurrence of discourse markers in second position, as well as those occurring as preverbs (a common grammatical element in Algonquian languages). With the contribution of the Ojibwe data, the cross-linguistic data show that discourse markers may essentially occur in any position within the domain of a sentence (or in its vicinity straddling sentence boundaries), showing that discourse markers cannot be defined by their location, as early characterizations have attempted to do (such as Schiffrin 1987). Nor can they be reliably defined by their linguistic form, since discourse markers appear to come in many forms, e.g. grammatical/lexical items, affixes, clitics, particles, including entire inflectional paradigms. Therefore, the general behavior of discourse markers cross-linguistically suggests that the identity of discourse markers and their likely locations are largely constrained by the linguistic machinery already existing in the language. For example, if a particular language does not make use of second position phenomena, we would not expect to find discourse markers in that position. The opposite case also appears to be true. If a language makes use of second position phenomena, second position would be a potential docking spot for discourse markers. The identity and the various docking spots of discourse markers are not only 
influenced by this already existing grammatical machinery, but also by grammatical options made available to speakers by language contact.

\subsection{The language}

The people at Mille Lacs normally refer to their language as Ojibwemowin, which is to be interpreted as 'Ojibwe language'. When they ask someone whether they can speak Ojibwe, they normally ask: Gidoojibwem ina? 'Do you speak Ojibwe?' (using the word ojibwemo 's/he speaks Ojibwe'). This contrasts with other sister dialects of Ojibwe where the common query is rather: Gidanishinaabem ina? 'Do you speak Indian?' (using the word anishinaabemo 's/he speaks Indian'). My personal experience has been that sister dialects situated more to the north in Canada, or those further east, make regular use of the term Anishinaabemowin 'Indian language' to describe their own language, rather than the term Ojibwemowin. This experience comes at the expense of being corrected quite often by native speakers from those areas who do not make regular use of the term Ojibwemowin to refer to their own language as I do. In his grammar of what is commonly known as the Odawa language (a sister language to Ojibwe), Valentine uses the term Nishnaabemwin to identify the language of his grammar, since "that is the term that its speakers, the NISHNAABEG (singular, NISHNAABE), typically use to identify their language" (Valentine 2001:1). ${ }^{2}$ He notes, however, that Odawa has also gone by other names such as Ottawa, Chippewa, and Ojibway. The emerging challenge here is that many dialects in Minnesota have also been known as Chippewa and Ojibway (or even Ojibwa). This, undoubtedly, can be confusing to readers who are trying to

\footnotetext{
${ }^{2}$ Speakers at Mille Lacs call themselves Anishinaabe 'Indian' as well.
} 
determine what language is being referred to by these various labels. To complicate matters further, Goddard in his discussion in the Handbook of North American Indians lumps together various dialects spoken by Indian groups such as Ojibwa, Chippewa, Saulteaux, Ottawa, Mississauga, Nipissing, and Algonquin under the label Ojibwa (see Goddard 1978:583). ${ }^{3}$ More recent classifications, however, have done away with the general Ojibwa label preferring now the term Ojibwayan to describe these various languages (Goddard 1996:4). In his foreword to the reprint edition of Baraga's famous "Otchipwe" dictionary, Nichols states that the "Otchipwe" language (Baraga's term), or as he generally refers to it, "Anishinaabemowin" is genetically related to about twentyfive other languages within the Algonquian language stock and is one of the most widespread of North American languages, being "spoken today in the United States in Michigan, Minnesota, North Dakota, and Wisconsin and in Canada in Manitoba, Ontario, Saskatchewan, and Quebec" (Nichols foreword in Baraga 1992:v-vi).

Therefore, given that term Ojibwe (and its various spellings) is often used as a blanket term to speak about a wide variety of related languages within the Algonquian language family which are spoken across a wide geographical area within the United States and Canada, it is important to distinguish the dialect being studied in this thesis from this blanket term. I, therefore, am not using the term Ojibwe to refer to a group of related Algonquian languages, nor am I suggesting that the description of "Ojibwe" discourse markers in this thesis is representative of the discourse markers existing in other "Ojibwa" dialects (although their functions and meanings may be quite similar).

\footnotetext{
${ }^{3}$ In this article, Goddard states that he did this as a convenience measure for sake of discussion, but also concedes that it was "clear that the conventional group labels just listed do not correspond well to the linguistic divisions" (Goddard 1978:583).
} 
While many speakers from other Minnesota dialects also refer to their language as Ojibwe, or Ojibwemowin, the term in this thesis refers to the variety of Ojibwe that is spoken at Mille Lacs. This is what my consultants (my elders) call it, and so I will call it that too.

1.2 Why study Ojibwe discourse markers?

As of 2008, there are over 4,000 enrolled members of the Mille Band of Ojibwe. This includes 2,100 members who live within reservation boundaries, 800 tribal members who live in the Minneapolis/St. Paul metropolitan area, 500 tribal members who live in other Minnesota towns, and 600 tribal members who live elsewhere in the United States and other places (Mille Lacs Band of Ojibwe website, 2008). The language spoken by the people of the Mille Lacs Band of Ojibwe is the Ojibwe language, and is an endangered language. Recent estimates reveal that only an estimated 80 fluent speakers remain out of these 4,000 enrolled tribal members, putting their current fluency rate (i.e. number of fluent speakers) at about two percent (Marge Anderson, personal communication). At Mille Lacs, all native speakers of Ojibwe are over fifty years of age.

The current state of the language for other Minnesota Ojibwe reservations is similar. In 1997, it was estimated that the White Earth Band of Chippewa (Ojibwe) had a fluency rate of one percent and that the Leech Lake Band of Ojibwe had a four percent fluency rate (Treuer 1997). It is likely, however, that the current number of speakers at White Earth and Leech Lake is now even lower. The number of fluent speakers for the other Minnesota Ojibwe bands such as Red Lake, Nett Lake, and Grand Portage, is unknown, but these bands reportedly share similar decreases in the number of native speakers. 
In response to a decline in speakers, there has been a recent movement to preserve and revive the Ojibwe language. This is evident in the many active community language classes, email lists, conferences, the publishing of language materials in various formats, and the recent move towards immersion education at both the pre-school and elementary levels. The Ojibwe language is also taught at various universities and tribal colleges.

There is also a growing number of fluent second language speakers of Ojibwe. These are usually young people who are of Ojibwe heritage who did not grow up speaking Ojibwe, but who have since attained a level of fluency as adults. Many of these second language speakers have become immersion teachers within the many emerging Ojibwe immersion programs across Minnesota and Wisconsin. Incidentally, many of these young immersion teachers are now speaking to their own children in the Ojibwe language.

While a long history of Algonquianist linguistics has brought to light many complex insights about the Ojibwe language as a whole, especially in the inflectional system and historical developments, there remain many aspects of Ojibwe which remain unexplored and misunderstood. There is no academic research that focuses on the general area of discourse for Minnesota Ojibwe (but see Rhodes 1979 for his work on what he identifies as the Central Ojibwa/Ottawa dialect), let alone research on discourse markers. To my knowledge, discourse markers are also not taught as part of the Ojibwe language curriculum at the university level, nor, from my vantage point, are they a significant part of second language speech. Their proper use and function, for the most part, is just not known. For example, the second position contrastive marker idash 'but, then' (to be 
discussed within the body of this thesis) is being taught to students at some Minnesota universities and colleges to be a sentence-initial element, a usage similar to the English additive marker and. ${ }^{4}$ This stems largely from the fact that the instructors at these particular institutions are non-native speakers themselves, and have apparently repatterned the use of second-position element idash to conform to the English usage. The other discourse structuring element $i z h i$ 'and then, and so' (also to be discussed), as well as a whole slew of other discourse particles, appear (from my vantage point) to be largely non-existent in the speech of even fluent second language speakers. Thus, discourse markers as a token of language use are largely unexplored and are a widely misunderstood area of the language. Also, because university curricula and many selfpublished grammars to date usually only amount to re-workings of prior research, revealing a scarcity of new research, further documentation and new research in the area of discourse markers would serve to broaden our knowledge and scope of the Ojibwe language as a whole. ${ }^{5}$

In formal linguistic circles, a study of discourse markers in Ojibwe would be a significant contribution to the area of discourse marker research in general, since the

\footnotetext{
${ }^{4}$ Some students from these institutions end up teaching in immersion programs. The concern here, of course, is that the incorrect use of discourse markers (as well as other syntactic phenomena) will be transmitted to the children participating in these immersion programs. Though many times native speaking elders accompany these younger speakers in the classroom, it is the language of the younger second language speaker that is primarily modeled for these children. Such a scenario appears to be common in immersion settings, since the younger, energetic speakers are usually the ones running classroom activities. ${ }^{5}$ What I mean here is that because many of the student grammar books for Ojibwe are largely written by non-native speakers (who are usually not linguists), the material that appears in these grammars typically do not represent new research, but largely amounts to re-workings (or re-hashings) of previously published materials, e.g. a heavy reliance on Baraga's grammar. Alternatively, if new aspects of the language are explored, they are usually not adequately characterized. While these grammars have their value, we are not moving on to new unexplored territory in the Ojibwe language. My point here is that we need new research on the Ojibwe language in order to capture what we still do not know about the language. There are student grammars, however, written by native speakers which have greatly added to our knowledge and insight to the language. One of these is the grammar written by Pat Ningewance (Ningewance 2004), a native speaker from Lac Seul, Ontario. We need more of these too!
} 
Ojibwe data presents a number of problems for the current theoretical characterization of discourse markers. The description of discourse markers provided in this thesis ultimately broadens our knowledge of the behavior of discourse markers in language in general and contributes to an already growing cross-linguistic body of work on the subject. Therefore, while this thesis is intended to be primarily a descriptive piece with the intention of preserving, documenting, and reviving the Ojibwe language, it will contribute to broader theoretic concerns as well.

\subsection{Methodology}

For an endangered language such as Ojibwe, there are not many sources from which to garner examples of discourse marker use. For example, in Minnesota, there are no radio broadcasts, television shows, newspapers, nor are there many books which are entirely published in Ojibwe. ${ }^{6}$ There is, however, a multitude of published texts (i.e. stories and narrations by various native speakers, including Mille Lacs speakers) available in issues of Oshkaabewis Native Journal (an academic journal), Omaa Akiing (Treuer 2000), Living Our Language (Treuer 2001), and Portage Lake (Kegg 1991). For this thesis, I examined texts by Mille Lacs speakers published in the Oshkaabewis Native Journal and Portage Lake and unpublished texts personally collected from my consultants. I also consulted my field notes taken over a period of 5 years of meetings with my consultants. My notes include a number of recorded tokens of discourse marker

\footnotetext{
${ }^{6}$ The New Testament has been translated entirely into Ojibwe (1875, published by the American Bible Society). Anton Treuer published a book in Ojibwe, called Omaa Akiing (Treuer 2000), which is largely a compilation of Ojibwe stories that he previously published in the Oshkaabewis Native Journal (published by Bemiji State University) and in his book Living Our Language : Ojibwe Tales \& Oral Histories (Treuer 2001). The Mille Lacs Band of Ojibwe published a CD of children's songs performed in the Ojibwe language, called Baswewe ("echo").
} 
use as they occurred in real time within interactions between speakers themselves, or with those of us visiting the elders.

Many of the texts published in the Oshkaabewis Native Journal, however, were limited in their usefulness for a rigorous study of discourse markers. One problem that these texts presented was that many of the authors of these published stories did not make it a practice to check their transcriptions and translations with their original speakers (or any other native speaker) for accuracy. Therefore, many of these published texts are riddled with both transcription and translation errors. In such cases, where there was an accompanying audio provided with the transcription (which is a common practice for the Oshkaabewis Native Journal), I redid both the transcription and translations for those that I looked at for purposes of this thesis, and checked my work with my consultants at Mille Lacs. These corrected texts provided a much clearer picture of discourse marker use. The Portage Lake texts, though not accompanied by original audio, were quite reliable as the editor of those texts vigorously worked out both the translation and transcription with the author of the stories. Many examples of discourse marker use are cited throughout this thesis. In regards to actual discourse marker usage either found in stories or within my notes, I queried my consultants as to their various meanings and usage. Many times, my consultants were easily able to provide translations for discourse markers, but other times they could not. This is no surprise, however, since discourse markers are notoriously difficult to translate. In all cases, however, I gave great attention to the context in which markers were used, and in what capacity they were being used. I have tried to incorporate these various contexts within the characterizations of the discourse markers appearing in this thesis. 
The description of these elements which one of my consultants described as "little bugs that are holding on for dear life" (Clark 2008, personal communication), and elements which I have analyzed as discourse markers, should not be viewed as exhaustive. My goal was only to provide a description of the most common uses for these markers found within stories and within the speech patterns of my consultants, so as to illuminate their core functions - core functions, which to date, have been either unknown, misunderstood, or unexplored. There are undoubtedly, however, other nuances and functions for many of these markers that remain unknown, or are inadequately described in this thesis. This thesis, it is hoped, will provide a starting point for further research into the topic of discourse markers in Ojibwe.

\subsection{Orthography}

The orthography (commonly known as the DOUBLE VOWEL ORTHOGRAPHY) used in this paper is the one devised by Charles Fiero for Ojibwe, a phonemic system now widely used by language teachers and linguists alike in both the United States and Canada (see also Nichols 1995:xxiii, Valentine 2001:29). Vowel length in Ojibwe is distinctive and Fiero's system has the advantage of capturing this feature. In short, identical vowels which are doubled represent long vowels, and single vowels represent short vowels. The long vowels are: $a a, i i, o o$, and $e$; and the short vowels are: $a, i, o{ }^{7}$ Nasal vowels are represented by the vowel followed by $-n h$, e.g. aanh, enh, iinh, oonh, rather than with the ${ }^{\sim}$ symbol used in IPA. Vowels which are nasalized before $s, s h, z$, or $z h$ are usually marked by the vowel followed by just $-n$, rather than $-n h$, e.g. oshkanzhiin

\footnotetext{
${ }^{7}$ Note that because long vowel $e$ has no short vowel counterpart, it is written as single vowel $e$, rather than as doubled vowel ee.
} 
‘someone's fingernail' (see Nichols and Nyholm 1995:xxv for full discussion of this convention).

The consonants consist of six lenis consonants, which often occur voiced at the word-initially, word-medially, and show devoicing word-finally: $b, d, g, j, z, z h[\mathrm{~b}, \mathrm{~d}, \mathrm{~g}$, क, z, 3]; their six fortis counterparts, which are voiceless and geminate (though not orthographically represented as such): $p, t, k, c h, s, s h$ [p:, t:, k:, tf:, s:, f:]; two nasals: $m, n[\mathrm{~m}, \mathrm{n}]$; two glides: $w, y[\mathrm{w}, \mathrm{j}]$; and two glottal consonants: $\mathrm{h},{ }^{\prime}[\mathrm{h}, \mathrm{P}]$ (see also Nichols and Nyholm 1995:xxvi-xxviii for more discussion).

The use of the double vowel orthography within this thesis represents a break from the traditional orthography used by others in earlier work on Ojibwe. For example, in his dissertation titled Ojibwe Morphology, Nichols largely followed Leonard Bloomfield's orthography which made the relationship between lenis (voiced, short) and fortis consonants (voiceless, long) morphologically transparent, representing the lenis consonants $p, t, k, c, s, \check{s}$ as orthographically doubled in the representation of the fortis consonants $p p, t t, k k, c c, s s, \check{s}$. This had the advantage of showing the morphological relationship argued to exist between lenis and fortis consonants in Ojibwe and its various dialects, namely, that the juxtaposition of two identical lenis consonants as a result of some morphological or phonological process results in the formation of a fortis consonant (see Valentine 2001:76-78, Bloomfield 1958:viii, but see also Hockett's forward in Bloomfield 1958 where he argues for the analysis of fortis consonants as clusters, rather than as single phonemes). While the representations of short and long vowels remain identical to Nichols's treatment (e.g. doubled vowels to show long vowel length), the use 
of the double vowel orthography sacrifices the ability to show the relationship between the lenis and fortis consonants as effectively. For example, while the fortis consonants are actually long consonants, or geminate, learners who rely upon reading for pronunciation often do not recognize this and many times pronounce geminate consonants as non-geminate, e.g. fortis (geminate) consonant $s h$ in zhiishiib [zhiš.šib] 'duck' as non-geminate $s h$ as in [zhi.šsib]. In other words, readers unaware of the geminate nature of the Ojibwe fortis consonants may view the distinction between the lenis obstruent $z h$ and its fortis counterpart $s h$ as being one only of voicing, rather than length. Despite this small disadvantage, however, the double vowel orthography has increased overall readability, since it allows learners to accurately pronounce short and long vowels.

With regard to the use of hyphens, it has been a common practice with the double vowel orthography to offset tense markers and other preverbal elements or prenouns from their host words by the use of hyphens, such as in the verb phrase gaa-izhi-wiisinid 'and so s/he ate', which is made up of the past tense marker gaa (ablaut form of gii), the relative root $i z h i$ 'and so', and the verb wiisini 's/he eats' (inflected for third person). Since common interlinear glossing conventions in linguistics papers also utilize hyphens to offset morphological content within words, the use of hyphens in this thesis may be confusing to those unfamiliar with the use of hyphens in the double vowel orthography. Most of the interlinear glosses provided in this thesis, however, will be broad and will not utilize hyphens to separate content below the word level. The use of hyphens, for the most part, will reflect the normal use of hyphens within the double vowel orthography. 
In some cases, however, where a narrow gloss is necessitated, hyphens may be used to offset morphological content below the word level, but the gloss itself will be specific enough so as to make it clear what is being offset. For example, clitic elements which normally would not be explicitly marked in the gloss as clitics will be specifically marked as such $($ clitic $=$ "CL") in narrow interlinear glosses. This practice will be applied to other elements not explicitly marked or accounted for in the broad glosses.

In regards to clitics, the common convention for Ojibwe has been to simply leave them unattached as separate words, rather than to use hyphens to attach them to their host words. For example, for the sentence mii go ge-zhi-wawaabishkiganzhiiyan 'you will have telltale white spots on your fingernails', all preverbal elements such as the emphatic clitic $g o$, tense marker $g e$ 'future', relative root $i z h i$ 'and so', as well as the main verb wawaabishkiganzhiiyan 'that you have telltale white spots on your fingernails' are offset by hyphens. This is the normal practice, but because I have analyzed go as a clitic (its full form being igo), I normally adjoin clitics to their hosts with a hyphen, for example, mii-go rather than mii go. There is some evidence to suggest that such a practice is warranted. For example, one of my consultants who could write the double vowel orthography, but who did not utilize hyphens, normally adjoined clitics to their hosts while also adjoining all tense markers and other preverbal content seamlessly with the main verb yielding the following arrangement: miigo gezhiwawaabishkiganzhiiyan 'you will have telltale white spots on your fingernails'. My consultant's arrangement shows that she intuitively prefers to adjoin a clitic such as the emphatic go to its host word mii, yielding miigo rather than mii go. If a clitic such as the emphatic go appears in its full form as igo instead, I usually write it as a separate word although my consultant still 
preferred to write the full form igo as adjoined, e.g. boochigo, rather than separated as in booch igo. ${ }^{8}$ The reason for this stems from the fact that a minimal word in Ojibwe is bimoraic. In other words, the shortest content words in Ojibwe must be words consisting of either two short vowels such as $a s h i$ 'put him/her there', or a word consisting of one long vowel such as miizh 'give it to him/her' (see also Hayes 1995:217 for a similar analysis for Eastern Ojibwa). ${ }^{9}$ In the case of igo, its distribution (a full accounting of which is beyond the scope of this thesis) appears to suggest that igo is its full form, and its clitic form is the phonologically reduced go. While it may be tempting to analyze the initial segment on igo as epenthetic $i$, this appears to be negated by the fact that $g o$ may appear on words ending in a consonant without a connective vowel, such as in wiin-go ogii-ayaan aw gwiiwizens ge-miijid 'the boy always had something to eat'. This suggests that the initial segment on igo is not epenthetic $i$ and that igo, when it occurs, is indeed the full form. Such a practice will also be extended to discourse markers which have full forms and clitic forms.

There are times when traditional convention takes precedence over the practice of using hypens to connect clitics to their host words. For example, in the case where the particle mii combines with the contrastive particle idash to get miish 'and then', strict

\footnotetext{
${ }^{8}$ William Jones, a Fox Indian and a native speaker of Fox, who transcribed many Ojibwe stories in the early 1900s often adjoined what may be analyzed as clitics to their host words. Here are some random examples from his transcriptions followed by the convention I use in parentheses: $m \bar{i} s a^{\prime}$ (mii-sa), mìdac (mii-dash, although the convention has been to leave separated as mii dash), migu (mii-go), and one not involving mii: cigwasa (zhigwa-sa). See Jones 1919 for further investigation. I have to admit though that my hyphen usage may not be entirely consistent as aesthetics also play a role in my decision making about hyphen usage. For example, if adherence to $m y$ convention for hypens would result in what I see as an unattractive expression, such as in mii-sa-go namaj 'I have no idea', I usually minimalize the number of hyphens which occur, preferring instead mii-sago namanj. Note that the traditional method would leave all elements separated as mii sa go namanj. In short, the general orthographical conventions for written Ojibwe are far from standard.

${ }^{9}$ Function words, such as the Ojibwe demonstratives, may occur as mono-moraic however, but they are truncations of bimoraic words, e.g. $a w$ from $a^{\text {'aw ' }}$ 'that (animate)' and $i w$ from $i^{\prime} i w$ 'that (inanimate)', and many times may cliticize to their head nouns, e.g. i-mashkiki 'that medicine' from full form i'iw mashkiki.
} 
adherence to the rule suggested here demands that this be written as mii-sh. The convention, however, has been to write this combination as simply miish. In such cases, I will stick to convention.

While hyphens most likely will have little benefit for the native speaker reader, the use of hyphens in written Ojibwe serves to delineate for non-native speaking readers (and language learners) the various levels of morphological complexity which exist in even the simplest of phrases or sentences. For this reason, I make regular use of hyphens in this thesis, including the use of hyphens to attach clitics to their host words (a practice done by others, as noted by Valentine 2001:72). Sentences quoted from already published texts that utilize the double vowel orthography, I keep the orthographic style of the published work even if it means keeping clitics unattached. If I had to transliterate any transcriptions written in a different orthography, this is duly noted. If I had to rework any transcriptions because of poor transcription quality on the part of the original collector (which I had to do on occasion for the purposes of this thesis), I use the convention of attaching clitics to their host words using hyphens in $m y$ version of the transcription provided in this thesis. In such cases, the audio is cited rather than the published text, but I still provide the page number so that readers may quickly find the original text (albeit, my version of the transcription may differ from the published transcription). 


\subsection{What is a discourse marker?}

There has been a struggle in the literature to precisely define the elements which are widely known as DISCOURSE MARKERS (the term to be used in this thesis). This situation has been compounded by the many names by which these elements are known, for example (just to name a few): DISCOURSE MARKER (Schiffrin 1987, Brody 1989, Jucker \& Ziv 1998, Fraser 1990), PRAGMATIC MARKER (Brinton 1996), DisCOURSE PARTICLE (Schourup 1985, Massam et al. 2006, Davidsen-Nielsen 1996, Hakulinen 1998), UtTerance PARTicle (Kwong 1989), ConNeCtive (Park 1999, Sadler 2006), and DisCourSe CONNECTIVE (Biq 1990), ${ }^{10}$ and by the many functions that discourse markers are said to have, such as: "discourse connectors, turn-takers, confirmationseekers, intimacy signals, topic-switchers, hesitation markers, boundary markers, fillers, prompters, repair markers, attitude markers, and hedging devices" (Jucker and Ziv 1998:1, 2).

Perhaps the biggest difficulty in pinning down a definition, or in delimiting these elements into some sort of distinct category, stems from the fact that linguistic items or expressions serving as discourse markers are members of various distinct word classes "as varied as conjunctions (e.g. and, but, or), interjections (oh), adverbs (now, then), and lexicalized phrases (y'know, I mean)" (Schiffrin 2001:57). This also forces the question as to whether these are the only word classes from which discourse markers could be drawn (as noted by Schiffrin 1987:40). ${ }^{11}$

\footnotetext{
${ }^{10}$ Both Brinton (1996) and Jucker \& Ziv (1998) also give sizeable lists of names for these elements.

${ }^{11}$ This thesis, in fact, will expand the known word classes or categories from which discourse markers may be drawn.
} 
To further compound an already complex situation, there is also some disagreement in the literature on which particular linguistic expressions qualify as discourse markers, and which do not. For example, while Schiffrin $(1987,2001: 66)$ characterizes expressions such as $y^{\prime}$ know as a discourse marker, Fraser (1990:392) does not. While Schourup (1985) includes interjections such as $a h a$ as a discourse marker, Fraser (1990:391), does not. These disagreements stem, no doubt, from the fact that the study of discourse markers is relatively new. There were only scattered studies on these elements in the 1980s, when serious study of discourse markers in English began (Fraser 1990:384). Since then, a vast amount of literature, including cross-linguistic studies, has appeared leading Fraser to conclude that "the study of discourse markers has turned into a growth industry in linguistics, with dozens of articles, both theoretical and descriptive, appearing yearly" (Fraser 1998:301). While earlier scholarly works have produced various definitions for discourse markers (see Goldberg 1980, Schourup 1985, Blakemore 1987, Schiffrin 1987, Fraser 1990, Redeker 1990:372, et al.), the vast majority of literature on discourse markers to date relies heavily on the characterization made by Schiffrin for English discourse markers (Schiffrin 1987), and most papers on the topic of discourse markers appear to cite her initial characterization. Because her framework provides, in my opinion, the most comprehensively descriptive view of the behavior of discourse markers, I will both utilize and expand her initial characterization to include findings from languages other than English, including Ojibwe. Even at the time of her initial characterization, Schiffrin admitted that she did not have the benefit of crosslinguistic data to inform her definition for discourse markers. In the following sections, I hope to tighten up this definition based upon such cross-linguistic evidence. 


\subsection{Schiffrin's definition of discourse markers}

Much of the literature relies heavily upon the characterization that Schiffrin made for discourse markers, as many scholarly works and articles cite her initial characterization. That initial characterization was made in her 1987 work, where Schiffrin operationally defined discourse markers as "sequentially dependent elements that bracket units of talk (1987a:31), i.e. nonobligatory utterance-initial items that function in relation to ongoing talk and text" (Schiffrin 1987a:31, Schiffrin 2001:57). Schiffrin analyzes the following items as discourse markers: ${ }^{12}$

(1) English discourse markers (from Schiffrin 1987a:327) ${ }^{13}$
a) oh, well
(particles)
b) and, but, or, so, because
(conjunctions)
c) now, then
(time deictics)
d) y'know, I mean
(lexicalized clauses)

By "sequentially dependent elements," she means those elements which function at the discourse level (i.e. above the sentence), and which are not dependent upon their containing clauses, or smaller units of talk, but are sequentially dependent on the structure of the discourse (see Schiffrin 1987:39-40). For example, the coordinating

\footnotetext{
${ }^{12}$ An "operational definition" allowed the reader, not yet familiar with the identification and designation of discourse markers, to be able to follow her analysis.

${ }^{13}$ These are only the discourse markers she considered in her analysis, but she acknowledges the existence of others, e.g. the perception verbs see, look, and listen; the locative deictics here, there; the adverbial why; interjections gosh, boy; the verb say, meta-talk such as this is the point, what I mean is...; and the quantifier phrases anyway, anyhow, and whatever (Schiffrin 1987a:327-328).
} 
conjunction and (in sentence level grammar) may only link items of the same word class or sentence constituent, but when used as a discourse marker (above the sentence level), and may link distinct linguistic units. For example, in (2) below, discourse marker and links a declarative sentence with an interrogative sentence, showing dependence not upon smaller linguistic units (such as when and connects two noun phrases or two verb phrases), but upon the discourse structure itself.

(2) Discourse marker and linking distinct units (from Schiffrin 1987:38)

$\left.\begin{array}{l}\text { Debby: I don't }\left[\begin{array}{l}\text { like that. } \\ \text { Zelda: }\end{array}\right] \text { don't like }\end{array}\right]$ that. And, is he accepting it?

By "brackets," she means the marking of the boundaries of discourse units, or what she calls "units of talk" (Schiffrin 1987:31). The term "units of talk" is intentionally kept vague in this definition since discourse markers do not demarcate only sentences, but may mark other units of talk such as a propositions, speech acts, or tone units (see Schiffrin 1987:31). According to Schiffrin, “[m]eta-linguistic brackets, for example, can mark a discourse unit as long as a conversation or as short as a word; they can mark units embedded within larger units, e.g. reasons within explanations, or answers within question/answer pairs" (Schiffrin 1987:36). So, it is in this manner that the term "bracket" is being used in her operational definition.

Later in that work, her operational definition for discourse markers was refined into a more theoretical one, where she tentatively ("tentative" because she admittedly did not have the benefit of cross-linguistic data to inform her formulation) specifies the 
conditions that would allow an expression to be used as a discourse marker. ${ }^{14}$ Her conditions are given below.

(3) Schiffrin's “tentative suggestions” (Schiffrin 1987:328)

a) "it has to be syntactically detachable from a sentence

b) it has to be commonly used in initial position of an utterance

c) it has to have a range of prosodic contours (e.g. tonic stress and followed by a pause, phonological reduction)

d) it has to be able to operate at both local and global levels of discourse, and on different planes of discourse this means that it either has to have no meaning, a vague meaning, or to be reflexive (of the language, of the speaker)"

In order to understand her theoretical definition, it is first important to understand her framework for discourse. This is the framework in which she embeds both her understanding and characterization of discourse markers in general. In regards to understanding discourse markers, she states:

\footnotetext{
${ }^{14}$ In chapter 2 of Schiffrin (1987), Schiffrin provides an "operational" definition for discourse markers which aided the reader in identifying discourse markers on a rudimentary level. Then in the last chapter (chapter 10), she offers a refinement of that operational definition based upon the behavior of the English discourse markers she described throughout the book. This refinement is the set of "tentative suggestions" provided in (3). Later in Schiffrin (2003), she refers to that set of tentative suggestions as "theoretical definitions of markers" (Schiffrin 2003:58), and so the designation of her "tentative suggestions" as "theoretical" is hers, not mine.
} 
DMs function in relation to aspects of language that can be defined only through discourse per se (a linguistic unit larger than the sentence) and in relation to communicative processes underlying (and realized through) situated language use. Sometimes the unit being marked is a sentence; at other times, the unit is defined as an action, an idea unit, or turn at talk (Schiffrin 2003:458)

In other words, when we undertake a conversation with someone, there is a multitude of things we are trying to accomplish simultaneously. For example, we negotiate turns, make points, concede points, acknowledge receipt of information, request receipt of information, hedge, emphasize, signal speech acts, initiate repairs, as well as conveying the basic message to be communicated, all in the attempt to establish discourse coherence. In dialogic discourse, speaker and hearer jointly interact in the creation of discourse coherence using many of the devices just mentioned. Discourse coherence is thus achieved by the "joint efforts from interactants to integrate knowing, meaning, saying and doing" (Schiffrin 1987:29). In monologic discourse, she explains, the speaker is primarily burdened with the task of creating coherence, i.e. opening a story, making points and proposals, and making sure those proposals are understood in culturally appropriate ways. Schiffrin proposes that discourse coherence may be understood as an interdependency between differing levels or planes of discourse, planes which represent our cognitive, social, expressive, and textual knowledge (Schiffrin 2003:458). These discourse planes are given in (4). 
(4) Planes of discourse (from Schiffrin 1987:24-29)

$\begin{array}{ll}\text { EXCHANGE STRUCTURE } & \text { turns in talk } \\ \text { ACTION STRUCTURE } & \text { speech acts } \\ \text { IDEATIONAL STRUCTURE } & \text { propositional content, ideas } \\ \text { PARTICIPATION FRAMEWORK } & \text { how speakers/hearers relate to each other } \\ \text { INFORMATION STATE } & \begin{array}{l}\text { organization \& management of knowledge } \\ \text { and meta-knowledge }\end{array}\end{array}$

It is against the background of this discourse model (which is a sociolinguistic one as opposed to a purely semantic/pragmatic one) that Schiffrin identifies and characterizes the discourse markers observed in her data. Recall that the discourse markers that Schiffrin described were: oh, well, and, but, or, so, because, now, then, I mean, y'know. These markers were all taken from a corpus of live conversations between herself and a group of Jewish neighbors in a Philadelphia neighborhood. Some examples of these markers from Schiffrin's data are provided below, with all markers provided in bold type. Note that commas in these examples mark brief pauses, and that no commas indicate that the marker in bold is part of the intonational unit of the following content.

(5) Schiffrin's discourse markers (from Schiffrin 1987)
a) Oh, well they came when they were a year. (p. 73)
b) Well, when y'get to the cemetery, y'make a right. (p. 122)
c) And, he says, 'Well I don't know.' (p. 133) 
d) But, I went into the army (p. 155)

e) Or some good uh:... very good literature. (p. 179)

f) So, yeh, she would hit kids with a ruler. (p. 199)

g) Because the Jewish people are the most liberal minded people in the world. (p. 213)

h) Now our street isn't that nice. (p. 231)

i) Then when they went ho-off eh for their nap, I:- (p. 251)

j) Y'know when you get older, you just don't keep socializing anymore. (p. 277)

k) I mean let's get married! (p. 297)

Examining these various examples, it is easy to see that Schiffrin's criteria for what would allow an expression to be used as a marker are based upon the distribution of the markers occurring in her data. For example, her discourse markers all appear on the periphery of the sentence in such a manner that they remain "independent of sentential structure" (Schiffrin 1983:32). According to her, this means that their removal from the sentence "leaves the sentence structure intact" (Schiffrin 1987:32). It is in this manner that Schiffrin's discourse markers are "detachable from a sentence."

Their positional distribution reveals that Schiffrin's markers appear predominantly in initial position. While this appears to be the common position for her markers, the markers then and $y^{\prime}$ know may also occur in other positions. For example, she notes that then may occur utterance initial and utterance final, but states that "initial then has wider scope as a discourse marker than final then" (Schiffrin 1987:247). She also notes that most of the tokens of then in her corpus were usually preceded by other markers (see Schiffrin 1987:247 for discussion). For y'know, Schiffrin's examples show that while 
most occurrences of $y^{\prime}$ know appear in initial position, it may also occur in medial and final positions. Despite the distributional flexibility of these two markers, the overall pattern suggests that the discourse markers occurring in her data clearly had a strong proclivity to occur in initial position. This appears to be the reason why she characterizes her markers as "commonly used in initial position of an utterance".

Schiffrin's markers also showed that they may either occur with tonic stress (i.e. with their own stress followed by a pause), or occur with the intonational contour of its containing sentence. Though the chosen examples above make it appear that only some appear with tonic stress, while others do not, this is an accident of my presentation of examples (in the spirit of sampling a variety of her examples). Her data shows that each one can appear with, or without tonic stress. For example, in the follow examples, marker oh may appear with both tonic stress (indicated by a comma), or without it.

(6) Marker oh (Schiffrin 1987:73)
a) $\mathbf{O h}$, well they came when they were a year.
(with tonic stress)
b) Does he like opera? Oh maybe he's too young.
(without tonic stress)

In addition to these markers' various prosodic contours, some of Schiffrin's markers appear as phonologically reduced, such as the discourse markers $y^{\prime} k n o w$ (which is lexicalized as phonologically reduced) and because, which sometimes occurs as its phonologically reduced form cause. This behavior is shown for because in the following examples. 
(7) Marker because (Schiffrin 1987:204)

a) Because we got too many of our old friends, y'know, that uh... (p. 197)

b) cause the younger one's gonna come for dinner. (p. 204)

While the first three criteria in (4a-c) speak to syntactic or phonological features, the criterion in (4d) speaks to the multifunctionality of discourse markers, which according to Schiffrin, is "one of the central defining features of discourse markers" (Schiffrin 2001:67). This multifunctionality has two aspects to it. First, Schiffrin's discourse markers showed that they are able to display relationships between both local and global levels of discourse. For Schiffrin, a local level of discourse is the relationship that a discourse marker displays between adjacent utterances, while a global level of discourse is the relationship that a discourse marker displays between wider spans of discourse. This can be seen in the following example where marker because operates on both a local and global level of discourse.

(8) Marker because at both local and global levels of discourse (Schiffrin 2003:57-58)

Debby: (a) Yeh. Well some people before they go to the doctor, they'll talk to a friend, or a neighbor.

(b) Is there anybody that $[\mathrm{uh} . .$.

Henry: (c) [Sometimes it works.

(d) Because there's this guy Louie Gelman,

(f) he went to a big specialist,

(g) and the guy ... analyzed it wrong. [narrative not included]

(j) So doctors are - well they're not God either! 
In (8a), Debby makes the statement that some people talk to a friend or neighbor before seeing a doctor, to which Henry seeks to validate that statement by an experience of a friend of his. In (8c) he says sometimes it works, and then proceeds to give his justification for his statement in (8d-g). As Schiffrin explains, because operates locally by linking Henry's statement sometimes it works in (8c) with Henry's opening of a justification because there's this guy Louie Gelman in (8d). But then because operates globally by linking sometimes it works with Henry's narrative of his friend's experience in $(8 \mathrm{f}-\mathrm{j})$. It is in the manner that markers may work on both local and global levels of discourse.

The second aspect of multifunctionality is the ability of markers to connect utterances on either a single plane or across different planes simultaneously. This multifunctionality is demonstrated below with the markers because and but.

(9) Multifunctionality of discourse markers (from Schiffrin 2001:57)

a) On a single plane

Yeh, let's get back, because she'll never get home.

b) On multiple planes simultaneously

Jack: [The rabbis preach, [“Don't intermarry"

Freda: [But I did- [But I did say those intermarriages that we have in this country are healthy. 
In (9a), because connects two actions in a single plane of discourse (action plane): a request and the justification for that request. In (9b), however, but connects an utterance defined on several different planes of discourse simultaneously, and thus relates (or anchors) the different planes of discourse to one another. As Schiffrin explains, Freda's but prefaces an idea unit (i.e. intermarriages are healthy), displays a participation framework (nonalignment with Jack's proposition), realizes an action (i.e. a rebuttal during an argument), and seeks to establish Freda as a current speaker in an exchange (opens a turn at talk). The discourse marker but thus locates an utterance "at the intersection of four planes of talk" (Schiffrin 2001:57). The usage of but in this example demonstrates quite nicely the anchoring ability that discourse markers have across different planes of discourse. This anchoring ability, according to Schiffrin, is due to their status as INDEXICALS (Schiffrin 1987:322-325), or as CONTEXTUALIZATION CUES (Schiffrin 2001:58, 1987). This means that discourse markers (due to their meaning and/or grammatical properties) are able to guide the hearer as to how particular units of discourse are to be interpreted.

One last point that Schiffrin makes about discourse markers in order to help us understand the contribution of discourse markers to coherence is their role as INDEXICALS, or as having indexical functions (Schiffrin 1987:322-326). Discourse markers propose, according to Schiffrin, contextual coordinates by anchoring simultaneously differing levels of discourse. What this essentially means is that, as indexicals, discourse markers "index their containing utterance to whatever text precedes them (proximal), or to whatever text is to follow (distal), or to both. In other words, they either point backward in the text, forward, or to both" (Schiffrin 1987:323). For example, 
the additive marker and indexes an utterance with both prior and upcoming talk since its additive function is forward looking to the next idea or action, while the marker but only indexes an utterance with prior talk since it seeks to contrast an utterance to prior talk (Schiffrin 1987:323-324).

This indexical role, however, is partly delimited by the individual functions that markers may have. The meaning relations between utterances which they select (and consequently display, rather than create) are constrained by both their respective referential (semantic) meanings and their grammatical or lexical properties, if any. For example, conjunctions and and but (in sentence grammar), when used as discourse markers (i.e. in discourse grammar), are used in ways which reflect their grammatical use as conjunctions, and may have distributions at the discourse level which do not parallel their distribution in sentence grammars (as we saw above with and). ${ }^{15}$ The point here is that these discourse markers have a primary function as conjunctions in the ideation plane in conjoining idea or propositional structures, but may also have secondary functions as discourse markers in other planes of discourse (see Schiffrin 1987:315-317). For example, all the conjunctions have their primary function within idea structures (propositional structures), but are, in a sense, borrowed to accomplish more global functions at the discourse level. ${ }^{16}$ Their functions at this level of discourse, because of

\footnotetext{
${ }^{15}$ Early on, Grimes also recognized this tendency, stating: "the kinds of relationships that are involved once we go beyond the sentence are different from those that operate within sentences" (Grimes 1975:4). Schiffrin too has observed this tendency in regards to the use of conjunctions within discourse: "But we have also seen several features of discourse that point to differences between discourse grammars and sentence grammars, and thus suggest that the principles governing [the] use of conjunctions in discourse do not totally parallel those for conjunctions in sentences" (Schiffrin 1987:320, see also Schourup 1985:123).

${ }^{16}$ Fraser appears to disagree with this, suggesting: "In short, discourse markers are not adverbs, for example, masquerading as another category from time to time" (Fraser 1990:388). Oddly, before and after that statement, he seemingly contradicts this statement by recognizing that discourse markers are indeed drawn from various grammatical sources, and proceeds to give examples of both grammatical and
} 
their referential and/or grammatical usage as conjunctions, are largely mirrored in their use as discourse markers.

On the other hand, discourse markers $o h$ and well, have either no, or very little, referential meaning. These types of discourse markers are much freer to have functions within other planes of discourse. Schiffrin notes that "if an expression used as a marker does have meaning, its primary use in discourse will be in the organization of referential meaning at a textual level - and that if a marker does not have meaning, its primary use will be elsewhere" (Schiffrin 1987: 319). This tendency is exactly what we observe in the behavior of discourse markers cross-linguistically. ${ }^{17}$

So, this naturally divides discourse markers into two groups: those which are primarily textual (e.g. connectives such as and, but, or, so, because, now, then), and those which are interpersonal in nature, or largely pragmatic (e.g. oh, well). Brinton (1996:38) also suggests that discourse markers fall into two categories (having a two-fold function): those which belong to the textual mode of language, and those which belong to the interpersonal mode of language. ${ }^{18}$ According to Brinton, in the textual mode, the speaker structures meaning as text, creating cohesive passages of discourse. The interpersonal mode is the expression of the speaker's attitudes, evaluation, judgments, expectations,

discourse uses of various items such as now, well, and however. The cross-linguistic literature is replete with this sort of behavior by discourse markers: Maschler (1997:197-198) for Israeli Hebrew where discourse marker ta yode'a 'y'know' may occur with the literal meaning 'you know'; Biq (1990:205) for Mandarin where discourse connective na and name also have grammatical functions as demonstratives; Jucker \& Smith (1998:183-184) for English where discourse marker like has lexical uses as a verb, preposition, suffix, and conjunction; Shloush (1998:62) for the Hebrew discourse marker bekicur 'in short' which has a function as an adverbial; Ariel (1998:226) for the Hebrew discourse marker harey 'after all' which has a grammatical function as a sentence adverbial, et al. So, there is ample cross-linguistic evidence in support of the primary and secondary features of discourse markers.

${ }^{17}$ This natural divide is what is observed for Ojibwe discourse and explains the organization of this paper into textual and interpersonal discourse ("mystery particles") markers.

${ }^{18}$ She uses the term PRAGMATIC MARKER as synonymous with the term DisCOURSE MARKER. 
and demands, as well as the nature of the social exchange, the role of the speaker and the role assigned to the hearer (Brinton 1996:38). Brinton also notes that this two-fold function of discourse markers is already recognized by Schiffrin, since Schiffrin recognizes discourse markers as providing "coordinates within their context by indexing utterances either to the participants (focus on the speaker is proximal and on the hearer is distal) or to the text (preceding discourse being proximal and the following discourse being distal) (Brinton 1996:39, summing up Schiffrin 1987a:316-317, 1987b:25). More recently, Schiffrin has stated: "discourse is defined both as structural - a unit of language larger than a sentence - and as pragmatic, that is, language in use. Thus it is not surprising that DMs, as terms that define units of discourse, can also be identified as both text- and speaker-based" (Schiffrin 2003:459). The cross-linguistic evidence also speaks to this duality of function of discourse markers, but as we will see in Section 2.3.4, the cross-linguistic data also show that some discourse markers may have both textual and interpersonal functions simultaneously.

\subsection{Relevance theorists' view of discourse markers}

Before we examine the cross-linguistic evidence, it is perhaps worth mentioning the approach that relevance theorists have taken towards the characterization of discourse markers. Their view of markers is embedded within the framework of RELEVANCE THEORY ("RT"), a theory which characterizes human communication in terms of a communicator who provides evidence of their intention to convey a certain meaning and an audience (the interlocutor) who must infer what that meaning is based upon the evidence put forth (Wilson and Sperber 2004). The underlying principle here is that the 
communicator presents just enough evidence of their intention without putting the interlocutor through too much processing effort. To put this in RT terms: "[e]very ostensive stimulus conveys a presumption of its own optimal relevance" (Wilson and Sperber 2004:612). Provided that the ostensive stimulus presented by the communicator is relevant enough for the interlocutor to process it, the interlocutor will then follow a path of least effort in computing cognitive effects (i.e. working out a relevant interpretation). Once the interlocutor's expectation of relevance is satisfied (i.e. once they figure out what the interpretation is), the interlocutor stops. In short, communication is achieved through a inferential process which culminates in the interlocutor's appropriate interpretation. According to Wilson and Sperber, this approach to communication (i.e. inferential pragmatics) is to be contrasted with the classical code model which characterizes communication as the encoding of an intended message into a signal which then must be decoded by an interlocutor who has the same copy of the code. While utterances, they add, constitute linguistically coded evidence (necessitating interlocutor decoding), they represent only one type of input possible within a nondemonstrative inference process which yields an interpretation of the speaker's meaning (Wilson and Sperber 2004:607). As they also point out: "[t]he goal of inferential pragmatics is to explain how the hearer infers the speaker's meaning on the basis of the evidence provided" (Wilson and Sperber 2004:607). A non-verbal example of this process was offered by Wilson and Sperber, and goes like this: If someone leaves their empty glass in your line of sight, and you then notice it, you might conclude that she might want a drink. If, on the other hand, she deliberately waves it at you, you would then be justified in concluding that she would like a drink (example from Wilson and 
Sperber 2004:611-612). In essence, you are able to infer that your guest (the person with the empty glass) wants another drink because she provides just enough evidence of her intention such that your processing effort was minimal and worth your time. Your natural human tendency to search for relevance then allows you to infer what your guest's intention is. It is in this manner in which relevance theorists strive to characterize discourse markers.

As Blakemore points out, relevance theorists are not interested in the behavior of discourse markers (as Schiffrin and I are) in regards to their distribution or structure, but rather in what kinds of meaning they encode and how their functions might be pragmatically inferred by the search for relevance. For example, Blakemore argues in regards to Schiffrin's analysis for but that while but may be analyzed as functionally marking the continuation of a turn at talk (i.e. continuing a speaker's action), it is not clear whether but, or any other discourse marker for that matter, actually encodes information about turn taking (Blakemore 2004:236). In other words, Blakemore has serious doubts whether but actually encodes a meaning of 'turn taking', or whether the turn taking function can be inferred from the encoded meaning of but (whatever that may be) taken together with the assumption that the speaker has been optionally relevant (Blakemore quoting Wilson 1994b, Blakemore 2004:236).

What figures predominantly in RT is the idea that there are two types of linguistic meaning, CONCEPTUAL or PROCEDURAL. When a linguistic construction (i.e. an utterance) encodes conceptual representations (i.e. a concept, or what Schiffrin might term as an idea unit) it is said to be conceptual. If an utterance encodes procedures for manipulating those conceptual representations, it is said to be procedural. Therefore, 
"[i]nferential comprehension involves the construction and manipulation of conception representations" (Wilson and Sperber 1993:10). Applied to discourse markers, then, discourse markers aid in the search for relevance by guiding an audience to the appropriate contextual affects which ultimately lead to the appropriate interpretation of an utterance. While it has been claimed by some that discourse markers encode only procedural information and are not truth-conditional in the sense that they do not affect the truth-conditionality of the expressions that contain them (see Andersen 1998, Jucker 1993, Fraser 1996, 1998, 1999), it is largely recognized now that discourse markers may encode both types of information (i.e. procedural and conceptual). For example, Ziv showed that the Hebrew marker kaze encodes procedural meaning while at the same time affecting truth conditions of its containing utterances (Ziv 1998, Blakemore 2004:230). On the other hand, non-truth-conditional discourse markers such as in contrast, in other words, as a result have been argued to encode concepts rather than procedures (Blakemore 2004:230).

Fraser $(1990,1999)$ is one of the contributors within the RT framework for the characterization of discourse markers, and I will briefly describe his approach. Fraser's characterization assumes that sentence meaning is analyzable into two separate types of conventionally encoded information: content (propositional content) and pragmatic (signals of the speaker's communicative intentions). He calls the "signals of speaker's communicative intentions" pragmatic markers, and further divides pragmatic markers into three major types: BASIC PRAGMATIC MARKERS, COMMENTARY PRAGMATIC MARKERS, and PARALlel PRAGMATIC MARKERS. Basic pragmatic markers include expressions such as please, and performative expressions such as I claim and I promise, 
which signal the force of the basic message. Commentary pragmatic markers include expressions such as frankly, incredibly, amazingly, if I may be personal, well), and signal the force and content of an entire message, rather than just the basic message. Parallel pragmatic markers include expressions such as damn as well as vocatives Sir, and My friend, and encode an entire message, but one separate from and in addition to the basic and/or commentary message(s) (Fraser 1990:386-387).

To Fraser, discourse markers are a type of commentary pragmatic marker which signals a sequential discourse relationship. In other words, discourse markers "impose a relationship between some aspect of the discourse segment they are a part of, call it S2, and some aspect of a prior discourse segment, call it S1" (Fraser 1999:938). In short, they "signal how the speaker intends the basic message that follows to relate to the prior discourse" (Fraser 1990:387). Examples of his discourse markers are given below in bold type.

(10) Fraser's discourse markers (examples from Fraser 1990:383)
a) John can't go. And Mary can't go either.
b) A: I like him. B: So you think you'll ask him out then.
c) A: Did you like it? B: Well, not really.
d) But when do you think he will really get here?
e) I think it will fly. Anyway, let's give it a change.
f) Now, where were we? 
Elements which do not relate some segment with some prior segment would not be included as discourse markers by Fraser. Therefore, expressions such as frankly, obviously, and stupidly are not counted as discourse markers, since they do not signal a two-place relationship between the adjacent discourse segments. Rather, they are commentary pragmatic markers as they "signal a comment, a separate message, that relates to the following segment" (Fraser 1999:942). Excluded also are focus particles such as even, only, just, pause markers such as hum, well, oh, ahh, modal particles such as indeed, vocatives such as sir, Mr. President, anyone?, as well as interjections such as Oh!, wow!, and shucks!

Other stipulations that Fraser has for discourse markers is that "when an expression functions as a discourse marker, that is its exclusive function in the sentence" (Fraser 1990:389). He explains that while discourse markers may have "homophonous" forms (one form analyzable as an adverb, and one as a discourse marker) they do "not serve in both roles in the same sentence" (Fraser 1990:389). In regards to positional distribution, Fraser characterizes discourse markers as typically occurring only in utterance-initial position, but notes that there are also occasions where they are utterance-internal and utterance-final, such as with the marker however. Finally, Fraser considers discourse markers to have a core meaning distinct from the meanings of their homophones, noting that discourse markers are not drawn from a single grammatical source, but drawn from a variety of grammatical sources, including: adverbials (now, then, still); literally used phrases (to repeat, what I mean to say, similarly, overall), idiomatic phrases (while I have you, still and all), verbs (look, see), interjections (well), coordinating conjunctions (and, or, but), subordinate conjunctions (so, however), as well as the terms such as anyway and 
$O K$. His point here is that "discourse markers are not adverbs, for example, masquerading as another category from time to time," and that discourse markers (and not their adverb homophones) have a core meaning which "places restrictions on the details of the relationship between S2 and S1" (Fraser 1998:308), and that "discourse markers should be analyzed as having a distinct pragmatic meaning which captures some aspect of a speaker's communicative intention" (Fraser 1990:393).

In sum, the approach taken by Schiffrin (the approach used in this thesis, but expanded to include cross-linguistic details) and the one taken by relevance theorists are not really at odds with one another, since they are asking different questions in regards to the characterization of discourse markers. While Schiffrin, for example, is interested in describing the behavior of discourse markers within actual language use via a sociolinguistic model of discourse, relevance theorists attempt to explain how discourse markers encode meaning and how that meaning is interpreted by interlocutors to achieve some cognitive effect in the search for relevance. Having said that, each approach does has some bearing on what expressions are counted as discourse markers. For example, while Schiffrin considers expressions such as $o h$ as a discourse marker, Fraser does not. This is largely due to the fact that Schiffrin defines discourse markers as not only working to display discourse relations, but to display interpersonal relations as well. Fraser, on the other hand, sees discourse markers as only displaying a discourse relation between S2 and S1, relegating the interpersonal marker $o h$ to a separate designation as an interjection. Interjections, he admits, are a group of expressions which "share certain properties with discourse markers" but he argues that they are not part of a sentence but are an entirely separate 'sentence' expressing the emotional state of the speaker (Fraser 
1990:391). Since most researchers agree that discourse markers must be described at a level of discourse above the sentence level (see also Blakemore 2004:221), it is odd that oh would be excluded as a discourse marker when $o h$ serves a discourse function - to express the emotional state of the speaker. Others, such as Aijmer and SimonVandenbergen, have since followed Fraser by making a formal distinction between discourse markers and pragmatic markers, in that, they consider discourse markers to be a subclass of pragmatic markers, which function only to "mark coherence relations"; and pragmatic markers, to be the "signals in the communication situation guiding the addressee’s interpretation" (see Aijmer and Simon-Vandenbergen 2006:2-3).

What I find equally unattractive about Fraser's approach is that because he (and now others) does not include interpersonal type markers into his inventory of "discourse markers," he is forced to create various classes of "pragmatic" markers in order to account for a multitude of expressions which all appear to work at a level above the sentence. In short, since they all appear to serve some discourse function, why not call them all discourse markers? Also, one overreaching consequence of his approach is that the "multiple functions of markers - including, critically, social interactional functions are downplayed (if noted at all) and not open to linguistic explanation" (Schiffrin 2003:59). The result is that analyses such as those espoused by Fraser (and others), miss, I believe, the central defining characteristic of discourse markers: their multifunctionality on different planes of discourse. "It is this multifunctionality on different planes of discourse that helps to integrate the many different simultaneous processes underlying the constructions of discourse, and thus helps to create coherence" (Schiffrin 2003:58). 
The purpose of this thesis is not to explain how discourse markers work, but to describe their behavior within a sociolinguistic model of discourse developed by Schiffrin. While her initial characterization lacked the benefit of cross-linguistic data, it provides the most comprehensive view of discourse markers, and provides a framework in which to embed the exposition of Ojibwe discourse markers.

\subsection{Cross-linguistic data}

Because Schiffrin did not have the benefit of extensive cross-linguistic scholarship to inform her theoretical definition for discourse markers, she was forced to qualify her initial characterization as "tentative." Though her initial characterization has often been quoted, even in recent literature, it is perhaps time for a definitional "tightening up" to include observations about the behavior of discourse markers cross-linguistically. Since the 1980s, there has been a growing body of cross-linguistic literature on the subject of discourse markers, including Chinese (Biq 1990; Kwong 1989; Or 1997), Danish (Davidsen-Nielsen 1993), Finnish (Hakulinen and Seppanen 1992; Hakulinen 1998), French (Cadiot et al. 1985; Hansen 1998; Vincent 1993), German (W. Abraham 1991), Italian (Bazzanella 1990, Bruti 1999), Portuguese (Silva 1992), Hungarian (Vasko 2000), Indonesian (Wouk 1998), Japanese (Cook 1990, 1992; Fuji 2000; Matsumoto 1988; Onodera 1994, 1995), Spanish (Koike 1996; Schwenter 1996), Latin (Kroon 1998), Korean (Park 1999), Andean Spanish (Zavala 2001), Bulgarian (Tchizmarova 2005), Hebrew (Ariel 1998, Maschler 1997, 1998; Ziv 1998, Shemesh 2006), Maya and Nahuatl (Torres 2006), Niuean (Massam et al. 2006), Yagua (Payne et al. 1990), etc. (see Schiffrin 2003:54 where she notes many of these works also). The cross-linguistic 
inventory is replete with an array of discourse functions, including: attention getters and explanatory connectives (Finnish), sequential connectors (Portuguese, Tojolab'al Mayan), textual cohesion (Tojolab'al), emotional intensifiers (Spanish), phatic connectives (Italian), agreement markers (Italian), discourse coordination (Japanese, English), equivocation markers (Finnish), softeners (Spanish), evidentials (Spanish), hedges (Hebrew, Spanish, Bulgarian), explanations (Portuguese), clarification and confirmation devices (Andean Spanish), common understanding markers (Cantonese, Indonesian), reaction markers (Danish), affirmative markers (Niuean), and requests for feedback (Portuguese), just to name a few. While this body of work shows a large number of discourse markers, all of which are in line with Schiffrin's analysis for discourse markers, the cross-linguistic data also show that discourse markers may differ in their positional distributions, in what types of expressions are used as discourse markers, or for marking discourse in general. Section 2.3.1 below discusses the positional distribution of discourse markers across languages, Section 2.3.2 discusses the use of clitics and affixes as discourse markers, and Section 2.3.3 discusses the use of TAM forms, or inflectional systems, as a way that some languages mark discourse.

\subsubsection{Position}

While a significant amount of the cross-linguistic literature shows discourse markers occurring primarily in the sentence-initial (or utterance-initial) position, some show them occurring sentence-finally, e.g. Bulgarian, Hebrew, Quechua, Chinese, Maya and Nahuatl, Niuean, Spanish, et al. Others show them occurring in both initial and final 
positions, such as in Finnish; or as occurring in initial, medial, and final positions, such as in Italian.

(11) Sentence-initial ${ }^{19}$

a) Niuean (Massam, Starks, and Ikiua 2006:197)

mafola, fai nakai he magafaoa haau ne ne fai kitekiteaga hokulo lahi ke hevagahau Niue tuga e pehe ka ha akoako faiaoga?

'okay, is there anyone in your family who has an in-depth interest in the Niuean language, like a pastor, teacher?

b) Spanish (Schwenter 1996:856)

mi tía Pepita viene el día 20.

'My aunt Pepita is coming on the $20^{\text {th }}$.

o sea el viernes que viene.

O SEA, next Friday.'

c) Tojolab'al (Brody 1987:512, Torres 2006:616)

Entonse ti $=$ wa yajni jaw $=7 i$

'And that's how it was.'

d) Bulgarian (Tchizmarova 2005:1149)

Xajde stiskajte zăbi ošte malko tam, dano neštata da se opravjat.

'Come on, hang on in there a bit more, let's hope things will get better.'

\footnotetext{
${ }^{19}$ Unfortunately, the following examples were not accompanied by word-by-word glosses in their original sources. I, therefore, could not provide them here.

${ }^{20}$ Schwenter states that $o$ sea is a connective and is often translatable as English that is, but because this translation is not always a felicitous reading for $o$ sea, he leaves $o$ sea untranslated in his examples.
} 
(12) Sentence-final ${ }^{21}$

a) Korean (Park 1999:194)

cey -ka tayphyokito pwuthaktuli -lyekwu ha -nuntey:

'I wanted to ask you to do the representing prayer nuntey'

b) Andean Spanish (Zavala 2001:1006)

Sí, en esa misma pe

'Yes, in the same one pe'

(13) Sentence-initial, medial, and final

a) Italian (Bazzanella 1990:633)

i) Insomma era una difesa mista [...]

'After all/well it was mixed defense [...]'

ii) [...] i pagani ormai erano stati eh scon- insomma distrutti totalmente. 'pagan were by now eh won- after all/I mean totally destroyed'

ii) Ma se mi dimettevo (chi) lasciavo, Zamberletti? ABBIA pazienza Padre Zanotelli insomma eh ((laughter)).

'If I resigned, whom was I leaving, Zamberletti? Don't be funny, Father Zanotelli after all.

While this growing body of literature has expanded the distribution of discourse markers

to include medial and final positions, little mention has been given to discourse markers

\footnotetext{
${ }^{21}$ Both authors, Park and Zavala, left the discourse markers unglossed in the translations, preferring to define their use in the body of the text. This appears to be the practice of some authors when speaking about their various functions. In making requests in Korean, Park suggests that marker nuntey is used to set up an "accountability relevance point, inviting the interlocutor to figure out what the speaker is implying" (Park 1999:198). In Andean Spanish, Zavala suggests that marker pe (or pues) is used to confirm a request for confirmation or clarification based upon an inference from a previous utterance (Zavala 2001:1006).
} 
which may occur in second position (or Wackernagel's Particles). ${ }^{22}$ Of all the works cited above, only Payne (et al. 1990) mentions the existence of such a marker, jịita or jịí, in Yagua, an Amazonian language. ${ }^{23}$ Payne hypothesizes that as a discourse-structuring element, jịita shows "progression through a discourse. This may be progression along the main event line (in narrative), or progression from one thematic paragraph to another" (Payne 1990:427). An example of this usage is given below.

(14) Yagua second position discourse clitic jịíta (Payne et al. 1990:427-428) ${ }^{24}$

dily rabyeejyérya riícya jidyé rácąatąasa

'There I set the fish trap yesterday in the afternoon in the middle (of the stream).' ratyęéryajay jịíta rumusiy jiyu roorimyúju

'I returned here to the house from there.'

rąásaqachąásiy juịita

'This morning it dawned.'

rayąásiy jụíta ránaacho

'I went this morning towards it.'

\footnotetext{
${ }^{22}$ For Latin, Kroon (1998) appears to have examples which show second position clitics acting as discourse markers, albeit she never refers to them as second position markers per se. Latin is famously reputed to have second position clitics, but this widely accepted analysis has recently come under attack by Agbayani (et al., forthcoming) who argues that a proper understanding of conjunction in early IE ("Indo-European") undercuts the traditional notion of second position in IE (Agbayani et al. forthcoming). According to Agbayani, what has been traditionally analyzed as second position elements in Latin (including Ancient Greek and Hittite) is more correctly analyzed as clause-initial elements. Even with Latin, despite this recent controversy, the literature on second position discourse markers is scanty, and further scholarship on this subject would help to enrich the already growing knowledge of discourse markers.

${ }^{23}$ The Yagua marker jilita does not appear to be well known as I can find no references to it in the literature. ${ }^{24}$ Payne states that the second position clitic jiilta is written as a separate word for orthographic reasons.
} 


\subsubsection{Clitics and affixes}

As it turns out, there is a significant amount of literature which speaks to the various discourse features of many indigenous languages of the Americas (literature existing at the time of Schiffrin's analysis) which shows that the word classes from which discourse markers are drawn must also be expanded to include CLITICS and AFFIXES (see Brody 1989 who first made this point). For example, in Tojolab'al Mayan, Brody not only identified discourse markers of the type described by Schiffrin (i.e. syntactically detached items such as $t i$ 'when', entonse 'then, pwes/pwe/pes/pe 'well', este 'um', etc.), but also those which occur as clitics, e.g. -xa 'now', -ta 'already', -to 'still, -xta 'durative', cha/cho 'repetitive', as well as utterance-final clitics such as -tak 'emphasis, anyway', $b^{\prime} a$ 'contrast, emphasis', -ye7/ye7n 'emphasis, anyway'. In Huichol, an indigenous language of western central Mexico, Grimes reveals that "both words like méri $+k \Lambda 4 t e$ 'well, then' and postfixes (suffix-like forms that follow enclitics) like -rii 'definitely"' (Grimes 1975:93) have functions in discourse. For the Ecuadorian language Cayapa, and the Columbian languages Cubeo, Inga, Guajiro, and Ica, Longacre shows that both particles and affixes may serve as discourse markers, since they are "found to have a function which relates to a unit larger than the sentence, i.e., to the paragraph and the discourse" (Longacre 1976:468). In these languages, both particles and affixes which are used as discourse markers have largely a common function in marking the main characters and the main actions (or main eventlines) of stories and narratives. For one of these particles, 'cari, for example, Longacre states that "if one copies out all the sentences from a discourse which have this particle within them, one gets a tolerably good abstract 
of the whole discourse" (Longacre 1976:468). In other words, these elements mark the backbone of the discourse. Because of this backbone marking function, this lead Salser et al. to label 'cari as a "backbone tag" (Longacre 1976:469, Salser et al. 1976). Affixes, such as the Cayapa suffix - ren, may carry this function as well. Some of these elements may also either show digressions from the main event, or that important events which entail role reversals are eminent or forthcoming. Longacre demonstrates the role reversing function with the following example from Cayapa where the suffix $-n$ shows up on a variety of words, i.e. verb, noun, conjunction, and adverbials, within a narrative to show such a distant role reversal is coming later on in the narrative. In the following example, strategic words in the story are marked by $-n$ to preface the eventual downfall of a man who forgot to pay his bill.

(15) Suffix $-n$ as a discourse marker (from Longacre 1976:471)

"He was seated at a table eating, and since he was long conversing (-n), he arose and left without remembering to pay the bill. This man took a long time before he returned. Three years later he went to the same place (-n) and ordered another meal. Then he said to the owner, 'Godmother, long ago I ate (-n) a meal here but I forgot to pay for it and left. Now I want to pay for it: what do I owe you?' So the woman answered, 'You owe me seven pesos.' So-being (-n) the woman's son spoke to her, "Mother, why do you say seven pesos? That isn't right, Mother..."

As Longacre explains, this story turns on the unpaid bill. When the son interceded and demanded an outrageous amount of money instead, difficulties ensued which eventually 
lead to the man's death. Relevant events which lead to this downfall are strategically marked by the role reversing suffix $-n$. $-n$ on the verb conversing marks the fatal circumstance from which the whole ordeal originates. $-n$ on the noun place marks the relevance of the place where the man returned after three years to pay his bill. $-n$ on the verb ate marks the narrator's imposed point of view that trouble is coming (since the man at the time would not have known that these were fatal circumstances). And finally, $-n$ on the conjunction so-being 'then' marks that it is the woman's son speaking up which leads to the eventual trouble.

What is striking about the use of $-n$, is that it also has a grammatical function in lowlevel structure (i.e. sentence level) showing contrast, much like the English but. This is shown below.

(16) Grammatical function of suffix $-n$ (from Longacre 1976:472)

His father him to work ask (-n), the boy refused.

'His father asked him to work but the boy refused.'

The use of $-n$ at the sentence level affirms the observed tendency for discourse markers in English (and as we will see, in Ojibwe as well) that some items which have a primary use grammatically (i.e. in the ideation plane of discourse), may also be used as discourse markers, above the sentence level.

Ojibwe makes a contribution here as well, in that, it further expands the pool of candidate markers to include both SECOND POSITION DISCOURSE MARKERS (supporting claims for Yagua above), and PREVERBS (which include prefix-like words which act like 
deictics and which attach to verbs) in support of the claim made for affixes. Such classes are common features to Algonquian languages such as Ojibwe, and their description will be provided in the body of this thesis.

\subsubsection{TAM (tense-aspect-mode) systems}

Perhaps another relevant dimension to this discussion is the use of tense-aspect forms (i.e. inflectional morphology) in discourse, or in marking discourse. Brinton notes that tense-aspect forms have been the subject of study by historical discourse analysts, stating that "[t]ense-aspect morphology, because of its function in conceptualizing and placing event in time, plays a special role in discourse structuring” (Brinton 2003:142). What this essentially means is that it is not a particular lexical item which serves as a discourse marker, per se, but the shape of the words themselves which give global coherence. $^{25}$ Therefore, targets for discourse use are, essentially, entire verbal inflectional paradigms. While I hesitate to call an entire paradigm a "discourse marker" per se, it is undeniable that inflectional morphology may be utilized for discourse work in the same way that individual linguistic items which have lexical or grammatical uses at the sentence level are enlisted for work above the sentence level. In other words, TAM forms which have specific functions at the sentence level such as tense, aspect, mood, and temporality, for example, may have more global functions above the sentence level. Such behavior is not new to the literature. The historical present (i.e. the use of the present tense in a past tense narrative) in medieval texts, for example, has been argued to serve various discourse roles, such as marking foregrounded events, as devices for

\footnotetext{
${ }^{25}$ What I mean by "word shape" is a word might be changed in form by morphological or inflectional processes.
} 
internal evaluation, denoting main events, introducing central characters, highlighting key descriptive details, framing and staging narratives, marking transitions between episodes, distinguishing speakers, etc. (see Fleischman 1985, 1986 for Old French; Richardson 1991 for Middle English; Richardson 1995 for Old Norse, also Brinton 2003:143). The preterit tense in Totonac (a Mesoamerican language) narratives, while indicating past time and completed action in sentence grammars, serves a discourse function of marking mainline events in narratives. This use of the preterit to mark eventlines in Totonac is further contrasted by the use of other tense-aspects (such as the imperfect tense) to mark non-eventline, supportive material (Bishop 1979). Conjunct mode verbs (which indicate subordinate clauses in sentence grammars) in Kickapoo, an Algonquian language, are used to mark eventlines, and may do the work of independent clauses at the discourse level. This is surprising since conjunct verbs, rather than independent verbs, are utilized in representing independent clauses at the discourse level. When conjunct verbs are used in this fashion within discourse, independent verbs primarily mark background, setting, participants, mental or emotional states, topic or participant prominence (Jones and Coleman 1979). Such use of the conjunct verb has puzzled researchers, since while it was known that conjunct verbs may do the work of the independent mode, it was not understood why. ${ }^{26}$ Jones and Coleman suggests that it is because the Algonquian literature largely restricts study to isolated sentences. In regards to Kickapoo, in particular, they state:

\footnotetext{
${ }^{26}$ Rhodes noticed that in Ojibwe too, conjunct verbs may sometimes act as independent clauses, stating: "This traditional characterization of verb forms as independent versus dependent can be quite misleading to a non-Algonquianist syntactician because of the great variety of syntactic contexts in which dependently inflectioned verbs appear, some of which are not obviously subordinate" (Rhodes 2006:6, a lecture originally given in 1998 before the University of Manitoba).
} 
"it would have been impossible to analyze these functions of Kickapoo modes and tenses without a discourse perspective. We believe this is why many of these functions have been heretofore unnoticed in Algonquian languages, at least in the published literature, since much of the published material has been based on the study of isolated sentences, whether isolated due to elicitation technique or due to their extraction from texts."

Because the heavy use of conjunct verbs in discourse is also a feature of Ojibwe, this will also be discussed in the body of this thesis. What this means in general, however, is that while individual lexical items (i.e. traditional discourse markers) which have sentence level functions may be targeted for work above the sentence level, tense-aspect-mode systems which have specific sentence level functions which would lend themselves for discourse work may also be targeted. In the case of TAM forms, it is not the word itself which lends itself for discourse work, but its shape.

\subsubsection{Simultaneous textual and interpersonal functions of discourse markers}

Recall that both Schiffrin and Brinton recognize the two-fold function of discourse markers, in that, there are those which contribute to the textual mode of a language, and those which contribute to the interpersonal mode of language (Brinton 1996:38, Schiffrin 2003:459). To my knowledge, neither researcher has explicitly claimed that a discourse marker could function in both a textual (connective) and interpersonal (epistemic or epistemic) function simultaneously. By 'simultaneous', I do not mean to refer to the multifunctional feature of discourse markers which refers to the ability of discourse markers to anchor units of talk to various planes of discourse, since both textual and 
interpersonal discourse markers can be multifunctional. Recall that the Schiffrin example above in (9) characterized the discourse marker but (a textual marker because it organizes chunks of text) as being 'multifunctional' because its ability to anchor an utterance to four planes of talk, i.e. it prefaced an idea unit (a proposition), displayed a participation framework (nonalignment with a prior proposition), realized an action (a rebuttal during an argument), and sought to establish the speaker as a current speaker in an exchange (opens a turn at talk). Schiffrin also showed that the marker well (an interpersonal marker because it contributes an attitude toward a proposition) may be multifunctional, since it may "convey the fulfillment of a conversational obligation, for example, an answer to a question [displaying a participation framework], at the same time that it conveys speaker attitude, for example, distance from a proposition [realizing an action)" (Schiffrin 2003:459, Schiffrin 1987). In other words, interpersonal marker well too may anchor an utterance to various planes of discourse. The question here then becomes: Can a discourse marker be both textual and interpersonal simultaneously? The answer is apparently yes. For example, Schwenter showed that the Spanish discourse marker o sea may serve both a textual and interpersonal function simultaneously, since it may connect upcoming talk to prior discourse (i.e. in the form of explanations, reformulations, setting off background information from foregrounded information) while at the same time serving as a command softener, thereby decreasing the illocutionary force of the command "to something more along the lines of advice that should be followed" (Schwenter 1996:862). This is shown by the example below with the discourse marker cluster o sea que. 
(17) Spanish o sea que (Schwenter 1996:869) ${ }^{27}$

$Y$ eso lo dice todo el mundo.

'and that's what everybody (lit. the whole world) says.

o sea que debe ser verdad

[o sea que] it must be true.'

According to Schwenter, o sea que in this example "is both connective, in that it specifies how the meaning relation between the two utterances is to be construed, and epistemic, in that it constitutes a subjective speaker comment on the propositional content of the second utterance such that 'I, speaker, believe that this must be true because the whole world says it" " (Schwenter 1996:869). Schwenter also comments that this is a problem for Fraser who makes a clear distinction between discourse markers (markers which mark a sequential relation between $\mathrm{S} 2$ and $\mathrm{S} 1$ ) and other commentary pragmatic markers (markers which are pragmatic in nature) since such a distinction "ignores instances of DMs that seem to be performing both tasks at the same time" (Schwenter 1997:869).

Koike (1996) makes a similar observation regarding the Spanish discourse marker $y a$, which serves to highlight certain constituents of an utterance in order contribute an emotional emphasis, but also to establish a cohesive link to prior discourse. According to Koike, the emotional emphasis contributed is a feeling of intensity about the proposition and allows a listener who perceives this intensity to become interested and involved in a sequence of events (Koike 1996:272). This function is illustrated in the following example.

\footnotetext{
${ }^{27}$ Although I would prefer to provide a word-by-word gloss, the original author does not provide one.
} Therefore, I cannot do so here. 
(18) Spanish ya (Koike 1996:275-276)
a) Yluego en Chiapas ... en la ... estabamos en la ... ¿cómo se llama? En la sierra, ¿sí?
b) Todo era al revés.
c) Los refrescos eran calientes, ?si?
d) Las tortillas eran frías.
e) O sea, todo al revés ya.
f) No, llegaba el momento en que ya no podiamos nosotros.
a) 'And then in Chiapas ... in the ... we were in the ... what o you call it? In the mountains, yes?
b) Everything was backwards.
c) The soft drinks were hot, yes?
d) The tortillas were cold.
e) That is, everything backwards.
f) No, the time was coming that we couldn't [take it] any more.'

In this short narrative, the proposition todo al revés 'everything was backwards' is repeated twice (both tokens underlined for clarity), first in (18b), and then again in (18e) where it is followed by $y a$. According to Koike, discourse marker ya in (18e) serves to highlight it preceding phrase todo al revés, giving it an emotional emphasis, while also serving as a cohesive element by making reference to the first occurrence of the same phrase in (18b) todo era al revés.

While many discourse markers in the cross-linguistic literature contain markers which show textual functions, and those which show interpersonal ones, the Spanish examples above suggest that some discourse markers may indeed contribute textual and interpersonal functions simultaneously. Though these types of discourse markers appear to be rare (or maybe just unnoticed), our definition of discourse markers must be broad enough to include such markers. 


\subsection{Defining discourse markers}

Based upon these cross-linguistic data then, we can make several observations which might aid in defining discourse markers. First, languages may use available lexical and/or grammatical resources for discourse purposes. In other words, linguistic categories which would lend themselves to discourse work based upon their lexical or grammatical properties would make those categories prime targets for discourse work. So, it is not surprising that in Ojibwe, as well as other languages, second position words, clitics, affixes, and preverbs as possible candidates for discourse marker work, since languages such as Ojibwe make heavy use of these items. Since English is not a heavily inflected language, nor does it contain second position words, ${ }^{28}$ English would not be likely to contain second position discourse markers, nor those which occur as clitics or affixes. What we do see for English, however, is the exploitation of existing lexical and grammatical items for discourse work, e.g. the use of conjunctions and, but, or, because; the use of adverbials now, then; and the use of lexicalized phrases y'know, I mean (Schiffrin 1987). We see this behavior in other languages as well. In Israeli Hebrew, ye 'and' has a grammatical role as a sentence-level conjunction, but may "emerge as a discourse marker" from interaction in conversation (Maschler 1997:197-198). In Niuean, the lexical item mitaki 'good' may have a grammatical role as a modifier, as a predicate, may form more complex words such as the adverb fakamitaki 'well, properly', and may

\footnotetext{
${ }^{28}$ But see Altenberg 2006 who shows that certain exemplifying connectors such as for example and for instance, and certain contrastive connectors such as however often occur in parenthetic second position in order to "highlight the initial element, syntactically and prosodically, thereby indicating a significant break or shift in the development of discourse" (Altenberg 2006:35-36). This sort of second position work, I argue, differs fundamentally from languages like Ojibwe which have discourse markers which are syntactically restricted to second position and which must always occur there (to be discussed in the body of this thesis). Altenberg's data show that connectors such as for example, for instance, and however clearly show a proclivity for initial position, but when they occur in second position, they "create specific discourse-related orientations" (Altenberg 2006:12, citing Smits 2002:135).
} 
occur in a variety of non-initial positions throughout sentences and clauses. As a discourse marker (they use the term "discourse particle"), mitaki 'right' occurs in utterance-initial position, and has a discourse function as an affirmation marker, i.e. acknowledgment of information (see Massum, Starks, and Ikiua 2006:194-195).

Second, while the foregoing markers all have double lives, one as a grammatical or lexical item, and another as a discourse marker, the cross-linguistic data also show discourse markers which have no (or very little) referential meaning, and have only one function as interpersonal markers, or as I prefer to call them, MYSTERY PARTICLES (following Longacre 1976). These markers work full-time as discourse markers, and are notoriously hard to define. What both types of markers have in common is that they are multifunctional, able to function on different planes of discourse, and do work above the level of the sentence.

Third, since discourse markers are not limited to the initial position, but appear to occur in all positions cross-linguistically, as well within the morphological environment as affixes, location cannot be a test for identifying linguistic items as discourse markers. Yet, despite this fact, the cross-linguistic data appears to suggest that languages do have predispositions or affinities for certain positions as docking spots for discourse markers. For example, English discourse markers show an affinity for initial position (Schiffrin 1987). Cantonese discourse markers show an affinity for final position, having been labeled by modern Chinese grammars as "sentence-final particles" (Kwong 1989:39). Various Danish discourse markers have been analyzed as "positionally restricted to the 
central field of the sentence" (Davidsen-Nielsen 1996:299). ${ }^{29}$ As we will see, Ojibwe discourse markers show a broader affinity for docking spots, including initial position, second position, as well as those within the morphological environment in the form of clitics and preverbs.

Fourth, discourse work is not restricted to individual words, affixes, preverbs, or lexicalized phrases, or even mystery particles, but is extended to tense-aspect systems as well. TAM systems, i.e. inflectional morphology, are exploited in order to accomplish work above the sentence level in the same way that individual grammatical or lexical items are exploited for this same reason. As we already have seen, inflectional systems which have a particular grammatical function within sentence grammars, may be used to provide overall textual cohesion. This aspect of discourse marking is largely left out of discussions surrounding discourse markers, especially in defining them. ${ }^{30}$ The exploitation of inflectional morphology for discourse work in this way has to be included, I argue, if we are to understand the true mechanism behind discourse markers. This perhaps means that we need to broaden the term discourse marker to include the use of inflectional morphology.

Fifth, there is no evidence that discourse markers must be syntactically detached from their host clauses, as suggested by Schiffrin's initial characterization. While flexibility of position might be a trait sometimes observed for discourse markers in some less-inflected languages such as Spanish (Schwenter 1996:858 for o sea) and Italian

\footnotetext{
${ }^{29}$ Still, in small number of languages, the movement of discourse markers is more free to float within host clauses. Italian and Finnish, for example, show examples of individual discourse markers which may appear in various locations throughout the clause (Bazzanella 1990 and Hakulinen et. al 1992, respectively). English has discourse markers which may move freely within utterances as well, e.g. $y^{\prime}$ know, but the overall preference for English discourse markers is still initial position.

${ }^{30} \mathrm{I}$ am using the term discourse marking as a way of making a distinction between discourse markers (individual items or lexicalized phrases) and the use of inflectional morphology for discourse work.
} 
(Bazzanella 1990:633 for insomma), and to some extent English (Schiffrin 1987:276, 340), the cross-linguistic evidence shows that many discourse markers are morphologically bound to their host words as either clitics or affixes. Recall that in Yagua, discourse clitic jịita occurred in second position. As we will see also, Ojibwe has many markers which are confined to second position. Ojibwe also shows one marker occurring as a prefix-like element called a relative preverb (to be discussed in Section 3.1.3.1). Given these facts then, we cannot stipulate syntactic detachability as a test for the identification of discourse markers.

Finally, tonic stress, or the lack of stress, cannot be stipulated either, since many discourse markers do not appear to turn on this distinction. For example, as we will see for Ojibwe, the second position word idash and its phonologically reduced clitic form -sh both serve the same discourse function. In Schiffrin's data, there appeared to be no difference in discourse function between the full form of because and its phonologically reduced form cause. Moreover, there are no references in the cross-linguistic literature where tonic stress, or lack thereof, played any significant role in their status as discourse markers. Such a characterization would seem to exclude discourse markers which do not have a range of prosodic contours, such as the Ojibwe discourse marker sha (to be discussed within the body of this thesis). To my knowledge, this marker has only one prosodic contour, but still has a role within discourse. Whether a particular marker has stress or not appears to be constrained by the language itself, not by constraints 
originating from discourse processes. Therefore, whether or not a suspected marker has

tonic stress or not cannot be a viable test for its status as a discourse marker. ${ }^{31}$

Based upon the cross-linguistic behavior of discourse markers, I propose the

following definition for what expressions may serve as discourse markers, updating

Schiffrin's prior tentative definition.

(19) Definition of discourse markers, an update

Any linguistic expression, whether it be a word, particle, lexicalized phrase, affix, or TAM system, or whatever, may serve as a discourse marker, or discourse marking device, if it operates at both local and global levels of discourse (i.e. bracketing power), and operates on different planes of discourse (i.e. serves some discourse function), contributing to either textual coherence or interpersonal/epistemic meanings, or both simultaneously.

This definition essentially eliminates the first three requirements initially put forth by Schiffrin (1987) since they are not substantiated by cross-linguistic data, namely, that discourse markers be syntactically detached from a sentence, that they occur in initial position, and that they have a range of prosodic contours. Note also that this definition necessarily extends the status of discourse markers (or as I prefer to refer to this process, "discourse marking") to include TAM forms as well, if those forms are used for discourse work, e.g. creating textual cohesion. In this way, it is the manner in which words are cast

\footnotetext{
${ }^{31}$ Unless what is meant by Schiffrin's observation that a marker "have a range of prosodic contours" is that discourse markers show or exhibit a range of contours, such as appearing as stressed or not stressed. Then, the cross-linguistic data does support this. It is unclear to me, however, how this helps to determine whether an expression is a discourse marker or not. This was not made clear in her original 1987 work either. In my research, whether there was a significant pause or not occurring directly after markers did not appear to be diagnostic either. For languages like Ojibwe which make heavy use of affixes, pauses would not be a significant factor in their determination as discourse markers, nor have I found any differences between those markers which exhibited pauses, and those that did not.
} 
via the processes of tense, aspect, and mode, which are targets for discourse, rather than the individual linguistic form itself. Therefore, an inflectional paradigm may be exploited for discourse work in much the same way that individual lexical or grammatical items are exploited for the same reason if that inflectional paradigm has a function which might be exploited, used, or borrowed for discourse work. As the cross-linguistic data show, this is typical discourse marker behavior. Therefore, while unintuitive at first, the inclusion of "word shape" (the use of inflectional systems, or TAM forms) must be included within our definition of discourse markers, otherwise we would not be able to account for a large number of languages which make productive use of TAM forms in order to accomplish a variety of discourse functions. Until now, the literature has largely ignored the use of TAM forms within their definitions of discourse markers. This definition includes them.

Put simply, this definition says that any linguistic item or TAM form may serve as a discourse marker (or discoure marking device) if it contributes to the textual organization of a narrative, or contributes some interpersonal or epistemic meaning in a way that accomplishes some kind of discourse work, whether it be negotiating a turn at talk, realizing some speech act, establishing some distance from a proposition, or whatever. The criteria that discourse markers operate on both local and global levels of discourse means that discourse markers may link (or bracket) adjacent units of discourse or link units across wider spans of discourse, respectively. Recall that we have already seen this at work for the discourse marker because in (8) above where it linked adjacent utterances, as well as linking an utterance with a whole narrative. What is at the heart of this definition, however, is Schiffrin's observation that discourse markers are multifunctional, 
a feature of discourse markers which allows them to operate on different planes of

discourse. Multifunctional here does not mean a dichotomy of monofunctional vs. multifunctional, i.e. whether an individual item has one function (e.g. as a hedge) or many (e.g. as a hedge, aspectual marker, and discourse sequencer); rather, it indicates that when the English contrastive marker but is used, for example, the speaker may not only be textually creating coherence by contrasting upcoming discourse with prior discourse within the Ideational Structure ("idea units"), but may also be functioning interactively within the Action Structure to allow the speaker "to make a point in reaction to interruptions, distractions, challenges and disagreements" (Schiffrin 1987:164). In other words, a discourse marker is not merely signal some textual or interpersonal function in relation to some propositional content, but also simultaneously allows a speaker to express some social, cognitive, interactional, and/or cultural content. Recall that the English discourse marker but (as we already saw above) did not just do the mechanical work of contrasting idea units or propositions, but also allowed the speaker (Freda) to simultaneously establish her turn at talk (Exchange Structure), establish her nonalignment with the interlocutor's proposition (Participation Framework), and to provide a rebuttal (Action Structure). ${ }^{32}$ It is this multifunctional feature on different planes of discoure

\footnotetext{
${ }^{32}$ Not accounting for such social, interactional, or cultural aspects of discourse markers may be the reason why RT accounts of discourse markers have not been totally successful in accounting for the differences between the coherence relations of the discourse markers nevertheless, although, however, whereas, and yet. As Blakemore points out, these coherence relations "are not captured in an analysis which links them to a contrastive or adversative relation" (Blakemore 2004:235). In other words, to say that they mark a contrastive or adversative relation is not sufficient to explain why one contrastive marker would be used over another. While I provide no analysis here which would account for the subtle differences between these contrastive markers (an analysis which would require the examination of actual language data and not made-up examples), I venture to say that such differences might be accounted for if viewed not just in light of their mechanical "contrastive" or "adversative" function (which RT theorists appear to do), but also in light of what social, interactive, and cultural motivations speakers might have in using them.
} 
which is the core defining feature of discourse markers, and is a feature which appears to hold true for discourse markers across languages, whatever their form or position.

Finally, while this definition is broad enough to include any form that a language (or their speakers rather) may designate as a discourse marker, it must be reiterated here that the actual form or docking spot of discourse markers appears to be largely constrained by the existing grammatical machinery (i.e. grammar, grammatical categories, lexical inventory). In other words, if a language makes heavy use of affixes, such as many of the indigenous languages of the Americas, then it should be no surprise that some discourse markers in those languages would occur as affixes. Conversely, in languages which are not richly inflected, we would not expect to find many, if any, discourse markers which occur as affixes. This is indeed what we find for English. The same is true for potential docking spots for discourse markers. Recall that the Amazonian language Yagua has a discourse marker which occurs as a second position discourse clitic. Ojibwe, as we will see, has this as well. These languages make regular use of second position, and so naturally, second position serves as a potential docking spot for discourse markers. To my knowledge, we find no such markers in English (except for special discourse related phenomena such as when exemplifying or contrastive markers are used to highlight the initial element), or in other languages which do not make regular use of second position. My ultimate point here is that speakers of a language tend to use the existing machinery available in their language in order to accomplish discourse related work. Not just any machinery, but machinery which might lend itself to the speaker for work at the discourse level. 
There is evidence that existing machinery from other languages resulting from language contact can influence both the identity and location of discourse markers. For example, Torres (2006) noted that some Spanish discourse markers have been borrowed into the indigenous speech of both Tojolab'al and Yucatec Maya speakers, and now cooccur with indigenous native markers (Torres 2006:616).

(20) Spanish markers borrowed into indigenous speech (Torres 2006:616)

a) Tojolab'al (Torres 2006:616 quoting Brody 1987:512)

Entonse $\boldsymbol{t} i=$ wa $\quad$ yajni jaw $=7 i$

then $\quad$ then $=$ but now when that $=$ term

'And that's how it was.'

b) Yucatec Maya (Torres 2006:616 quoting Solomon 1995:293)

DESPWÈESE'ká $t \quad u$ tukul $t \quad u$ bino'o[b] kàahahchik'intz'ono'ot after-top then prog erg3 think-incomp prog erg3 go/incomp-P town Chikindzonot

'After, then they were thinking of going to the town of Chikintzonot.'

In these examples, the standard Spanish words entonces 'then' and después 'after' have both been borrowed into Tojolab'al and Yucatec Maya as markers entonse and despwèese, respectively; and now co-occur with the native markers $t i$ 'then' and $k a$ ' 'then', respectively.

Other types of borrowings occur as well. Maschler (1997), for example, noticed that in Hebrew-German bilingualism "discourse may be separated from its frame of markers 
so that the discourse happens in one of the two languages and the discourse markers are verbalized in the other" (Maschler 1997:203). Also, Zavala (2001) showed that Quechua-Spanish bilinguals have restructured a standard Spanish conjunction, pues, as a discourse marker, pe or pes, in Andean Spanish.

What is particularly interesting about Andean Spanish is that not only have the speakers phonologically reduced pues to pe or pes (given that Quechua does not permit vowel sequences in its syllabic structures), they have also restructured the position of pes from initial position (where Spanish particles borrowed into indigenous languages usually occur) to final position seemingly based upon Quechua structure (Zavala 2001:1003-1004 quoting Brody 1995:137). The point here, of course, is that speakers appear to make use of available linguistic machinery either via their own language, or by the machinery made available by language contact situations. In the case of Andean Spanish, the identity of the marker pes originates from the contact language (Standard Spanish), but is constrained by the indigenous language (Quechua) in both phonological form and location. 


\subsection{Ojibwe Discourse Markers}

The discussion of Ojibwe discourse markers will be divided up into two major classes: 1) discourse connectives, and 2) 'mystery particles'. Discourse connectives in Ojibwe are largely borrowed items (my wording) - items which have sentence-level uses, but which lend themselves for work at the discourse level. They contribute to the overall textual structure of a discourse, functioning to relate units of discourse in prior discourse with upcoming discourse. Ojibwe mystery particles, on the other hand, are markers which are largely interpersonal, attitudinal, or epistemic in nature. They are somewhat different from the Ojibwe discourse connectives in that they are not borrowed sentence level functions which are then used at the discourse level, but are full-time discourse markers. Ojibwe mystery particles work at both the sentence and discourse level, all the time. The one common trait that both types of markers share as discourse markers is that they do work at a level above the sentence to contribute some discourse effect, either structurally (discourse connective) or pragmatically (mystery particles). The organization of Ojibwe discourse markers into these two categories is largely motivated by the natural division of discourse markers observed by Schiffrin and Brinton into textual and interpersonal functions (Schiffrin 2003:459, Brinton 1996:38, respectively). All markers in this thesis will be further divided into those which occur in initial position, those which occur in second position, and those which occur as a relative root. 


\subsection{Discourse connectives}

\subsubsection{Initial position}

The following discourse markers fit most of the criteria for English discourse markers described by Schiffrin, in that, they all occur in initial position, may have tonic stress, show syntactic detachability from their containing clauses (except for mii dash which shows loose detachability), and have both primary functions in the ideational plane of discourse (in sentence grammars) and secondary functions in other planes of discourse (above the sentence level). In other words, like some of the English discourse markers such as and, but, because, for example, these discourse markers (except for onzaam) have functions which reflect their grammatical or lexical use in sentence grammars. Their sentence level functions are essentially exploited to perform work above the sentence level. While this is the predominant pattern, onzaam 'because' does not show this tendency; or at the very least, it is not transparent how its discourse function is related to its sentence level meaning 'overly, too much', if at all. This is not problematic, however, since it has been observed that some functions of discourse markers do not entirely reflect their functions within sentence grammars (see Grimes 1975:4, Schiffrin 1987:320, Schourup 1985:123). Nevertheless, all of these discourse markers bracket linguistic units in some way on both local and global levels, relating prior text to upcoming text in ways which achieve textual coherence. In other words, they act as the "discourse glue" which holds or binds the text together. The type of coherence created is largely dependent upon the discourse marker in use. The major discourse connectives observed in the data are discussed below. 


\subsubsection{1 inashke}

In sentence grammar, the interjection command particle inashke 'look!' is an attention-getter, similar to the function of the Japanese interjection word hora 'look!, see!, listen!' (Nakao 1995:93). It also has various truncated forms, e.g. nashke, shke, ke, inake, ina, or just $n a .^{33}$ Its function is actually two-fold in that it not only attracts attention (much like the English hey! would do), but attracts attention to something or someone as a way of pointing something or someone out. Like its Japanese counterpart, the linguistic form inashke is not based upon a 'seeing' root per se, and is never involved in the formation of words indicating sight, seeing, or looking. It is purely an attentiongetting word, and may optionally occur with words which denote seeing or hearing. This usage is demonstrated below, glossed as AT ("attention getter") for convenience.

(21) Attention-getter nashke (Mille Lacs Sessions)

a) Nashke maakigiyaan.

AT I am healing over

'Look where I'm healing over!'

b) Nashke bizindan.

AT listen

'Listen!'

\footnotetext{
${ }^{33}$ There might be some doubt whether forms such as inake, or ina, are actually variations of inashke. My consultants tell me that they are, so I have listed them together here with inashke.
} 
c) Nashke!

AT

'Look!, See!, Listen!, What's that?'

As a discourse marker, this basic attention-getting function of inashke is also seen above the sentence level, where it is used as a discourse highlighter, highlighting salient information. When used as such, it has a function similar to the English discourse marker you see, but again, while the English counterpart is based upon an actual 'seeing' word, the Ojibwe marker nashke is not. It is, therefore, not its lexical meaning, but its grammatical function as an attention-getter that is borrowed for discourse work. ${ }^{34}$ In its general discourse function as a discourse highlighter, inashke brackets and marks upcoming talk as being more salient, allowing speakers to mark special insights or knowledge which might provide the listener with perspective, to draw out distinctions, to mark the exposition of examples, or confirming speaker disposition. This highlighting function shows that inashke is both forward- and backward-looking since it sets off (or brackets) upcoming text in order to mark it as salient in relation to prior text. These functions are discussed below.

An example of inashke marking insights occurred in a narrative about traditional healers. Prior to the inashke utterance in the following example, the speaker first relates the method by which traditional healers were given knowledge of medicines and how to diagnose illnesses, i.e. via spiritual means. The speaker then reveals what they were able

\footnotetext{
${ }^{34}$ It is unclear whether the inashke function in Ojibwe fully mirrors the English you see, since it is unclear exactly what all the functions of you see are in English.
} 
to do with that knowledge, an utterance preceded by shke (glossed as DM for "Discoure Marker"). ${ }^{35}$

(22) inashke marking insights (Clark 2003:54, audio)

a) Ongow wiin mewinzha-go gekenimagig nenaandawi'iwejig, manidoon these contrast long ago the ones I knew healers spirits ogii-miinigowaan onji-gikendamowaad mashkiki miinawaa ezhiwebizinid they gave it to them from whence they know medicine and what's wrong with them anow owiij-anishinaabewaan awiiya nanaandomigowaad. them their fellow Indians someone when s/he asks them for help

b) Shke mewinzha, dibaajimowaad ongow gaa-nanaandawi'iwejig, DM long ago they tell these who healed people mii miinawaa-go gaa-zhi-mikamowaad biinjayi’ii awegonen etenig imaa DP and and found inside it what put there owiiyawing wa'awayaakozid, awegonen o'ow gaa-aakozhiishkaagod. in his/her body this sick person what this what made him/her sick

a) 'As for the healers long ago that I know of, the spirits gave them their knowledge of medicine and to know what was wrong with their fellow Indians when someone asked them for help.

b) You see, a long time ago, these that healed people would diagnose, and found inside the sick person's body what was ailing them.'

The information highlighted by shke in this utterance is special knowledge, knowledge that might not be well-known these days about traditional healers. The speaker first explains where traditional healers received their knowledge, and then follows that statement up with an insight, that is, what the traditional healers used to do with their attained knowledge. The use of shke to highlight upcoming text in (22b) allows the

\footnotetext{
${ }^{35}$ The particle mii in these narratives will be glossed as DP for "Deictic Particle". This particle is discussed
} in Section 3.1.1.5. 
speaker to set that information off as significant from prior text in (22a). This use also occurs in the next few lines of this story where the speakers highlights their healing instruments, i.e. bones. Because the use of bones to heal people is somewhat of a lost art and largely an unknown fact these days among the younger generation (and non-Indians), the use of shke here allows the speaker to give special attention to this fact.

(23) inashke marking insights (Clark 2003, audio)

a) Mii dash i'iw imaa, nashke mii noongom inigaaziyang gaawiin awiiya and then that there DM DP today we're pitiful not someone ayaasiiwag geyaabi aapiji ongow ge-nanaandawi'inangig. there is no one anymore hardly these those who could heal us

b) Shke wiinawaa ongow, mewinzha gaa-nanaandawi'iwejig DM they these long ago those that healed people miinawaa anow odookanimiwaan gii-aabaji'aawaad nawaa awegonen and those their bones they used them and what gaa-miinindwaa ji-aabajitoowaad. what was given to them for them to use

a) 'See, that's why we're so pitiful these days, there aren't very many people anymore who could heal us.

b) You see, these who healed people a long time ago, would use their bones and whatever they were given to use.'

Inashke may also highlight upcoming text in order to draw out distinctions. In the following example, inashke is used to show such a distinction between the use of the Ojibwe and English languages. 
(24) inashke (Clark 2003:50, audio)

a) Gaawiin ige gidaa-gashkitoosiimin weweni ji-ikidoyang i'iw ge-ikidoyangiban. not also we wouldn't be able to carefully for us to say that what we would say

b) Shke ojibwemoyang gigikendaamin waa-ikidoyang. DM when we speak Ojibwe we know what we want to say

a) 'We also would not be able to say correctly what we would say.

b) You see, when we speak Ojibwe, we know what we want to say.'

The distinction being drawn here is the one between the use of the English language and the Ojibwe language by a bilingual speaker. In short, an Ojibwe speaker could not be exactly sure of what s/he is saying when using English, but would know were they to use Ojibwe. The use of shke in (24b) allows the speaker to draw special attention to the use of Ojibwe so as to make the distinction more salient in relation to prior text.

Sometimes inashke may precede the exposition of examples, having roughly the force of the English expression for example. In such cases, upcoming text highlighted by inashke usually represents a a real life example of a description given in prior text. This example giving function is given below.

(25) inashke in providing examples (from Clark 2003:55, audio)

a) Mii dash bebakaan weweni ogii-kikendaanaawaa awegonen o'ow enaabadak then and each different carefully they knew it what this how utilized o-mashkiki. this medicine 
b) Shke, wa'aw nookomisiban mii-ko gaa-paa-izhi-mamood o-mashkiki see this my grandmother used to would pick this medicine

gekendaagwadinig ge-inikaagod a'aw anishinaabe, gii-agoodood known to be to affect him/her that Indian hanged it up

endaad, gii-paasang, gii-na'inang.

her house dried it put it up

c) Nashke ingoding miinawaa, ogii-pi-odisigoon awiiya, "wa'aw nenaandawi'iwed see pretty soon and s/he approached her someone this healer

indig, gidayaan i-mashkiki giiwenh ge-minokaagoyaan”.

tells me you have the medicine apparently that would be good for me

a) 'And so they each knew different utilizations of medicine.

b) You see, my grandmother used to pick medicine known to affect people, and would hang it in her house, dry it, and put it away.

c) [Nashke] Pretty soon, someone came to her, "This healer told me you apparently have the medicine that could help me.",

The function of inashke in (25) is to point out examples of a process, event, or tradition. A description is given, and then followed by illustrating examples. Prior to the example in (25a), for example, the speaker was describing how each village had their own particular knowledge of different medicines known to heal people, and that traditional healers would send people to particular villages where there were people who had the appropriate medicine. It is after this description that the speaker gives the example of his grandmother, and the example of someone visiting her. Both utterances are prefaced by inashke. This example giving function of inashke can be seen in the following example as well where the speaker gives a description about Ojibwe clans, and then proceeds to give an example of that description. 
(26) inashke in providing examples (Kegg 1991:142)

a) Mii ingiw anishinaabeg, mii giiwenh ezhi-inawendiwaad akeyaa

DP those Indians that apparently how they are related way

ezhi-odoodemindiwaad.

when they have the same totem

b) Nashke a'aw waabizheshi, iniw waabizheshiwan gaawiin odaa-wiidigemaasiin. see that marten that marten not s/he couldn't marry him/her

a) 'Those Indians were related to each other in a way when they had the same totem. $^{36}$

b) A marten, you see, couldn't marry another marten.'

In (26), the speaker first describes the tradition that persons having the same clan did not marry each other because they are related by clan. This description is then followed up with an illustration, i.e. that a marten clan member could not marry another marten clan member. In this way, inashke allows the speaker to provide an example of how the general taboo against marrying a member of your own clan might be violated.

Sometimes speakers may use inashke to make clarification or explanations as part of its highlighting function. One example of this is illustrated in an excerpt below where the speaker clarifies his own contribution to the language loss of the younger generation.

(27) inashke to make clarifications (Clark 2003:58-59, audio)

a) Gaye niin igo imaa indaa-anaamindiz igo dibishkoo epiitiziwaad ongow also I EMPH there I should blame myself EMPH same as age these niij-anishinaabeg epiitiziyaan gaa-izhaajig imaa gikinoo'amaadiiwigamigong. my fellow Indians the age I am who went there to school

\footnotetext{
${ }^{36}$ In other words, those that had the same clan. My consultants prefer the use of the term clan here, rather than totem (as published).
} 
b) Nashke azhigwa eni-apiitiziyaan, gaye niin gii-maajii-noodendamaan see now as I come of age also I I started feeling flirtatious

o-dibishkoo gaye niin gii-kikenimagwaa ongow ikwezensag

same as also me when I knew them these girls

ayaawaad ikwezensiwiwaad gii-gikenimagwaa.

there are are girls when I knew them

c) Mii imaa gii-wiikwajitooyaan gaye niin wii-shaaganaashiimoyaan.

that there I tried also me to speak English

a) 'I too should blame myself the same as the others that are of my age who went to school.

b) You see, after I came of age, I too started feeling flirtatious when I noticed that the girls were girls.

c) That's when I too tried to speak English.'

In (27a), after stating that he and his generation are to blame for the loss of Ojibwe language use, he immediately gives the reason in (27b), accenting it with nashke. In short, he explains that his contribution to the current predicament originated from his personal desire to talk to girls at school. Since they did not speak Ojibwe, he had to speak English. Used in this way, inashke marks this clarification.

In arguments between two people, inashke may be used to point out something that was perhaps obvious to the speaker, but not to interlocutors, having roughly the force of the English see! (with rising intonation). In these argumentative situations, inashke may appear as ina, e.g. [In $\Lambda$ ], [Ina], with rhetorical lengthening on both vowels accompanied by stress on the initial vowel [i:na:]. The following example provided by one of my consultants illustrates this usage. 
(28) ina

Ina, gidaano-inin.

see I tried telling you

'See, I told you.'

In monologic narratives where there is only one speaker, this function can be seen also.

This is shown below where the speaker points out a result of not having any traditional healers anymore (from the example from above).

(29) inashke (Clark 2003:54, audio)

a) Shke mewinzha, dibaajimowaad ongow gaa-nanaandawi'iwejig, see long ago they tell these the healers

mii miinawaa-go gaa-zhi-mikamowaad biinjayi'ii awegonen etenig imaa DP and they found it inside it what be put there

owiiyawing wa'aw ayaakozid, awegonen o'ow gaa-aakozhiishkaagod. in his body this who is sick what this what made him/her sick

b) Mii dash i'iw imaa, nashke mii noongom inigaaziyang gaawiin awiiya ayaasiiwag DP and that there see that today we are pitiful not someone they don't exist

geyaabi aapiji ongowge-nanaandawi'inangig.

anymore extremely these who could heal us

a) 'You see, a long time ago, these that healed people would diagnose, and found inside the sick person's body what was ailing them.

b) See, that's why we're so pitiful these days, there aren't very many people anymore who could heal us.'

In both examples, inashke functions to point out something that has the effect of strengthening the point of view of the speaker. In (28), the speaker uses ina to point out a 
predicted event. In (29b), the speaker uses nashke to point out that because there are so few traditional healers these days, that this is the reason why Indians are adversely affected in modern times. In both cases, this "pointing out" or highlighting function of inashke has the affect of confirming a pre-existing belief or condition put forth by the speaker, a belief or condition that perhaps was not previously obvious or appreciated by interlocutors.

While the above examples show that inashke may have various functions in discourse, i.e. prefacing descriptions of special insights as a way to provide perspective, drawing out distinctions, presenting examples, and confirming speaker disposition, these realizations are only manifestations of the underlying function of inashke as a discourse highlighter, which is its function at the sentence level. In other words, inashke allows the speaker to highlight upcoming text in order to mark it as salient in relation to prior text.

\subsubsection{2 miinawaa}

In the dictionary, miinawaa has the listing 'and, also, again' (Nichols and Nyholm 1995:89). Its primary role in sentence grammars is as a coordinating conjunction, but it may also have minor functions as an adverb, or as an adjective. As a coordinating conjunction, miinawaa may coordinate various constituents as long as they are the same category, and it usually occurs in between the coordinated clauses. This is shown below where miinawaa is shown to coordinate noun phrases, adjective phrases, and verb phrases. 
(30) coordinating conjunction

a) (Kegg 1991:66-67)

$\begin{aligned} & \text { Wegwaagi } \\ & \text { look iniw aya'aan mashkodesiminan miinawaa } \\ & \text { that whatchamacallem beans and ark }\end{aligned}$
ezhi-dagozonid.
cooking with something

'Why look, there were beans and pork cooking in there.'

b) (Anderson 1991)

Naawigiizisookwe gii-onaanigozi, miinawaa gii-kizhewaadizi.

Naawigiizisookwe she was happy and she was kind

'Naawigiizisookwe was happy and kind.'

c) (Kegg 1991:154-155)

Mii eta go gaa-izhichiged, apane gii-izhaad iwidi Gabekanaansing DP only EMPH what he did always he went over there Portage Lake

bibooninig, agoodood miinawaa wanii'iged.

in the winter that he snares and that he traps

'That's all he did, always going there to Portage Lake in the winter, snaring and trapping.'

In (30a) miinawaa coordinates two noun phrases: mashkodesiminan 'beans' and gookooshan 'pork'. In (30b), it coordinates two verb phrases (independent clauses): giionaanigozi 'she was happy' and gii-kizhewaadizi 'she was kind'. In (30c), it coordinates

\footnotetext{
${ }^{37}$ My consultants were not familiar with the word wegwaagi as it appears in Kegg 1991, which is a compilation of stories collected in the 1970s. This term appears to have gone out of use with modern speakers.
} 
two subordinate verb phrases (subordinate clauses): agoodood 'that he snares' and wanii'iged 'that he traps'. 38

As an adverb, miinawaa has a meaning equivalent to the English again, signaling the re-occurrence of an event. As an adjective, it has an additive meaning, having roughly the meaning of the English another. These meanings are shown below.

(31) miinawaa

a) adverb (Kegg 1991:106-107)

"Gego miinawaa ingoji daa-izhaasiin, ${ }^{39}$ Naawakamigookwe," ikido. don't again somewhere s/he should not go Naawakamigookwe she says

“"Don't let Naawakamigookwe go anywhere again," she said.'

b) adjectival (Clark 1998:8, audio)

Mii imaa naaniibawiyaan gomaapii go miinawaa bezhig mindimooyenh it is there I'm standing around a while EMPH another one old lady

zaagewe.

$\mathrm{s} /$ he appears

'I stood there a while and another old lady appeared.'

\footnotetext{
${ }^{38}$ There is much to be explored in regards to conjunction in Ojibwe however. While the above examples showed that the two coordinated clauses were identical in category, i.e. NP miinawaa NP, VP miinawaa VP (for independent and conjunct order verbs, respectively), examples can be found where verbal modes are mixed, e.g. Asemaan gii-izhiwidamoonangwaa, miinawa ogii-ni-apenimonaawaa miigwanigikiwe'on. 'They carried tobacco for us, and relied on an eagle staff.' For this example, while the two coordinated clauses (underlined) are verb phrases, the first is a conjunct order verb and the second is an independent order verb.

${ }^{39}$ The verb here might actually be da-izhaasiin (with the use of the future tense marker $d a$-, rather than the modal marker $d a a-$ ) as this would be more fitting of the translation 'don't let Naawakamigookwe go anywhere'. I have not been able to confirm this, however, against the original audio recordings, and so I am only noting this here.
} 
Above the sentence level, miinawaa has a function which largely mirrors its sentence grammar usage as a coordinator, but works on a more global level in order to coordinate idea units. It acts as a discourse coordinator, coordinating similar discourse units. As Schiffrin showed for the English discourse marker and: "the presence of and signals the speaker' identification of an upcoming unit which is coordinate in structure to some prior unit" (Schiffrin 1987:141). This is certainly true for Ojibwe as well. In other words, when miinawaa occurs, it is coordinating upcoming discourse units with some prior discourse unit. This is shown in the following example. Note that I have formatted the sentences containing miinawaa to make its discourse structure more visible.

(32) miinawaa (from Kegg 1991:108-109)

a) Gaawiin awiiya iwidi daa-daasiin imaa wanako-neyaashi. not someone over there should not live there end of the point

b) Gii-taawag iko iwidi anishinaabeg, ingodogamig. they lived used to over there Indians one household

c) Bezhig iwidi inini gii-taa, gaa-izhi-nibod. one over there man he lived there then he died

d) Mii miinawaa gaa-izhi-adaawangewaad oshk'-aya'aag, mii i'iw waakaa'igan, DP and they then rented young couple DP that house

e) miinawaa iniw oniijaanisan imaa gaa-izhi-nibonid. and that his/her children there then died

f) Miinawaa imaa aabiding akiwenzii gii-adaawanged miinawaa mindimooyenh. and there one time old man he rented and old lady

g)

Mii miinawaa a'aw akiwenzii gaa-izhi-nibod. DP and that old man then died 
a) "Nobody will live there on the end of that point.

b) There used to be some Indians living there, one household.

c) One man lived there, and then he died.

d) And then a young couple rented that house

e) and one of their children died there.

f) And once again an old man and old woman rented it.

g) Then again the old man died. ..."

In this example, there are three sets of discourse units, here, in the form of set-up propositions and their consequent propositions, which are both: 1) someone rents the house, and 2) they consequently die. Strikingly, each occurrence of miinawaa in this example coordinates a similar prior discourse unit. For example, coordinated with the set-up proposition a man lived there in (32c), are the set-up propositions and then a young couple rented that house in (32d) and and once again an old man and old woman rented it in (32f). Coordinated with the consequent proposition and then he died in (32c) are the consequent propositions and one of their children died there in (32e) and then again the old man died in $(32 \mathrm{~g})$. With the coordinated structures extracted, the structure of each coordination would look like the following.

(33) Coordinated discourse units

a) Discourse unit \#1: set-up proposition - someone rents the house One man lived there

miinawa then a young couple rented that house miinawa once again an old man and old woman rented it 
b) Discourse unit \#2: consequent proposition - they consequently die then he died

miinawa one of their children died there

miinawa the old man died

What is striking about this example is that it also contains a sentence level usage of miinawa in ( $32 \mathrm{f}$ above) where it coordinates two noun phrases, old man and old woman, i.e. akiwenzii ... miinawaa mindimooyenh 'an old man ... and old woman. What this ultimately shows is that miinawaa, like the English discourse marker and, is multifunctional (i.e. functioning on more than one plane of discourse), since it may work at the sentence level coordinating two nouns, but also may operate at both local levels (i.e. adjacent units) and global levels (i.e. across wider spans of discourse) of discourse in order to create textual coherence.

While miinawaa may act as a discourse coordinator much like its English counterpart and, there are differences. For example, Schiffrin has shown that the English marker and may work locally, globally, or at both levels (Schiffrin 1987:138-141). In other words, and may link events associated with individual discourse topics on a local level, and it may also link discourse topics. This structure would look like the following, where and coordinates the two topics, TOPIC 1 and TOPIC 2, and also coordinates the local events associated with each of those topics. 
(34) English discourse marker and at both local and global levels

$\begin{array}{cr}\text { TOPIC 1 } & \text { (global) } \\ \text { and EVENT } & \text { (local) } \\ \text { and EVENT... } & \text { (local) } \\ \text { and TOPIC 2 } & \text { (global) } \\ \text { and EVENT } & \text { (local) } \\ \text { and EVENT... } & \text { (local) }\end{array}$

This structure is exemplified by an example given in Schiffrin 1987 which shows and working on both local and global levels within the same discourse. For convenience, the topics are underlined, and the event structures indented. All occurrences of and are in bold type. This is shown below.

(35) Example from Schiffrin 1987:140

[Do either of your daughter in laws work?]

a. No but they did.

b. Both my daughters in laws worked.

c. Uh: my older daughter in law worked for four years while my son was in school.

d. $\quad$ And she didn't become uh pregnant until he graduated.

e. And uh: she feels that once her children are in school, she'd like to go back.

f. And my younger daughter in law, uh: they got married when she was eighteen.

g. And she uh: was just starting Beaver.

h. She took up that pre nursery school?

i. For two years?

j. Y'know that get set program?

[continues with discussion of school program]

In (35b), the phrase both my daughters in laws establishes the speaker's daughters-in-law as the two discourse topics. Each discourse topic (i.e. global level) is then expanded into event structures, i.e. local units, such as events within general support, and within specific 
support (Schiffrin 1987:137). (35c-e) describes the experiences of the older daughter, and (35f-j) describes the experiences of the younger. For example, the first topic, $m y$ older daughter (underlined), is expanded into two event structures: 1) she didn't become uh pregnant until he graduated, and 2) uh: she feels that once her children are in school, she'd like to go back, both of which are prefaced by and. The second discourse topic, my younger daughter (also underlined), is expanded into two event structures as well: 1) they got married when she was eighteen, and 2) And she uh: was just starting Beaver. What this ultimately shows is that and in English is able to link discourse topics as well as linking their associated event structures. A major pattern in Ojibwe, however, shows that miinawaa usually only links the discourse topics, leaving event structures associated with those individual topics to be marked with asyndetic connection 'zero' (i.e. the juxtaposition of clauses or sentences). ${ }^{40}$ This can be demonstrated with the following example.

\footnotetext{
${ }^{40}$ A distinction must be made here regarding topics which are semantically related and those which are not. The discourse topics spoken of here are those which are semantically related. For example, in the upcoming example, the two topics being coordinated are semantically related to the main topic of the story, an old man and his daily traveling habits. Schiffrin does not make a distinction, since English may mark both semantically related topics and unrelated ones with and. As we will see, this is not the case for Ojibwe, since the broad topics which make up a narrative in Ojibwe which are not semantically related are marked by contrastive marker idash. In this way, it is idash which allows speakers to move on to new topics within narratives. The point here is, however, that Ojibwe appears to make more use of asyndetic connections in coordinating expanded event structures than does English. This is true for asyndetic connections in Ojibwe in general.
} 
(36) miinawaa (Kegg 1991:152-153)

a) Mii dash ayi'ii misko-waabowayaan iko- gii-izhi-wiindewan

DP then whatchamacallit red blanket used to it was called thus

mewinzha gichi-waabowayaanan - mii i'iw egwazhed.

long ago big blankets it is that what he covered up with

b) Miinawaa gaawiin wiikaa gii-kiichiwakwaanesiin.

and not ever he did not take his hat off

c) Gii-waabizhagindibe.

he was bald

d) Mewinzha giiwenh gii-aakozi.

long ago apparently he was sick

e) Akina dash ogii-wanitoonan iniw wiinizisan.

all but he lost them those his hairs

f) Oonh, gichi-aya'aawi a'aw akiwenzii.

Oh he is very old that old man

a) 'And a misko-waabowayaan 'red blanket' - that's what they called those big blankets long ago - that's what he wore.

b) [miinawaa] He never took off his hat.

c) He was bald.

d) It was said that he had been sick long ago.

e) He lost all his hair.

f) Oh, that old man was ancient.'

In (36), there are two topics (which are semantically related to the overall topic of the old man): 1) the blanket the old man wore, and 2) the old man never took off his hat. Only the second topic, however, is expanded into event structures in (36c-f) which amount to background information, i.e. he was bald, it was said he had been sick long ago, he lost all his hair, and oh, that old man was ancient. This has the following structure. 
(37) miinawaa at both local and global levels

$\begin{array}{cc}\text { TOPIC 1 } & \text { (global) } \\ \text { miinawaa TOPIC 2 } & \text { (global) } \\ \text { EVENT } & \text { (local) } \\ \text { EVENT... } & \text { (local) }\end{array}$

While the two topics are coordinated by miinawaa, the event structures associated with the second proposition are not. Rather, it is asyndetic connection 'zero' which links the event structures associated with TOPIC 2 . There appears to be no requirement, however, that discourse topics themselves be linked by miinawaa in Ojibwe, since topics may be found which are not marked by miinawaa. Schiffrin showed this for marker and as well, where she found that the transition from the first discourse topic to the second may be linked by so, rather than and (Schiffrin 1987:139). She also showed that and may share environments with other markers as well, even the contrastive marker but. Discourse topics may also be transitioned by other markers in Ojibwe, such nashke, mii, or by asyndetic connection 'zero'.

Just based upon these examples alone, it appears that Ojibwe makes use of asyndetic connections much more productively than does English. ${ }^{41}$ This perhaps explains why miinawa does not appear in narratives with the frequency that and appears to have in English. For example, Schiffrin noted that 1002 clause-sized idea units in her corpus were prefaced by and, compared to 440 by but, 206 by so, and only 53 by or (Schiffrin

\footnotetext{
${ }^{41}$ This is supported by the general use of asyndetic connection (i.e. juxtaposition of two constituents without a connector) in the language as a whole where a multitude of grammatical relations may be selected and displayed by the use of asyndetic connection. One example is in the displaying causality, e.g. Miish ezhi-mookawaakiiyaan wii-pimishkaayaan. 'I started crying because I wanted to go paddling' (Kegg 1991: 134). In this example, there is nothing within this sentence meaning because. It is the asyndetic connection within context which allows the grammatical relation of causality to be displayed.
} 
1987:128). A quick scan of the Ojibwe narratives examined for this thesis show no such frequency for miinawaa - not even close. In fact, the frequency of miinawaa appears to be relatively small compared to the frequency of other sentence-initial markers such as nashke, marker complexes based upon mii, or even asyndetic connection 'zero'. This ultimately speaks to the general optionality of discourse markers as noted by Schiffrin (1987), which appears to be the case with miinawaa.

\subsubsection{3 onzaam}

In the dictionary, onzaam is listed as meaning 'too much, excessively, extremely' (Nichols and Nyholm 1995:109), e.g. onzaam gisinaa 'it's too cold'. This is, in fact, its use within sentence grammars, and is well known. Its discourse function, however, display a relation of causality between units of discourse, having the force of the English because. The following shows this usage of onzaam (or zaam).

(38) onzaam (Staples 2007, unpublished transcription)

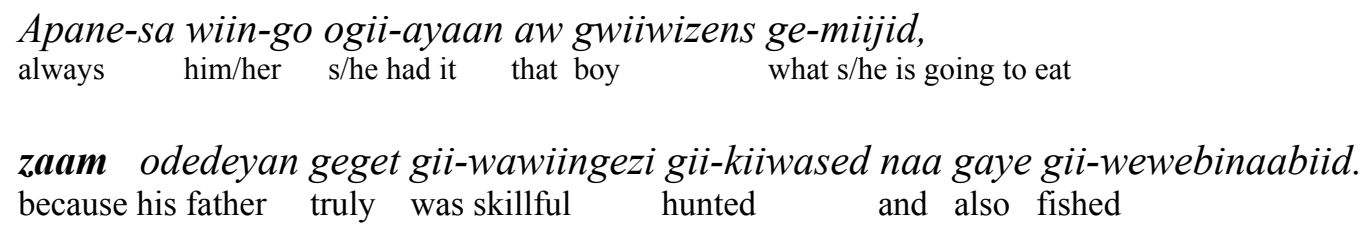

'But the boy always had something to eat, because his dad was especially good at hunting and fishing.'

In (38), there are two propositions: 1) the boy always had food, and 2) his dad was especially good at hunting and fishing. The comma after the first clause indicates a 
significant pause, showing that onzaam occurs within the intonational contour of the following clause. The use of onzaam to accent (=to occur with) the second proposition allows the interpretation that the second proposition is the cause of the first proposition, i.e. $P 1$ because $P 2$. What is also important about this example is that onzaam bears little resemblance to its lexical meaning of too much, excessively, extremely since there is no degree distinction being made in this example by the use of onzaam. In other words, the meaning conveyed here is because his father was skillful, not that the boy's father was too skillful. The fact that it does not denote extreme degree (at least for Mille Lacs speakers) is shown by the following example provided by my consultants.

(39) Onzaam (Mille Lacs Sessions)

a) Aanish ge-onji-anoonag bezhig indinawemaaganag da-naadid o'ow? why should I have one my relatives to get it this

b) Gidaa-miizh igo onzaam geyaabi gibaakaakosijige. you should give it to me because still you are open

a) 'Why should I have one of my relatives get this.

b) You should just give it to me since you're still open.'

In (39), onzaam precedes the proposition you are still open. Since stores are either open or closed, a degree distinction cannot be indicated by onzaam here. In other words, a store cannot be too open, or extremely open, it is just open. This appears to suggest that onzaam, in its discourse role, has become fully lexicalized at Mille Lacs as a marker which denotes causation, rather than as a marker of degree. Other dialects are reputed to have this usage as well, although the variety of Ojibwe spoken at Red Lake (another 
Minnesota dialect) appears not to have undergone a complete lexicalization, since onzaam appears only to be used where extreme degree is involved (Nichols, personal communication).

The use of onzaam, however, is not the only way to express causality in Ojibwe. Causality may be expressed by using a variety of linguistic devices, such as asyndetic arrangement of clauses (pragmatically inferred), or grammatical elements, i.e. the use of relative root onji- 'because'. The use of onzaam as a causality marker, then, appears to be optional, since other linguistic devices may be used to accomplish the same work. This is shown by the following examples.

(40) Causality without onzaam

a) (Mille Lacs Sessions)

Gidaa-miizh igo geyaabi gibaakaakosijige. you should give it to me still you are open

'You should just give it to me since you're still open.'

b) (Kegg 1991:134-135)

Miish ezhi-mookawaakiiyaan wii-pimishkaayaan. and then I cried I want to go ride in a boat

'I started crying because I wanted to go paddling.' 
c) (Eagle 1998:18, audio)

Wa'aw gimiinin asemaa ji-maanenimigoyan gidoonji-baapi'isinoon. this I give you tobacco so you won't feel bad because I wasn't laughing at you

'Here's some tobacco so you won't feel bad because I wasn't laughing at you.'

d) (Kegg 1991:114-115)

Mii gaa-onji-gosag, "Ingitigaan" gii-izhid. that why I was scared of him my garden he told me

'I was really scared of him because he said "Ingitigaan 'my garden"” to me.'

In $(40 \mathrm{a}, \mathrm{b})$, there is no one word which means 'because'; rather, it is the arrangement of clauses and context which allows a causal relationship. In other words, causality is pragmatically inferred. For both examples in $(40 \mathrm{c}, \mathrm{d})$, it is the use of the relative root onji- which allows a causation interpretation. The fact that onzaam is non-obligatory is not surprising, since discourse markers are commonly said to be "non-obligatory utterance-initial items that function in relation to ongoing talk and text" (Schiffrin 2001:57). The fact that other linguistic devices may do the work that onzaam does is not surprising as well, since, as Schiffrin argues for English, discourse work may be accomplished by other linguistic devices, such as lexical repetition, reiteration, thematic continuity on the local levels (clause to clause), meta-linguistic phrases, and syntactic parallels (Schiffrin 1987:57-59). Here, it is asyndetic and grammatical devices which do the work that onzaam may optionally perform as a discourse marker. 


\subsubsection{4 dibishkoo}

In the dictionary, dibishkoo is listed as 'just like, even, equal, direct' (Nichols and Nyholm 1995:45). At the sentence level, those meanings are indeed in effect. The following are typical examples of dibishkoo.

(41) dibishkoo

a) $(\operatorname{Kegg} 1991: 14)$

Mii ezhi-desa'oniked, dibishkoo go nibaagan. that and so makes a platform just like EMPH a bed 'She made a platform just like a bed.'

b) (Mille Lacs Sessions)

Gaawiin na mii iw dibishkoo...?

not INTERR DP that same as

'Isn't that the same as....?'

c) $(\operatorname{Kegg} 1991: 60-61)$

Dibishkoo, bakwezhigaansan miinawaa ziinzibaakwadoons indashamig just like cookies and candy she fed me

a'aw adaawewininiikwe; ...

that lady storekeeper

'The storekeeper fed me things like cookies and candy, ...' 
In discourse, dibishkoo has a function similar to a reformulation marker, with roughly the force of the English in other words. In this function, dibishkoo reformulates prior discourse in upcoming text in order to either make prior discourse more clear, or to allow the speaker to elaborate on a general point. Within sentence grammars, dibishkoo is more or less a linguistic equals sign, equating one object with another, e.g. mii aw dibishkoo ma'iingan 'He is just like a wolf'. At the discourse level, however, dibishkoo brackets larger discourse units, i.e. sentences, in order to allow speakers to flesh out prior discourse in the attempt to make that prior discourse clearer. This is shown by the following examples.

(42) dibishkoo

a) (Clark 1998:8, audio)

i) Mii wapii nabaj idi gaa-maajaayaan, opime-ayi'ii gii-izhaayaan. DP when probably over there after I left on the side of it when I went

ii) Dibishkoo-go ingii-paa-nanda-bami’idiz. just like I was going around looking for ways to support myself

i) 'That's the time probably when I left there, when I went somewhere else.

ii) In other words, I was going around looking for ways to support myself.'

b) (Kegg 1991:152-153)

Mii miinawaa gigizheb goshkozigwen, mii miinawaa bi-maajaad, izhaad DP again morning must wake up DP again left here to go iwidi Gabekanaansing, dibishkoo sa go washki-giiwe. over there place name just like DM EMPH s/he comes back

'And in the morning when he woke up, he left here to go there to Portage Lake, just like a round trip.' 
The use of dibishkoo in both examples above shows that the speakers are reformulating prior discourse in order to make it more clear, or meaningful. For example, in (42a), the speaker implies that he left the reservation by the use of the expression opime-ayi' ii giiizhaayaan '(lit.) when I went to the side of it'. By the use of dibishkoo, the speaker then makes it clear what he meant by this implicit statement, i.e. that he was going around looking for ways to support himself. This same sort of reformulation can be seen in (42b). There, the speaker describes an old man's journeys throughout the course of a day. This description is then reformulated with the phrase dibishkoo sa go washki-giiwe 'just like a round trip'. What is particularly interesting about this example is that there is another word specifically meaning 'round trip': biskaabii. The question here is why didn't the speaker just use the word biskaabii rather than washki-giiwe, which literally means 'turns and goes home'? The answer, I suggest, is that the use of dibishkoo in discourse is to reformulate in order to clarify. The use of dibishkoo allows the speaker to describe exactly what is going on, rather than just providing the name for the old man's day journeys.

So, while dibishkoo could be thought of as an equals sign within sentence grammars, e.g. $N P$ is just like $N P$, this core function is active at the discourse level as well. At the discourse level, however, its function is not to show equivalence per se, but to allow the speaker to clarify or flesh out prior discourse in order to make that prior discourse more clear. In this way, dibishkoo textually brackets upcoming discourse in order to reformulate prior discourse. 


\subsubsection{5 mii dash}

The lone particle mii, on which mii dash is based, is a very prolific particle in Ojibwe, as it has a wide variety of uses both at the sentence level and within discourse. In an earlier work (Fairbanks 2008, forthcoming), I showed that mii has three major functions: as a deictic particle, as an aspectual marker, and as veridical marker. As a deictic particle, mii may stand in for physical referents (such as people or things), time frames, or it may act as a modifier by providing further focusing power to the item it is modifying.

(43) Deictic function of mii

a) mii as a pronoun (Mille Lacs Sessions)

\section{Mii gaa-ikidoyan \\ that what you said}

'That is what you said.'

b) mii as a temporal deictic (Clark 2003:56-57, audio)

i) Wiin odibendaan i'iw epiitagindaasod i'iw gikinoo'amoonang aaniin $\mathrm{him} /$ her s/he owns it that how much it costs that teaching us what enaapineyang. how we are sick

ii) Mii izhinizha'onang oodi mashkikiiwigamigong ji-izhaayang that when they send us over there to the drug store for us to go mii gii-ozhibii'ang imaa mazina'igan awegonen dino mashkiki DP that he wrote it there paper what kind medicine 
ge-miinigooyang.

that we'll be given

i) 'It's they who own it, how much they charge for giving us a diagnosis.

ii) That is when they send us to the drug store with a prescription that the doctor wrote out for the appropriate medicine.'

c) mii as a determiner (Mille Lacs Sessions)
i) A'aw (=) Jaaj.
that one George
ii) Mii a'aw (=) Jaaj.
DET that one George
'That one (focused) is George.' 'That very one is George.'

In $(43 \mathrm{a}, \mathrm{b})$, mii stands in for both a physical object and a temporal time frame, respectively. For example, in (43a), mii stands in for the noun phrase what you said. In (43b.ii), mii stands in for the time frame associated with the phrase how much they charge for giving us a diagnosis. Both tokens of mii make anaphoric reference to a prior referent. The only difference between these two occurrences of mii is that in (43a), the complement of mii is a nominalized verb, i.e. gaa-ikidoyan 'what you said'; and in (43b.ii), the complement of mii is a plain conjunct verb, i.e. izhinizha'onang 'that $\mathrm{s} / \mathrm{he}$ sends us'. In the nominal predicate construction in (43c.ii), however, mii does not stand in for anything, but rather, acts like a determiner, in that, it modifies another element. Its function as a modifier is to further focus the demonstrative $a$ 'aw 'that one', which is already in a syntactically focused position. ${ }^{42}$ The use of mii in this way allows speakers

\footnotetext{
${ }^{42}$ The unmarked word order for the nominal predicate construction "that is George" (no emphasis on that) would be Jaaj a' $a w$, putting the noun first followed by the demonstrative $a$ 'aw (with no copula). Switching the demonstrative $a^{\prime} a w$ to a position before the noun results in a focus construction which puts emphasis on $a^{\prime} a w$, the initial element, e.g. a'aw Jaaj 'that is George' (emphasis on that). See Fairbanks 2008 (forthcoming) for a full discussion.
} 
to spatially locate objects (especially when pointing to them so as to leave no doubt about their selection). This demonstrative vs. determiner function is similar to the use of demonstratives in English (though English has no other specifier that adds the focusing power that mii does in Ojibwe), since they too may stand alone (as pronouns), or act as modifiers (determiners) of other elements, such as in the following English examples involving the English demonstrative that: 1) that is red, and 2) that car is red. In the first example, that is a pronoun, but in the second example, that modifies the noun car. Such is the case with mii in (43c). When it appears by itself, it stands in for objects (as a pronoun), but with the additional ability to stand in for time frames as well. When it functions as a determiner (or specifier), as in mii a'aw Jaaj above, mii contributes a more exacting meaning to the demonstrative pronoun $a$ 'aw 'that one', getting a more exacting meaning: 'that very one'.

As an aspectual marker, mii marks what I have termed IMMEDIACY ASPECT. Immediacy aspect expresses the "immediate phasal change of a temporal event or condition, typically showing either the immediate completion of an event, or its immediate inception (Fairbanks 2008, forthcoming). Many times, expressions containing aspectual mii are translated by speakers using the English temporal adverb now.

(44) Aspectual use of mii (examples adapted from Fairbanks 2008, forthcoming)
a) Iskigamide.
boil down/INDEP
b) Mii iskigamideg.
ASP boil down.0/CONJ
(completive)
'It's boiling down.'
'It's boiled down.' 

c) Giwiisin.
2.eat/INDEP
d) Mii wiisiniyan. ASP eat.2/CONJ
(inceptive)
'You are eating.'
'Now you're finally eating.'

The aspectual use of mii can also be seen with the use of the past tense marker gii-. The expression without mii represents actions which occurred sometime in the past, but the expression with mii represents that the action has just occurred.

(45) Aspectual use of mii (examples from Fairbanks 2008, forthcoming)
a) Ingii-wanendaan.
1.PAST.forget/INDEP
b) Mii gii-wanendamaan. ASP PAST.forget.1/CONJ
'I forgot it (sometime in the past).'
'I forgot it (just now).'

As a veridical marker, mii has an epistemic function and marks that the "speaker has no doubt about the verity of a statement or proposition being proposed by its containing clause(s), resulting in roughly the English glosses: it is fact, it will happen, there is no doubt that, it's a sure thing, for good, really, etc." (Fairbanks 2008, forthcoming). I consider this function to be a discourse function, as discussed in detail in Section 3.2.1.1. Therefore, a quick example should suffice for now.

(46) Veridical marker (Mille Lacs Sessions)
a) Gaawiin nigikendanziin. not I don't know
b) Mii gaawiin nigikendanziin. VER not I don't know
'I don't know.' 'I have no idea.' 
In (46), there are two negative sentences, but it is the occurrence of mii with the negative sentence which projects the attitude that the speaker has no doubt about the proposition $I$ don't know.

From these data, we can see that mii has a variety of sentence level functions, but it is the deictic feature of mii that is borrowed for work at the discourse level within the discourse complex mii dash (or miish). Discourse complex (or cluster) mii dash consists of two components, mii and idash. The second element, idash, and is a discourse marker itself and will discussed in details in the next section (Section 3.1.2.1). In short, idash is a type of topic marker (used loosely here). ${ }^{43}$ It allows speakers to move on to new topics, breaking with prior discourse. Thus, while having separate individual functions, mii and idash function as a unit as a DISCOURSE SEQUENCER. This discourse complex has become such a common occurrence in Ojibwe discourse that it appears to show signs of lexicalization (though not complete), since mii dash shows a loose syntactic connection to its containing clauses. In other words, while mii at the sentence level shows a very strict syntactic requirement for conjunct verbs, e.g. aspectual use of mii where mii must occur with plain conjuncts, mii dash on the other hand may occur with both conjunct and independent order verbs. ${ }^{44}$ As a discourse complex then, mii dash has the overall function within discourse to advance narratives, having roughly the force of the English and then, or and so. A typical usage is given in the example below.

\footnotetext{
${ }^{43}$ I'm using the term topic marker very loosely (and cautiously) to be a marker which signals a break from prior discourse to a new topic (which may be simply the introduction of a new character, theme, or subject) It basically marks topic shifts. As we will see, this is one of the major functions of $i d a s h$ within discourse. It is merely a label of convenience.

${ }^{44}$ A fact also noted in my earlier work on mii (Fairbanks 2008, forthcoming). There, I provided examples from a northern dialect of Ojibwe, Northwestern Ojibwe, where mii dash (or miihsh for that dialect) occurred exclusively with independent order verbs in an environment where conjunct verbs would be expected to occur for southern dialects of Ojibwe like Mille Lacs.
} 
(47) Discourse sequencer (Benjamin 2006, unpublished story)

a) Gegoo wawaanimigooyaang, mii imaa ezhaayaang ingiw chi-aya'aag thing when we get stumped that when we go those elders gagwejimangidwaa.

we ask them

b) Mii dash weweni izhi-wiindamawiyangidwaa mii o-keyaa omaa giinawind and then carefully how-tell.3>1P/CONJ DP this way here we ezhitwaayang. our way of life

a) 'Whenever we need to know something, that's when we go to the elders and ask them.

b) And then they carefully tell us the way we do things here.'

In this example, we see that mii dash occurs with the plain conjunct verb izhi-wiindamawiyangidwaa 'how they tell us' (a behavior seen at the sentence level as well), and has the function of advancing the narrative to the next event, action, or detail. In this sense, mii dash is able to temporally relate prior talk with upcoming talk by showing the natural progression of events, i.e. going to the elders and then being instructed. This backward-looking and forward-looking feature of mii dash is characteristic of its underlying deictic function. In this example, the temporal deictic feature of mii is quite transparent, since the events are temporally based. There are cases, however, where mii dash brackets details or commentary, rather than temporally based events. This is shown in the following example where the speaker explains that a long time ago each community had knowledge about different types of medicines and that the knowledge of those medicines was a collective knowledge. 
(48) mii dash (Clark 2003:55, audio)

a) Gaawiin ongow anishinaabe, ganabaj awiiya kina gegoo mashkiki

not these Indian probably someone all things medicine

odaa-bi-gikendanziin.

s/he would not come to know it

b) Eniwek, eniwek ge-gikendaasopan kina ji-ganawendang o'ow mashkiki, quite quite s/he would have to be knowledgeable to keep it this medicine

awegonen ge-minokaagod a'aw anishinaabe, gegoo inaapined.

what what is good for him/her that Indian thing when s/he gets sick

c) Mii dash bebakaan weweni o-gii-kikendaanaawaa awegonen o'ow, and then each different carefully 3-PAST-know it.3P/INDEP what this

enaabadak o-mashkiki.

how utilized this medicine

a) No one person would know everything about medicine.

b) One would have to be pretty knowledgeable to keep all the medicine that's good for people when they got sick with something.

c) And so they each knew different utilizations of medicine.'

Examining this example, we find that mii dash occurs with independent order verb ogii-kikendaanaawaa 'they knew it' (contrary to sentence level behavior), and advances the narrative by providing additional commentary, not by providing the next temporal event. $^{45}$ Though the clauses are not temporally related, they are sequentially aligned with mii dash.

What these data really show is that mii dash is a cluster which occurs in initial position. While mii has specific sentence level functions, it is borrowed for work above

\footnotetext{
${ }^{45}$ The fact that mii dash may occur with both conjunct and independent order verbs is intriguing. The literature to date has opted to treat cases where mii dash occurs with independent forms as exceptions or as rare cases, rather than to offer an explanation for these occurrences. As it turns out, there is a discourse explanation. This explanation is provided in Section 8.2.
} 
the sentence level within the discourse cluster mii dash in order to sequentially link chunks of discourse. These chunks of discourse may either be temporal events, or they may be non-temporal events as well, such as commentary. Also, the fact that mii dash may also occur with both conjunct and independent order verbs (showing a loose syntactic attachment to its containing clauses, or perhaps none) further supports the claim that mii dash is indeed a discourse marker in its own right. Like other discourse connectives, it largely derives its discourse sequencing feature from sentence-level phenomena - in this case, from the underlying deictic feature of the deictic particle mii.

\subsubsection{Second position}

Ojibwe is a language which makes heavy use of the second position. For example, in the formation of common interrogative expressions in Ojibwe, the interrogative particle ina, or its clitic form -na, must occur as the second element of its containing sentence or clause, e.g. geyaabi ina gibakade 'Are you still hungry?' Given this fact, it is no surprise then that a significant number of Ojibwe discourse markers, such as idash below or the second position mystery particles to be discussed later, would find a home in second position as well. In the broader discussion of discourse markers across languages, the discussion on discourse markers which occur in second position must inevitably expand the locations in which discourse markers may occur to include second position. While location itself cannot be a formal criterion for the defining of discourse markers, a discussion delimited by location (as I have done here) shows that languages in general, including Ojibwe, may utilize the existing machinery or infrastructure (e.g. common use 
of second position words or clitics) already inherent within the language itself for discourse work. For Ojibwe, one of these existing mechanisms is the second position.

\subsubsection{1 idash as a contrastive marker}

While the foregoing markers largely satisfy Schiffrin's initial characterization that discourse markers occur in initial position, there are those which do not. One such marker is idash. In my earlier work, idash was formally labeled as a SECOND POSITION DISCOURSE MARKER, which sometimes may occur as a SECOND POSITION DISCOURSE CLITIC (Fairbanks 2008, forthcoming). As this label indicates, idash must occur in the second position of a clause or sentence. But like many discourse connectives, it has functions in sentence grammar, as well as within discourse above the sentence level. In sentence grammar, idash has a very restricted use within interrogative sentences as a pin pointer, adding focusing power, allowing speakers to ask for exact information, clarification, or elaboration. This function is illustrated below.

(49) idash in sentence grammar (Mille Lacs Sessions)

a) Wegonen? what

'What?'

c) Awenen?

who

'Who?'

\section{b) Wegonen dash?}

what exactly

'What does that mean (exactly)?'

'What (are you looking for)?'

\section{d) Awenen dash?}

who exactly

'Who is it exactly?' (out of a group of people) 
Note that in $(49 \mathrm{a}, \mathrm{c})$ where the examples appear without $i d a s h$, only the bare meaning of the interrogative particle is indicated. In $(49 \mathrm{~b}, \mathrm{~d})$, however, the use of idash has an exacting function. The expression in (49b) has differing glosses depending on the context, but the use of idash in these expressions has the same effect, that of clarification, or in eliciting exact meaning. On one occasion, one of my consultants was told that there was something wrong with her hotel room. In response, she used the expression in (49b) to get elaboration. Further inquiry revealed that the room was reputed to be haunted. On another occasion when she was looking around for something in the room in which we always meet, one of my other consultants used the expression in (48d) to ask her what she was looking for. To my knowledge, it is only in interrogative sentences that idash has this exacting function.

In discourse, idash functions as a contrastive marker. As such, idash allows the speaker to contrast upcoming text with prior text, having the force of the English but.

(50) Contrastive idash

a) (Mille Lacs Sessions)

Wenda-nibwaakaa inenindizo, bagwanawizi dash.

$\mathrm{s} /$ he is really smart $\mathrm{s} / \mathrm{he}$ thinks of him/herself $\mathrm{s} / \mathrm{he}$ is dumb but

'He thinks he's smart, but he's dumb.' 
b) (Clark 2003:50, audio)

i) Shke ojibwemoyang, gigikendaamin waa-ikidoyang.

see we speak Ojibwe we know what we want to say

ii) Zhaaganaashiimoyang idash, gaawiin kina gigikendanziimin i'iw

we speak English but not all we do not know

zhaaganaashiimowin.

that English language

i) 'See, when we speak Ojibwe, we know what we want to say.

ii) But when we speak English, we don't know all of the English language.'

The contrastive marker idash not only allows upcoming talk to be contrasted with prior talk, but is also able to show this contrastive relationship from second position, much like but is able to do from initial position in English. In (50a), for example, the proposition of the second independent clause he's dumb is being contrasted with the prior clause he thinks he's smart. In (50b.ii), the subordinate clause when we speak English is contrasted with the prior subordinate clause when we speak Ojibwe in (50b.i). Note, however, that because idash must occur in second position, it is not syntactically detached from its containing clause like its English counterpart but. This appears to suggest that discourse markers need not be detached from their surrounding clauses in order to show a discourse relationship, and that languages use existing machinery in the language to accomplish discourse effects. The use of the second position word idash, I argue, is an example of this.

While the previous examples have shown that idash may contrast single clauses on a local level, the data show that idash may contrast larger units of discourse on a more global level as well. In such cases, idash does not appear, at least on the surface, to be 
selecting a contrastive relationship with prior clauses. A case in point is the following example from a narrative where the speaker is talking about the return of the crow, which is the first bird to return before the spring.

(51) idash (Unknown author 2006:13) ${ }^{46}$

a) Gii-minwendam Anishinaabe azhigwa nwaandawaad bineshiinyan dagoshininid $\mathrm{s}$ /he was glad Indian time when after s/he hears birds arriving gii-kikendang azhigwa ji-aayaabawaanig azhigwa gabe-biboon giikajid. they knew when getting warmer after all winter being cold

b) Gii-ikidowag iko, "hey giwaabanishimin." they said customarily hey we are going to make it

c) Geget idash ogii-manaaji'aawaan iniw bineshiinyan, gii-inendamoog truly DM they respected him/her that bird they thought of them as mii ongow baadoonangig ziigwan. DP these the ones who bring us spring

d) Mii dash igaye, gaawiin ogii-nooji'aasiwaawaan baanimaa gakina DP DM also not they did not hunt him/her until all gii-paashkaawe'owaad wewaawanojig. that they had hatched their eggs those that have eggs

a) 'The Indians were happy when they heard the birds arriving because they knew that's when it starts getting warmer after a cold winter.

b) They used to say, "Hey, we're gonna make it."

c) And they really respected the birds. That's how they thought of these ones that bring us spring.

d) And also, they didn't hunt them until all the birds had hatched their eggs.'

\footnotetext{
${ }^{46}$ I have transliterated the original story into the Double Vowel orthography and have re-worked the placement of periods under the guidance of my consultants. Also, the original publication gives authorship to "a Mille Lacs Band Elder." My consultants and I suspect that it was James (Jim) Clark who wrote the story and provided it to the newspaper. I subsequently asked Jim for myself if he knew who wrote the story, to which he jokingly replied, "a Mille Lacs Band Elder!" So, I never quite got a straight answer, but I think he was implying that it was indeed him.
} 
On the surface, idash in (51c) does not appear to be showing a contrastive relationship, in that, it does not show a contrast between the propositions of its containing sentence with that of the preceding sentences. In other words, the proposition they really respected the birds in (51c) is not in semantic contrast with The Indians were happy when they heard the birds arriving in (51a), nor the proposition They used to say, "Hey, we're gonna make it." in (51b). The convention of translating these idash's as 'and' only further complicates what is really going on here. Closer examination of this narrative reveals, however, that while the propositions themselves are not being contrasted, topic flow is. Another way of saying this is that idash allows a break with prior text in order to transition to a new topic, a topic shift. This has an additive effect of marking transitions from topic to topic. In English, as Schiffrin has shown (as we saw already), these global transitions are marked by and, but in Ojibwe, transitions from global topics (which are dissimilar or unrelated) are marked by idash, leaving miinawaa to coordinate similar details (coordinated content) within these global topics, i.e. lower level event structures.

For example, in (51) above, there are three discourse topics: 1) Indians were happy when the birds came back, 2) Indians really respected the birds, and 3) they never hunted them until they had hatched their eggs. There is really no logical semantic link, nor temporal link, between the transition between the first topic to the second topic, or from the second topic to the third topic. Also, these topics do not contain any inherent contrasting content which would lend themselves for a contrastive relationship, as we saw for the examples in (50) above. Here, idash does not facilitate a propositional contrast, but a contrast in discourse action, i.e. transition. In other words, idash signals a 
break from further elaboration within a given topic in order to transition to a new one. Therefore, the contrast is realized with the introduction of new topics.

It is this contrastive action, i.e. breaking with prior content, which allows for smooth transitions into what may be new and unrelated content within a narrative. As a result, the use of idash has an additive effect, since it helps to organize topics and events within the development of a story. The following example illustrates this additive effect. The use of idash in the following excerpt of a narrative shows how idash is used by a narrator to provide information about three different participants in a story: a brave, his wife, and the curtain of their wigwam. In this story, some Ojibwes went out to search for their enemies, the Dakotas. This excerpt includes an explanation of the seating arrangement of an Ojibwe brave and his wife within their lodge, as well as an explanation as to the kind of door they had on that lodge. A Dakota brave then enters their lodge, and the brave being startled and frightened jumps over the fire in the lodge and falls down. The brave's wife, showing here bravery, then picks up a axe and clubs the Dakota over the head.

(52) idash (Nichols 1995:54-55, story told by Jim Littlewolf) ${ }^{47}$

a) Gii-miigaadim ingwana imaa, gaa-tazhi-miigaading gii-kabeshiwaad. there was a battle turns out there where the battle was they were camping

b) Mii imaa gii-miigaadiwiingen imaa dazhi-gabeshiwaad. DP there there must have been a battle there where they camp

c) Wiiwan-sh odayaawaan; and his wife he had her

\footnotetext{
${ }^{47}$ It is very difficult to accurately to provide a translation for the words mii and idash in these examples. Deictic particle mii can have various translations depending on its use, and while idash may be translated as 'but' in sentence level uses, this translation is many times infelicitous in its discourse use. For this reason, I have chosen to gloss mii as DP ("deictic particle") and idash as DM ("discourse marker").
} 
d) mii imaa wenji-wiidabimaad ishkwaandeming, mii a'aw ogichidaa, DP there why he sits with her at the door DP that brave

e) wiin igo niigaanizi gaye miigaadiwind wiin igo iwidi niigaan, he EMPH he leads also when there is a battle him EMPH over there in front

ani-miigaazod.

as he goes into battle

f) Wa'aw idash ogichidaa, mii imaa namadabiwaad ishkwaandeming this DM brave DP there that they are sitting at the door miinawaa iniw wiiwan. and that his wife

g) Gibiiga'igaade dash i'iw ayi'ii ishkwaandem wiigiwaam. be curtained DM that whatchamacallit door lodge

a) 'It turns out that there was a battle there, they were camping where the battle was.

b) There must have been a battle there where they were camping.

c) He has a wife;

d) he's sitting next to her at the doorway, that brave.

e) He leads the battle, he is at the front going into battle.

f) This is that brave, sitting at the doorway with his wife.

g) There is a curtain on the door of the lodge.'

After a brief background statement in $(52 \mathrm{a}, \mathrm{b})$ about a battle having taken place where they were camping, the narrator uses idash to introduce three topics (here, new participants or characters within the story), all accented by idash: that the brave had a wife in (52c), the brave's position by the door in (52f), and the curtained door of the lodge in $(52 \mathrm{~g})$. It is the contrastive feature of idash that allows the narrator to jump from participant to participant, in essence, breaking from prior discourse (details of a particular participant) in order to move on to other pertinent details or participants of a story. It is not propositional content itself that finds itself in contrast, but the narrator's discourse action of participant description that does. 
In the stories examined for this thesis, a pattern emerges. Basically, a topic is introduced which is not accented by idash. Thereafter, all transitions to new topics are accented by idash. It is the accumulation of these topics which serve in the development of stories. Once a topic is introduced by idash, however, the sub-topics or support structures attached to that particular topic usually do not contain any further occurrences of idash. Events attached to particular topics are usually connected asyndetically, and coordinated structures, should they occur, are usually coordinated by miinawaa. This pattern usually occurs until the end of a narrative. This pattern has the structure in (53), and is illustrated with the example in (54):

(53) $\operatorname{idash}^{48}$

\section{Topic 1}

SUB-TOPICS (background, events, support, elaboration) Topic 2 idash...

SUB-TOPICS (background, events, support, elaboration) Topic 3 idash...

SUB-TOPICS (background, events, support, elaboration)...

(54) idash (Kegg 1991:152-153)

\section{TOPIC 1}

a) Bezhig igo akiwenzii ingii-wiij'-ayaawaanaan. one EMPH old man we stayed with

b)

\section{BACKGROUND}

Ogii-odawemaawinan a'aw mindimooyenh. she had him as a sibling that old lady

\footnotetext{
${ }^{48}$ The term event is being used broadly here to include such actions such as providing background information, actual event processes, or elaborations.
} 


\section{BACKGROUND}

Aazhawakiwenzhiinh gii-izhinikaazo.

Aazhawakiwenzhiinh he was named so

TOPIC 2

BACKGROUND

d) Miish iko waasa, ingii-taamin Gabekanaansing gii-izhi-wiinde. DM used to far we lived there At the End of the Trail it was named so

\section{TOPIC 3}

e) Miish a'awakiwenzii

DM that old man

\section{EVENT}

gigizheb onishkaad, babiichiid, aniibiish
morning he gets up he puts his shoes on tea

gashkibidood, ziinzibaakwad miinawaa bangii

he ties up sugar and a little

bakwezhiganan, ezhi-bimoondang.

bread and packs it on his back

a) 'We had a certain old man staying with us.

b) He was the old lady's brother.

c) His name was Aazhawakiwenzhiinh.

d) We used to live far away at Portage Lake which was called Gabekanaansing 'At the End of the Trail'.

e) The old man got up in the morning, put his moccasins on, tied up some tea, sugar, and a little bread, and packed it on his back.'

The first three lines in (54a-c) bring up the first topic, i.e. the old man; (54d) introduces the second topic, i.e. that the speaker and the old man used to live at Portage Lake; and (54e) introduces the third topic, i.e. the old man's daily travels. Note that the event structures associated with these topics are not linked by idash, nor by miinawaa (except clause internally where there is coordination), but by asyndetic connection. Note also that while the first topic is not accented by idash, the last two topics in $(54 \mathrm{~d}, \mathrm{e})$ are. This general pattern exhibited in this excerpt prevails through the whole story, and serves as a major pattern for stories in general. 


\subsection{Digressions}

There is further evidence for this contrasting feature of idash within discourse in the form of discourse digressions or discourse asides, marking discourse which is not relevant to the flow of the narrative. Discourse marked by idash in these cases, usually allow the speaker to give a quick background detail in order to contextualize immediate upcoming talk. Note how idash only breaks the flow of prior discourse in order to perform this function. This is shown in the following examples.

(55) idash in digressions (Kegg 1991:104-105)

a) Ingoding igo aabanaabiyaan gaa-biijibatood enda-gichi-ginoozi pretty soon EMPH I look back who was running toward me he is very tall

a'aw inini.

that man

b) Imbiminizha'og, gichi-enigok maajiibatooyaan. he's chasing me real hard I started running

c) Ziibiins imaa bimitigweyaa, mitig imaa aazhawaakoshing, mitigoog igo niizh. creek there it flows by $\log$ there lying across logs EMPH two

d) Gaawiin-sh igo aapiji dimiisinoon i'iw ziibiins, aazhawigaaziibatooyaan but not EMPH very not deep that creek I wade across running

miinawaa ezhi-aabanaabamag.

and then I look back at him

e) Enda-gichi-mindido. he is quite big

f) Mii go ezhi-aazhawigwaashkwanid imaa ziibiinsing, gichi-enigok DP EMPH then he jumps across there at the creek real hard

bimibatooyaan.

I run 
a) 'Then I turned around to look and there was a real tall man running towards me.

b) He was following me, so I started running just hard.

c) There was a creek there with a log, two logs, lying across it.

d) That creek wasn't very deep, and I waded right across and looked back at him again.'

e) He was really big.

f) He jumped right across at the creek, and I ran real hard.'

Here, idash in (55d), which occurs as clitic -sh on the negator particle gaawiin, does not introduce a new topic on a global level, but only quickly breaks the flow of prior talk (i.e. a description of being chased by a tall man) in order to provide a brief background detail (i.e. the creek wasn't very deep) for upcoming talk (i.e. that she was able to wade through). This usage is seen again later on in the story, where the speaker breaks the flow of prior discourse in order to provide background for upcoming discourse.

(56) idash in digressions (Kegg 1991:104-107)

a) Ingoding igo omamaan iniw odoopwaaganan - ginwaakoziwan pretty soon EMPH he takes him/her that pipe s/he is long onashkina'aad. he fills him/her

b) Mii imaa nanaamadabid a'aw animosh. DP there sitting around that dog

c) Zagwaswaad, eshkwaa-zagwaswaad, ingoding igo eni-izhi-zaaga'ang he smokes him/her after he finishes smoking him/her pretty soon EMPH s/he goes out

a'aw animosh.

that $\operatorname{dog}$

d) Ingii-owiiyawen'enyinan dash a'aw akiwenzii. I am namesake to him but that old man

e) “Niiyawen'enh," indig, “gaawiin animoshiwisiin a'aw omaa ba-biindiged,” ikido. my namesake he tells me not not a dog that here who came in he says 
f) “Mii imaa iniw ozidan, bakaan izhi-naagwadiniwan," indig. DP there those his/her feet different how they look he tells me

g) Oo, yay, gichi-zegiziyaan.

oh my I am really scared

a) 'After awhile he took his pipe - it was long - and filled it.

b) That dog was sitting there.

c) He smoked and when got through smoking, the dog went out.

d) I was namesake to that old man.

e) "My namesake," he said to me, "that wasn't a dog that came in here," he said.

f) "His feet were different," he told me.

g) Oh, my, was I scared.'

In this story, a dog that was chasing the speaker, came into her house. An old man that stayed with her family filled a pipe, smoked it, and the dog subsequently left. The old man then tells the speaker that it was not a dog at all, because of its feet that were different looking. In the middle of describing this event, in (56d) the speaker breaks the flow of this description in order to provide a quick unrelated comment, accented by idash, that she is the namesake to the old man. While unrelated to the flow of the story and the eventline of the prior sentence, the use of idash appears to allow the speaker to contextualize the following sentence in which the old man calls the speaker $m y$ namesake.

Sometimes these digressions do not break with prior discourse in order to provide background information or contextualization for upcoming discourse, as we have seen in previous examples. Rather, the discourse marked by idash in such examples appears only to represent elaborations of prior discourse. While still representing a break with prior discourse, the use of $i d a s h$ in these situations only does so in order to allow speakers to provide a brief detail regarding previous discourse. This is shown in the 
following excerpt from a story where an old man goes to get medicine at a lake. After singing some spiritual songs, someone emerges from the water to provide the old man with medicine.

(57) idash in digressions (Kegg 1991:156-157)

a) Bezhig giiwenh a'aw akiwenzii ezhi-maajaad, naadid mashkiki. one apparently that old man then he leaves he gets medicine

b) Miish giiwenh iwidi jiigibiig ezhi-namadabid giiwenh, ezhi-nagamod and then apparently over there on the shore then he sits apparently then he sings

manidoo-nagamonan, ingoji-sh igo niiwin, niiwin nagamonan, spiritual songs about EMPH four four songs

iniw manidoo-nagamonan.

those spiritual songs

c) Mii giiwenh ezhi-maajijiwang i'iw zaaga'igaans.

DP apparently then it starts to whirl that little lake

d) Miish giiwenh ingoding, ingoding igo, mii imaa awiiya ezhi-mookiid. and then apparently pretty soon pretty soon EMPH DP there someone then he emerges

a) 'One old man went to get medicine.

b) He sat right on the lake shore and sang spiritual songs there, about four of them.

c) That lake started to whirl.

d) Then somebody came up from the water.'

The lines in (57a-d) describe a sequence: an old man leaves to gather medicine at the lake, he sits on the shore and sings some spiritual songs, the lake begins to whirl, and finally a being emerges from the water which eventually provides the old man with medicine. In (57b), however, the speaker uses idash (occurring here as clitic $-s h$ ) to break from the general event line in order to provide an elaboration (in bold type) to the 
preceding clause sang spiritual songs there. In short, this break in eventline allows the speaker to specify the number of songs that the old man sang.

In sum, it is these breaks in flow that shows the contrastive feature of idash in discourse. It is not the individual propositions which are contrasted, but the contrast in discourse action.

\subsection{Backgrounding and foregrounding}

While idash may break the flow of prior discourse in order to introduce a new topic or create a digression, idash may also be used to show a contrast between backgrounded and foregrounded content. This sort of contrasting function usually occurs on a more local level, usually within sub-topics, rather than in major transitions from topic to topic. Many times, these contrasts are part of larger discourse units, i.e. in the formation of major background themes.

(58) background vs. foreground (Kegg 1991:152-153)

a) Mii dash ayi'ii misko-waabowayaan iko- gii-izhi-wiindewan DP but whatchamacallit red blanket used to it was called thus mewinzha gichi-waabowayaanan - mii i'iw egwazhed. long ago big blankets it is that what he wore

b) Miinawaa gaawiin wiikaa gii-kiichiwakwaanesiin. and not ever he did not take his hat off

\section{background}

c) Gii-waabizhagindibe. he was bald 


\section{background}

d) Mewinzha giiwenh gii-aakozi.

long ago apparently he was sick

\section{foreground}

e) Akina dash ogii-wanitoonan iniw wiinizisan.

all DM he lost them those his hairs

f) Oonh, gichi-aya'aawi a'aw akiwenzii.

Oh he is very old that old man

a) 'And a misko-waabowayaan 'red blanket' - that's what they called those big blankets long ago - that's what he wore.

b) He never took off his hat.

c) He was bald.

d) It was said that he had been sick long ago.

e) $\mathrm{He}$ [dash] lost all his hair.

f) Oh, that old man was ancient.'

background

background

foreground

In (58), there are two tokens of idash, in (58a) and (58e). The first token in (58a)

introduces the global topic of what the old man wore, i.e. a red blanket and a hat that he never took off. The second token of idash in (58e) occurs within support of this major topic as a device to contrast local backgrounded content, i.e. events that lead to his hair loss, with local foregrounded content, i.e. that he lost all his hair. In short, the background information in (58c) and (58d) contextualizes the foregrounded information in (58e), and it is idash which links these two discourse actions.

This sort of contrast between local backgrounded and local foregrounded content can also be seen in another story where an Indian man is taken to court for fighting. Before this man is introduced in this story, however, the speaker provides this global background episode. 
(59) idash (Clark 1998:8, audio)

a) Mewinzha-sh igo idi, jibwaa-nisidotamowaad aapiji ingiw long ago EMPH over there before they understood very those

anishinaabeg i'iw chimookomaanimowin, gii-ayaawag idi

Indians that English language there were those over there

gaawiin igo gegoo ogii-kagwayakotanziinaawaa gegoo inindwaa.

not EMPH thing they didn't hear it right thing when they are spoken to

b) Miish ige apane, mii-go iw wapii, ganabaj gemaa-ge 1937, 1938, geget, and then also always DP that time probably maybe $1937 \quad 1938$ truly

gii-minikweshkiwag aanind ingiw anishinaabeg, gii-kiiwashkwebiiwaad.

they drank a lot some those Indians they got drunk

c) Aaningodinong-sh gii-tebibinaawag miigaadiwaad, gaa-zhi-gibaakwa'ondwaa, sometimes they were caught they are fighting and then they were locked up

i'iw miigaazong miinawaa-go awiiya bapakitewaawaad.

that fighting and someone they beat him/her up

a) 'And a long time ago over there, before those Indians understood English very well, they were those who sometimes didn't hear things correctly when they were told something.

b) And all the time at that time, maybe 1937 or 1938, some Indians were big drinkers and would get drunk.

c) And sometimes, they would get caught fighting each other and they would get locked up for fighting and beating someone up.'

There are three tokens of idash in this background episode, glossed with the English and.

The first two tokens introduce major topics in the development of the general background of the story, i.e. that Indians sometimes misheard what was being spoken to them in English, and that some Indians used to drink a lot and get drunk; and the third token of idash marks a local contrast between the foregrounded content in (59c), i.e. that sometimes they were thrown in jail for fighting and beating someone up, with the backgrounded content in (59b). The content in (59b) is analyzed here as backgrounded 
(locally), since it contextualizes upcoming discourse in (59c). In this sense, the content in (59b) is dependent upon the content in (59c), since (59c) is the important piece of information for understanding the rest of the story, not (59b).

\subsubsection{3 idash in adjacency pairs}

In the interactive plane of discourse, the contrastive feature of idash can also be seen within adjacency pairs. Adjacency pairs (following Schiffrin 1987) are situations where there is a query and a response, such as in the following exchange.

(60) idash within an adjacency pair

Q: Aaniin ezhi-ayaayan? 'How are you?'
how how are you
R: Nimino-ayaa. Giin dash? 'I'm fine. And you?'
I am good you and

In such situations within English discourse and in translating such situations from Ojibwe to English, the use of and is a common convention. We have already seen this above where many examples involving idash were translated using the English coordinator and, rather than with the English contrastive marker but. As we have seen, however, the use of the English coordinator and to translate idash is only a translating convention, and not a true representation of the function of $i d a s h$. After all, Ojibwe contains a discourse coordinator as well, i.e. miinawaa, but its use within adjacency pairs such as the one in (60) would be ungrammatical. Also, the discussion above showed that Ojibwe does not 
make use of the coordinator miinawaa in building texts via the accumulation of topics. Rather, it is uses the contrastive marker idash to do this work, the work that and does in English. So, it is no surprise that Ojibwe would use idash within adjacency pairs such as the one in (60). In short, the use of idash in (60) allows an interlocutor to break the flow of discourse centered around him or herself, in order to make the same query to the originator of the question.

\subsubsection{Preverbs}

\subsubsection{Relative preverb izhi}

Ojibwe has one additional element that I analyze as a discourse marker, but whose primary grammatical function is as a RELATIVE ROOT, or RELATIVE PREVERB

(Valentine 2001:160, 421-423, see also Nichols 1980:141-146 who calls them RELATIVE PREFIXES). This element is $i z h i$ 'thus, thither, how, in what manner'. In the Algonquian literature, relative roots (and by extension, relative preverbs) are defined as elements which "specify various relations between a verb and some element, which may serve to indicate the predicate's source, reason, manner, location, quantity, degree, or extent" (Valentine 2001:421, see also Nichols 1980:141). ${ }^{49}$ They may appear as either roots inside words, or as compounded prefixal elements attached to a verb called "preverbs". 50 This is shown for $i z h i$ in the following examples.

\footnotetext{
${ }^{49}$ There are six such elements, one of which is izhi: ako- 'so long, so far, since', apiichi- 'such intensity, such extent', izhi- 'thus, thither', onji- 'thence, therefore', daso- 'so many', and dazhi- 'there'. Their root variants are: $a k w-$, apiit-, $i N-$, ond-, dasw-, and daN, respectively (Nichols 1980:142, Valentine 2001:160, 421-423).

${ }^{50}$ Valentine defines a preverb as an "element which may [be] compounded to the front of a verb, to signal information such as tense, direction, etc. For example, in gii-ni-giiwe, 'Ansg [animate singular] went back home,' gii- and ni- are both preverbs. Each preverb is set off with its own hyphen" (Valentine 2001: 1050).
} 
(61) Relative element izhi

a) Relative root $i N$ - (Clark 1998:8, audio)

\author{
...odinaan giiwenh mii iw gaa-initang \\ he tells him apparently DP that how he heard it \\ '...he tells him how he heard it.'
}

b) Relative preverb izhi- (Mille Lacs Sessions)

\begin{abstract}
Aanawi-go minobii'igaadeni mazina'igan, gaawiin dash izhi-nibwaakaasiin. even though it is written good resume not but s/he is not that smart

'Even though he's got a good resume, he's not as smart as he says he is.'
\end{abstract}

There is a rather peculiar syntactical feature that relative roots exhibit that is worth mentioning here, since it will prove to be relevant later on when the use of plain conjunct verbs within discourse is discussed. In certain environments, when relative roots (relative preverbs as well) are present within the verb itself or within the verbal complex of verbs inflected in the conjunct, the mere presence of the relative root or preverb appears to invoke the use of initial change either on the verb itself, or on the verbal complex as a whole. ${ }^{51}$ This tendency was also noticed by Valentine for Odaawaa, a dialect of Ojibwe (see Valentine 2001: 960 where he notes this in regards to verbs within mii-clauses: "If the verb contains a relative root, it usually shows changed conjunct"). An example of this process is shown in the following examples.

\footnotetext{
${ }^{51}$ Initial change is an ablaut process which changes, mutates, replaces, or alters the initial vowel of a conjunct verb (see Bloomfield 1958:23, Nichols 1980:146-148, Mithun 1999:41).
} 
(62) Relative roots invoke initial change (Mille Lacs Sessions)

a) Gego anaamimishiken wiininoyan. don't don't blame me be fat.2/CONJ

'Don't blame me that you are fat.'

b) Gego anaamimishiken ekaamoyan. don't don't blame me IC.be so fat.2/CONJ

'Don't blame me for how fat you are.'

In this example, two words relating to fatness are used along with the same carrier sentence don't blame me that: wiinino 's/he is fat', and ikaamo 'be so fat'. While not so transparent on the surface, the morphological structure of ikaamo is made up of the relative root $i N$ 'in a certain manner' and -gaamo 'fat'. Within the same syntactical environment, it is ikaamo which undergoes initial change to ekaamoyan, not wiinino (which contains no relative root). At this point, it is unclear to me why initial change would be triggered by the mere presence of a relative root. This process applies to relative preverbs as well (to be discussed more in Section 4.2).

While $i z h i$ has its primary function as a relative root within verbs, or as relative preverbs within verbal complexes, it has a secondary function in discourse as a discourse connective. Nichols recognized this usage as well, saying that in narrative discourse, izhi “links clauses or sentences sequentially" (Nichols 1980:144). Though he did not characterize $i z h i$ as a discourse marker per se, $i z h i$ shows all the signs of a discourse marker, i.e. able to link prior text with upcoming text, adding textual coherence, having a function within sentence grammar as well as being borrowed for discourse work above 
the sentence level, etc. As a discourse connective, it carries the meaning roughly equivalent to the English and then, and so (see also Nichols 1980:144 who first noted this), showing that it is $i z h i$ 's indexical function as a relative prefix that is being exploited for discourse work. The following example is a typical usage. Note that when using izhi, no other discourse structuring device is needed in order to advance the narrative, although miish (a discourse marker complex, i.e. the abbreviated form of mii dash) may optionally occur before a clause containing $i z h i$. Note that I gloss $i z h i$ as RP ("relative prefix").

(63) Relative preverb izhi as discourse marker

a) (Eagle 1998:18, audio)

Gaa-izhi-wiindamawid nimaamaa, "Ambe wiib!"

IC.PAST-RP-ask.3>1 my mother come on hurry

'And then my mom told me, "Hurry!"

b) (example from Nichols 1980:144, transliterated) ${ }^{52}$

Miish gaa-izhi-gagwejimag wa'aw mindimooyenh "aandi..." and then IC.PAST-RP-ask. $1>3$ this old lady where

'And I asked the old lady. "Where...'

For these examples, izhi does not function as a relative root in the way that it does at the sentence level (i.e. where it may indicate manner or direction), but functions rather to

\footnotetext{
${ }^{52}$ I slightly changed the gloss from the original example in Nichols (1980:144) to be consistent with the analysis in this thesis.
} 
advance a narrative to the next event, linking prior and upcoming text. What it retains, however, within discourse is its indexical use. At the sentence level, izhi indexes an outside antecedent to its containing verb in order to indicate manner or direction. It is this indexical use, or pointing power, that is being borrowed for work at the discourse level in order to cohere larger discourse units on a more global scale.

In sum, what all these discourse connective have in common is that they all have sentence level functions which are then, in turn, exploited for work at the discourse level. It is those elements which have core lexical or grammatical functions within sentence grammars which find themselves as targets of discourse, since they easily lend themselves for work on more global levels. Recall that this was the case, for example, for the coordinating conjunction and in English. At the sentence level, it coordinates similar linguistic categories, but at the discourse level, it coordinates similar units of discourse. Recall that this was the case for the Ojibwe coordinator miinawaa as well.

As Schiffrin also noted, however, for some English discourse markers such as $o h$ and well, some markers have very little or no meaning. For these types of discourse markers, their meaning can only be defined by their use within discourse. This is why such markers are notoriously hard to define individually. They are dependent upon the context in which they are being used for their meaning to become clear. In this sense, because their use is not based upon an underlying sentence level use, i.e. lexical or grammatical, they are what I call full-time discourse markers. In other words, while discourse connectives may occur alongside their sentence level uses, these markers are always on the job. And as we will see, their job within Ojibwe is to project attitude. The next section will explore a number of these type of markers in Ojibwe. 


\subsection{Mystery particles}

The discourse particles to be described in the following sections are discourse markers which are notoriously hard to characterize, and are similar to some of the discourse markers described by Schiffrin for English, such as oh and well (Schiffrin 1987). The major difference between these markers and those already described in prior sections is that these particles carry no, or very little, lexical content. As a result, they are very difficult to characterize (if at all) as individual words. For example, English speakers would be hard pressed to explain the meaning of oh and well with any degree of confidence. The same is true for these Ojibwe particles. In the old missionary dictionary compiled by Frederic Baraga, for example, the difficulty in defining these types of particles is evident from his statement in regards to the particle gosh $a$, where he is forced to explain its pragmatic use within discourse rather than to provide a simple lexical meaning: "This word cannot be given in English. It signifies that a repetition is made, or that something which is told, is known" (Baraga 1878, 1880, 1992:142). Even in a pedagogical reference grammar written by a native speaker of Ojibwe from the Lac Seul community in Canada, mystery particles gosha, goda, and naa are listed only as "filler word[s]" (Ningewance 2004:254, 315). Like the markers $o h$ and well, these Ojibwe discourse particles can only be characterized based upon their function in discourse.

Therefore, in order to describe these largely indefinable particles, the term MYSTERY PARTICLE will be used. This term was first coined by Longacre (1976) in his description of such particles in some indigenous languages of Central and South America. In describing the following Ojibwe particles, I follow Longacre in the formal use of the term mystery particle, not because they are mysteries to their users who have an unconscious 
knowledge of their use, but because they "defy analysis even at a relatively advanced stage of research" (Longacre 1976:468). The reality is that they are difficult to define, even by their users. Because of this difficulty, all glosses for mystery particles will carry the abbreviated label of "DM" (for "discourse marker"), rather than a quick and dirty English gloss. While pauses may occasionally accompany these markers, many times they do not. Significant pauses, if any, will be marked with a comma. Three types of mystery particles will be discussed in the sections to come. Those which occur in initial position will be discussed in Section 6.2.1, those which occur in second position will be discussed in 6.2.2, and second position clusters will be discussed in Section 6.2.3.

\subsubsection{Initial position}

\subsubsection{1 mii as a veridical marker}

The particle mii has three major functions in Ojibwe, as a deictic particle, as an aspectual marker, and as a veridical marker (Fairbanks 2008, forthcoming). In that work, mii was characterized primarily as to function, not category. In terms of discourse, mii is certainly a discourse marker though, having both textual and epistemic functions in discourse. In fact, it shows behavior typical of discourse markers cross-linguistically, in that, its use in discourse is multifunctional. It has specific uses at the sentence level, but also additional uses at the discourse level. These functions were discussed in detail in my earlier work, and so only a concise exposition will be given here. In that work, mii was only described in terms of its function as a veridical marker. Veridical markers, according to Payne, express "an increased intensity of the truth of the proposition, something like the adverbial use of really in English" (Payne 1997:254). In other words, 
the use of mii as a veridical marker in Ojibwe reveals the attitude of the speaker toward their proposition, that their proposition is sure thing, viewed as fact, or that there is no doubt about the verity of their proposition, or that a serious statement is being made. Typical translations include: it is fact, it will happen, there is no doubt that, it's a sure thing, for good, really, etc. For example, in negative declarative sentences, the one with mii shows an increased intensity of truth of the proposition. I have heard my consultants use mii in this way on numerous occasions, especially when they get stumped about a question that was presented to them. Typical uses of mii in this manner are given below.

(64) Negative declarative sentences with mii (Mille Lacs Sessions)

a) Gaawiin nigikendanziin. not I don't know

'I don't know.'

b) Mii-sa gaawiin nigikendanziin.

VER-DM not I don't know

'I really don't know. (after much thought)'

'I have no idea. (after much thought)'

In the negative sentence above, it is the sentence accented with mii which strengthens the verity of the proposition, i.e. really, no idea, as opposed to a bare negative proposition $I$ don't know. As we will see, $s a$, a mystery particle itself, does not contribute this meaning; rather, it contributes the feeling of finality, i.e. after much thought. In other words, one of my consultants uttered the sentence accented with mii after having spent 
some time and effort trying to figure out an answer to one of my questions. This usage is found in a story by one of my consultants who was speaking about the difference between traditional medicine people and modern doctors. In short, when Indians got ill a long time ago, they were sent to a specialist, much like people today are sent to specialists for specific illnesses. In referring to a specialist, he uses the mystery particle mii.

(65) Veridical mii (Clark 2003:55, audio)

Mii iniw gaa-izhinizhawaad iwidi, awedi mii gekendang i'iw mashkiki DM that sent him/her over there another VER who knows it that medicine ge-minokaagoyan. that could heal you

'They then sent him over there, to a specialist who could heal you.'

In (65), to describe a specialist, the mystery particle mii and the nominalized verb gekendang 's/he who knows it' is used, not a specialized lexical item. In his explanation of traditional doctors, he explains that, in those days, different villages had people who knew different medicines. When someone got ill, they were sent to those people who possessed knowledge of the appropriate medicine for their particular illness. It is the use of mii which allows the speaker to describe those traditional doctors who possessed an expert knowledge for their respective medicines.

In the statement of cultural taboos or cultural beliefs, mii is utilized to show that the speaker is certain that certain events will happen, either as a result of a broken taboo or . speaker's attitude of surety. This is illustrated with the following examples. 
(66) mii in taboos (from Benjamin, unpublished document) ${ }^{53}$

a) Giishpin mindaweyan, miigo gezhiwawaabishkiganzhiiyan.

if you pout VER.EMPH you will have white spots on fingernails

'If you like to Mindawe [pout], you will have telltale "white spots" on your fingernails!'

b) Giishpin zazaagiziyan, miigo gezhizipogwayaweyan.

if you are stingy VER.EMPH you will have a crater in the back of your neck

'If you are Zazaagiz [stingy], you will have a crater in the back of your neck!'

The second clause of each statement in (66) is accented by mystery particle mii. Mii, in turn, is accented by the emphatic clitic go, and the presence of mii triggers the use of conjunct order inflection on the verbal complexes (i.e. mii-clauses), rather than the use of independent order inflection (which would not include the use of mii here). What this essentially means is that speakers have two morphological options in representing these future events, mii-clauses or independent clauses. The question here is, why use miiclauses when independent clauses would accomplish the same function. The answer lies in the function of mystery particle mii. As argued in my earlier work on mii (Fairbanks 2008, forthcoming), mii-clauses are stronger statements. They are stronger in the sense that mii conveys the speaker's attitude of certainty toward their proposition, i.e. an epistemic function. In other words, the use of mii in these statements signals that speakers see their proposition as a sure thing, and that there is no doubt that such events will happen. Independent clauses, on the other hand, would only convey propositional content, having no such effect, e.g. giga-wawaabishkiganzhii 'you will have telltale white

\footnotetext{
${ }^{53}$ I have kept the original orthography for this example as it appears in the original document. These examples come from a handout prepared by one of my consultants (Millie Benjamin). As you can see, she preferred not to use hyphens when using the Double Vowel orthography.
} 
spots on your fingernails', giga-zipogwayawe 'you will have a crater in the back of your neck'.

As part of its veridical function, the epistemic use of mii can be seen in related functions as well. These include the use of mii within emotionally charged statements, or in ribbing (i.e. teasing). This is illustrated below with examples that I heard from my consultants.

a) Emotionally charged statements (Mille Lacs Sessions)

Mii-go bijiinag gii-pi-naanind.

VER-EMPH just now came and got her

'They finally came and got her!' (after several days)

b) Ribbing

Mii na gii-tagoshinowaad bineshiinsag?

VER INTER they arrived little birds

'Did little birds come?'

The statement in (67a) was made by one of my consultants when it was learned that a murdered tribal member was finally found after having been left dead in her backyard for several days. In representing the proposition they finally came and got her, again, speakers have two morphological choices, the use of a mii-clause, or independent morphology, e.g. gii-pi-naanaa 'they came and got her'. When later queried about the use of mii in this statement, my consultant stated that the mii-clause captures the seriousness of the situation, where it otherwise would not were mii not used. The 
statement in (67b) was a ribbing that I received from one of my consultants. In short, she was teasing me about my messy handwriting on my folder, because it looked like a lot of little birds came and made a bunch of little tracks all over it. Again, the speaker has morphological options in representing this teasing proposition, but it is ultimately a miiclause which is chosen for the ribbing to which I was subjected to. I have heard this ribbing use of mii on various occasions.

What is ultimately significant here is that mii serves as a discourse stressor in much the same way that English uses intonation contours to mark the same function within English discourse. As noted in Fairbanks (2008, forthcoming), mii does not make use of intonation contours within discourse that English does. What this means then is that where English speakers make use of intonational contours to increase the illocutionary force of narratives, Ojibwe speakers use mii for this same function. When used in this way, mii makes the utterances that it occurs with more serious. This can be seen in the following excerpt from a letter written by a native speaker (Na-gan-i-gwun-eb 'LeadingFeather-Sitting') to Reverend Gilfillan in 1893.

(68) mii in serious statements ${ }^{54}$ (Na-gan-i-gwun-eb, letter dated March 26, 1893, Red Lake,)

a) Niijii bangii giwiindamoon. my friend a little I tell it to you

b) Mii-sa agaawaa gii-dagwishinaan. that-is barely that I arrived

\footnotetext{
${ }^{54} \mathrm{I}$ left the word-by-word glosses as represented in the original letter although I have disagreements with his glosses for mii. I would gloss them as generally VER for 'veridical marker', since this appears to be its function in this example. The glosses were presumably made by Reverend Gilfillan himself (a non-native speaker of Ojibwe) before he donated his letters to the Indiana Historical Society (and which later apparently ended up at the Minnesota Historical Society). I also transliterated the original orthography of the letter to be conform with the orthography used in this thesis.
} 
c) Mii-gegaa gii-pi-niboyaan. so-almost that I died coming

d) Aapiji ningii-pi-aakoz nayaanzh ${ }^{55}$ biinish noongom. extremely I was sick coming even till now

e) Gegaa zhayigwa negadamaan o'o aki. almost already I leaving this earth

f) Endogwen geyaabi midaasogon ge-bimaadiziyaan. it is doubtful yet ten days that I will be living

a) 'My comrade, a little I tell you.

b) $[$ Mii-sa $]$ I barely made it here.

c) [Mii] I almost died.

d) I'm really sick even until today.

e) It's almost time for me to leave this earth.

f) It is doubtful that I have ten days left to live.'

In (68), there are two tokens of mii within mii-clauses, and the question immediately becomes, why? If mii is understood to be a discourse sequencer here, then the use of miiclauses here is odd, since it is unclear what temporal events mii would be linking. The deictic uses of mii do not appear to be indicated here either. Furthermore, the use of miiclauses to begin letters in this fashion is inconsistent with the writing patterns of the other letters from native speakers to Reverend Gilfillan. If we take into account the context of this letter, however, it become immediately clear why the speaker uses mii-clauses in $(68 \mathrm{~b}, \mathrm{c})$. The speaker is using mii as a discourse stressor (or as a veridical marker). In other words, mii marks the speakers serious and dire statements I barely made it here,

\footnotetext{
${ }^{55}$ My consultants and I are unfamiliar with this word and so I am unsure of its correct spelling in the current orthography. The spelling in the original letter is nai-andj. My consultants and I also provided the translation of this excerpt, since most of the accompanying English translation was missing in the original document that I obtained from the Minnesota Historical Society. Only the first line and part of the second sentence of the English translation was available in the original document.
} 
and I almost died. The speaker is conveying to his interlocutor the seriousness of his statements, which were, indeed, very serious.

\subsubsection{2 mii as a command softener}

Mii may have a softening affect as well when used with imperatives. When used in this manner, mii usually co-occurs with the preverbal unit $i z h i$, and has the effect of decreasing the force of imperatives to the point that they are really not imperatives any longer, but suggestions. This may be seen in the following example where at one of my meetings with my consultants, I was eye-ing a bowl of delicious wild rice with cut-up wieners in it. I had already had a few bowls, but still wanted more. One of my consultants caught me looking at the bowl and said to me the following utterance accented by mii and the preverb (or relative root) $i z h i$.

(69) mii as an imperative softener (Mille Lacs Sessions)

\section{Mii-go izhi-gidaanawen. \\ DM-EMPH RR-eat it up \\ 'Go ahead and eat it up.' \\ 'It's okay if you eat it up.'}

Upon examining this example, a few things are noticeable. First, mii is not functioning as a deictic particle, as an aspectual marker, nor as a discourse sequencer. Rather, its function here is purely to soften the "blow" of the imperative gidaanowen 'eat it up!', so that it is less direct to interlocutors. Second, the preverbal unit izhi, whose function in other contexts is as a relative root or as a discourse sequencer itself, has both no referent 
outside the imperative construction nor sequencing function. The use of mii and $i z h i$ in this way is, therefore, characterized here as idiomatic. My consultants also report that the use of the emphatic clitic -go is optional, showing that forms such as mii izhi-gidaanawen are grammatical as well.

\subsubsection{3 awenh, inenh}

Mystery particle awenh is used to deny prior propositions, and always occurs in initial position, and is usually followed by a pause (marked in examples by a comma). It may occur alone as well. An example of this lone usage was when one of the elders was complaining about the state of the language, and made the comment that there weren't any more speakers left. To this, another elder interjected with a resounding: Awenh! 'Nuh uh!'. An example of awenh within texts is given below.

(70) Denying particle awenh

a) (Mille Lacs Sessions)

Awenh!

$\mathrm{DM}$

'Nuh uh!'

b) (Clark 1998:8, audio)

Awenh, gaawiin-sa niin wiikaa zhiiwitaagan gemaa-ge iw waasamoomakakoons nuh uh not-DM I ever salt or-also that battery ige ingimoodisiin. also I didn't steal

'Nuh huh, I never stole any salt or battery.' 
Interestingly, my consultants report that awenh is the word that males use, and that inenh is the women's version. In actual practice, however, women also use awenh. The consultant who made the resounding interjection in (70a) was a woman, and one of my other women consultants also admitted that even though she knows that awenh is primarily used by males, that she uses it too.

\subsubsection{4 aaniish}

Mystery particle aaniish has varying forms. Most often, it occurs as the cluster aaniish naa, with minor occurrences of a phonologically reduced form aanish naa, or lone particle aanish. The use of naa appears to increase the illocutionary force of aaniish ${ }^{56}$ Also, speakers, when queried, inflate the reduced form aanish back to aaniish . Therefore, I will collectively refer to all variants as just aaniish. The major function of aaniish is to mark justifications or qualifications of actions, behaviors, or conditions, having the force of the English well, after all, or the phrase what do you expect? A typical situation where aaniish might be used is where there is some misalignment of expectations or assumptions, either on the part of the speaker or some other person in relation to someone or something, and the speaker feels a need to provide some statement which would explain, qualify, justify, or reconcile that misalignment. Examples of this usage are shown with all three variants in the following examples.

${ }^{56}$ The function of naa is discussed in more detail in Section 3.2.2.7.3. 
(71) Justifying function of aaniish

a) (Kegg 1991:106)

"Aaniish naa indanokiimin gaye dapaabiyaan, "ikido.

DM DM we are working also that I look out she says

“"Well, it was because we were working, and I looked out," she said.'

b) (Kegg 1991:136)

Aanish naa mashkawizii a'aw biindaakwaan iidog, biindaakweng...

DM DM be strong that snuff must be taking a pinch of snuff

'[After all] How strong that snuff must be taken in a pinch.'

c) (Clark 1998:54-56, audio)
a) Aanish ingagwejimigoog.
DM they ask me
b) Mii gaa-izhi-wiindamawagwaa, "Mii-go izhi-boonitoog," ingii-inaag. DP and so I told them leave it alone I told them

a) 'Well, they asked me.

b) That's when I told them, "Leave it alone", I told them.'

In (71a), a woman had stated that the "drunks" were keeping her up all night, and when it had become calm, she looked out of her window early in the morning and saw a mysterious tall figure walking around at someone's house. It is then that she uses aaniish naa to accent the statement it was because we were working in (71a) where she appears to justify why she was looking out of her window. In short, she was checking on the 
drunks, but saw the mysterious figure instead. Prior to the statement in (70b), the speaker, related that as a little girl, she once got seriously ill from taking a pinch of snuff tobacco and putting it in her mouth (apparently to imitate the adults). She consequently became very ill and started throwing up. She was nearly convulsing. She uses aanish naa to accent her utterance in (71b) which represents a justification for her sudden illness. In (71c), the speaker was asked by a man to explain how one might mix the Indian religion with the White Man's religion in order to practice both. Rather than providing them with an answer they want, he tells them that they should not mix the two and to leave it alone. Because his answer was contrary to their expectations, he qualifies his statement they asked me within his retelling of this story with aanish in order to convey the attitude they asked me for my opinion and I gave it to them even though they didn't like it. In all of these examples, there is some misalignment of expectation to which the speaker must address. In (71a), a hearer might misunderstand why the woman was looking out of her window early in the morning; in (71b), the speaker did not expect snuff tobacco to be so potent, and in (71c), the man asking about combining religions was presumably expecting an answer that was in line with his question, but ultimately did not get one. For such misalignments, the various speakers in these examples provided statements which either sought to correct the respective misalignment, or justify it.

Sometimes, aaniish allows the speaker to provide extra-topical information or extratopical background information, through a qualification of some action or behavior. This is shown by the following example where the speaker uses aanish naa to qualify her own hard work. 
(72) Extra-topical background information (Kegg 1991:60-61)

a) Gii-agaasaani azhigwa ogitigaan gaa-o-bashkwashkibidood. it was small now her garden that she weeded

b) Aanish naa niwiidookawaa gaye niin bangii go imaa; DM DM I helpher also me a little EMPH there

azhigwa onaagoshig gaye gaa-izhi-giizhiitaad, imaa adaawewigamigong now evening also and so she finished there at the store

biindiged, dibaajimod, dibaajimoyaang gii-kiizhiikamaang gitigaan. enters tells of we tell of we finished it garden

a) 'The garden she went to weed was small.

b) Well, I helped her a little there, and then when it was getting to be evening she finished, went into the store, and said that we had finished the garden.'

In (72), the use of aanish naa appears to help the speaker qualify her own contribution to her grandmother's weeding. In other words, by the use of aanish naa, the speaker appears to be saying: Lest you think I didn't help my grandmother, you're wrong, because I did. The evidence for this comes from (72a) where the speaker explicitly states that it was her grandmother who went to weed the garden, apparently forgetting to include her own (the speaker's) contribution. As a remedy, she uses aanish naa in (72b) to qualify her statement of her own hard work, albeit a small contribution.

Sometimes, aaniish marks some resolve or determination to do something after a good reason or motivation to do so has presented itself. Many times, the resolution is the natural choice among other possibilities. This is illustrated below. 
(73) aaniish marking resolve

a) (Kegg 1991:110-111)

i) "Miinawaa giizhikaandag agoozh imaa endaayan." and cedar bough hang him/her there your house

ii) Aaniish naa mii azhigwa gaa-izhi-asag a'aw giizhikaandag imaa DM DM that when and so I put that cedar bough there ishkwaandeming. at the door

i) "“And hang a cedar bough there where you live."

ii) Well, then I put a cedar bough there at the door.'

b) (Clark 1998:20, audio)

i) Giwaabandaanaawaadog ko awiiya zhishigagowed. you all must see customarily someone vomits

ii) Miisa go gaa-izhinawag i'iw enaanzod that DM EMPH how I perceived him/her that how s/he is colored

a'aw bebezhigooganzhii.

that horse

iii) Aaniish mii sa iidog Zhishigagowaan inga-izhinikaanaa. DM that DM DUB Puke I'll call him/her

i) 'You must've all seen when someone throws up.

ii) That's how he looked to me in his color.

iii) Well, I'm going to name him Puke.'

In (73a), the speaker was advised by her cousin to hang a cedar bough at her house in order to keep an evil being from coming around. Not wanting to risk it, she resolves to hang the cedar bough up. Her resolve is marked by aaniish naa in (73a.ii). In (73b), the 
speaker was given a new horse, and because the horse had spots on it that resembled vomit (i.e. an appaloosa), he decided to call his new horse "Puke." He prefaces his statement of resolve in (73b.iii) with aaniish. In both cases, the speakers have choices. The expected choice, or the unexpected one. In (73a), for example, the speaker has two choices: hang the bough, or don't. Since it is in the speaker's best interest to hang the bough, she does so. In (74b), the speaker may call his horse anything he wants, but opts to call the horse as he perceives it, as looking like puke.

The common thread for all of these examples is the constant presence of competing expectations, a potential for misalignment of those expectations, and the pressure to reconcile those expectations. Many times, misaligned expectations or assumptions can have negative consequences for the speaker who runs the risk of looking lazy or foolish, or whose actions or motivations might be misunderstood by interlocutors. As a remedy for this, a speaker may use aaniish to provide justifications, qualifications, or explanations which would align interlocutor expectations and assumptions with those of the speaker.

\subsubsection{Second position mystery particles}

The mystery particles in the following sections all occur in the second position of a sentence or clause. The second position markers to be discussed in the following sections are isa, sha, gosha, bina, and naa. Many of these mystery particles occur within a number of discourse marker clusters as well. The clusters to be discussed will be $s a g o$, sha go naa, gosha naa, sha naa, da naa, bina naa, and sa naa. Also, because it has been the practice for other researchers to analyzed such clusters as occurring in one position, 
rather than in multiple positions, I will follow that practice here (see Brody 1989, Davidsen-Nielsen 1996, Torres 2006). Therefore, the cluster in bold type in the expression gaawiin sha go naa inde-apiitizisiin 'I'm not that old' will be analyzed in this thesis as collectively occurring in second position, not in second, third, and fourth positions, respectively. Also, since the semantics of the individual markers involved in clustering largely remains transparent, i.e. a product of its parts, a small section following a discussion of the individual markers will be provided, rather than providing one huge section on all the clusters. Therefore, the following sections will first characterize each marker individually, and then directly follow-up that discussion with a discussion of their use within clusters.

\subsubsection{1 isa}

Mystery particle isa (which sometimes occurs as clitic $-s a$ ) is a general marker of CONCLUSIVITY. In other words, isa signals that some event, utterance, or narrative has come to an end. This core function has differing manifestations within discourse, such as marking narrative closings, relinquishments (signaling that the speaker's efforts have ceased), conclusory gist statements (statements which get to the point after the speaker has provided some fuzzy details), resulting action (actions which occur as a result of some event or events), and strengthening the speaker's position or disposition (abating the position or disposition of others in prior discourse). One other minor function of $i s a$ is as a place holder, allowing speaker pause within discourse. These various manifestations are discussed in the following sections. 


\subsubsection{1 is a as a marker of closings}

One of the most common uses of isa is its use by speakers to mark the end of a story or narrative, marking conclusivity on the action plane of discourse. It has roughly the meaning or attitude of the English it is finally time. It is on the action plane of discourse because the speaker uses isa to signal that an end to their discourse has arrived. These closings typically involve the use of demonstrative pronoun $i^{\prime \prime} i w$ 'that' and quantitative particle minik 'amount' along with the deictic particle mii in the formation of mii-clauses (see Fairbanks, forthcoming, Valentine 2001:963-973, Rhodes 1998:286-294 regarding mii-clauses). The following expressions are typical endings for the stories in Kegg (1991).

(74) Narrative closings

a) Mii sa go i'iw. that DM EMPH that

'That's it.'

b) Mii sa go minik. that DM EMPH amount 'That's all.'

In the Kegg collection of stories (a total of 41 stories), closings which employed the use of $s a$ were, by far, the most common. Less common were the closing statements without $i s a$. In such cases, in the absence of the $i s a$, it was the propositional content which bore much of the burden of signaling the end to the story. As with the conclusory closings 
involving isa above, these conclusory expressions employed the use of mii-clauses as well. For the Kegg collection (Kegg 1991), there were only three such occurrences. These closing expressions are given below.

(75) Closing mii-phrases without isa

a) Mii i'iw. (lit. 'that is it', but idiomatically to end a discourse) that it

'That's it'

b) Mii eta go imaa minik gezikwendamaan. that only EMPH there amount what I remember 'And that's all I remember of that.'

c) Miish eta imaa minik gekendamaan. and that only there amount what I remember 'That's all I remember.'

While explicit propositional content may form the basis of a closing, mystery particle isa shows that it may carry much of the burden that a purely propositional expression may have. With the exception of the idimatic expression in (75a), the amount of burden carried by isa is evident, for without it (at least for these examples), more propositional content appears in order to do the work of concluding, or giving up the floor. 


\subsubsection{2 isa as a marker of relinquishment}

While isa marks narrative closures on an action plane of discourse, it has another function within the interactional plane of discourse marking a general attitude of speaker relinquishment. This function is interactional because isa may be used to signal that a speaker has relinquished their time to provide an answer to a question, or that they have given up trying. For example, any time questions arose which required a lot of discussion and contemplation on the part of my consultants and which did not eventually end with an answer, the use of $i s a$ was commonly heard in their expressions of relinquishment. In such cases, there is a question put forward, a period of contemplation on the part of the addressee, and then a relinquishing expression accented by isa which releases the addressee from the responsibility of providing an answer, i.e. is a shows that the speaker has relinquished their effort, and has, in effect, given up in trying to either recall or figure out what the answer was. I have heard the following phrases from my consultants on numerous occasions.

(76) General attitude of relinquishment

a) Mii-sa go namanj. VER-DM.CL EMPH don't know 'I have no idea.'

$\begin{array}{ll}\text { b) Mii-sa } & \text { gaawiin nigikendanziin. } \\ \text { VER-DM.CL not I don't know }\end{array}$ 'I really don't know.' 
This is also shown by the following email interaction with a Mille Lacs Ojibwe speaker. The speaker was asked how he would translate a certain English expression into Ojibwe, to which he stated the following, accenting his response with isa:

(77) isa in relinquishment expressions (from Aubid 2008, email)

a) Iw dash gaa-gagwejimiyan. that and what you asked me

b) Amanj isa iidog. don't know DM DUB

a) 'And what you asked me about.

b) I [isa] don't know.'

The propositional content of the expression amanj iidog in (77b) itself means I don't know. Mystery particle isa projects a relinquishment from providing a definitive answer. This is evident, because after he made that comment, he then offered up seven possibilities, one of which he was quite unsure of. Marker isa signals to listeners (or email readers) that, after some thought, he has relinquished his responsibility to provide a definitive answer.

\subsubsection{3 isa as a marker of conclusory gists}

Within monologic narratives, is $a$ has a related function in marking conclusory GISTS, having a meaning similar to the function that the discourse markers at any rate, or anyways, have in English. What is meant by gist is that the speaker's precursory descriptions culminate in a main point. The exact details of those precursory 
descriptions, however, are not important, and are in a sense, relinquished in order to get to the point. In such cases, the speaker offers up a set of general descriptions (which may be guesses, or a sub-group of events) of some process, event, or even utterances by people, after which the speaker provides a gist sentence or expression, accented by isa, which gets to the eventual main point. This usage is quite consistent in the Kegg stories, and the following example is typical. The following excerpt comes from a story about a little girl seeing a steam boat from off shore. Before seeing this boat, however, she describes the circumstances which allowed her to see it.

(78) isa (Kegg 1991:26-27)

a) Mii eta go imaa gikendamaan namadabiyaan jiigibiig. DP only EMPH there I know I am sitting on the shore

b) Maagizhaa gaye gaa-wewebanaabiiwaagwen, maagizhaa gaye maybe also they must have been fishing maybe also gaa-ishkwaa-iskigamizigewaagwen. they must have finished boiling sap

c) Gii-paakibii'an sa wiin igo. lake was open $\quad$ DM for sure EMPH

d) Namadabiyaan ganawaabandamaan gichi-jiimaan bimibidemagak naawagaam. I am sitting I am watching it big boat going by middle of lake

a) 'All I remember is sitting on the shore.

b) Maybe they were fishing or had just finished boiling sap.

c) The lake was open anyway.

d) I was sitting there watching a big boat go across the middle of the lake.'

In this story, we find a little girl sitting on a shore. In (78b), she tries to recall the possible reasons why she was sitting on that shore, i.e. that they were either fishing or 
had finished boiling sap. In (78c), using clitic $-s a$, she gets to her point, i.e. that the lake was open anyway. This point allows her to provide the circumstances which led to the eventual seeing of the big boat in (78d). Note that the exact details in (78b) are really not material to her gist statement in (78c). The use of the hedge word maagizhaa 'maybe' and dubitative inflection on the verbs in (78b), i.e. -gwen, suggests that she is unsure of the exact reasons why she was on that beach. The point that she was making in the end was that the lake was open, and it was this expression that was accented by $-s a$.

Sometimes these gist expressions are summations of prior guess work. In such cases, there are precursory descriptions of events or objects which represent only a subgroup of those events or objects, and then a follow up expression, accented by is a, which sums up those descriptions. The following example illustrates this usage of $i s a$.

(79) isa (Kegg 1991:44-45)

Akina gegoo omaajiidoonaawaan iniw akikoon, bakwezhigan, akina sa gegoo all thing they take him/her along that kettles flour all DM thing waa-aabajitoowaad wii-wiisiniwaad. what they want to use when they want to eat

'We took everything along, kettles, flour, everything [sa] they wanted to have to eat.'

In this example, kettles and flour represent only a sub-group of items that they would bring along. Again, the exact items are not important. Rather, the point being made here is that they would bring what they wanted to eat, i.e. akina sa gegoo waa-aabajitoowaad wii-wiisiniwaad 'everything they wanted to have to eat', and it is this point, or gist expression, which is accented with isa. 


\subsubsection{4 isa as a marker of resultant action}

Sometimes, isa marks RESULTANT ACTION, or a RESULTANT CONDITION. In such cases, there are two essential elements surrounding the use of is $a$ in these types of constructions: the event (or events), and a resultant event (accented by isa) emanating from that event (or events). In other words, an event (or a series of events) occurs, and as a result of that event (or events), some action or condition, or a logical next step, occurs as a natural consequence of that action. What this means is the existence of the resultant action is dependent upon the prior event. This does not mean, however, that there is necessarily a cause and effect relationship (though one may exist) between the event and its resultant event. It only means that the resultant action or condition somehow emanates from the initial event, either because it is a logical consequence of that action, or that it is $a$ next possible logical step following that event. In short, the first event (or events) acts as a set up for what eventually happens. This is shown in the following example where a mallard duck is killed.

(80) isa (Kegg 1991:58-59)

a) Zhiishiib imaa gii-paa-ayaa, ininishib; mamaad iniw asiniin, duck there was around there mallard takes him/her that rock gaa-izhi-bakite'waad. and so she hit him/her

b) Mii sa gaa-izhi-niiwana'waad. DP DM and so she killed him/her

a) 'There was a duck there, a mallard, and she picked up a stone and hit it.

b) She [sa] killed it.' 
In (80a), a series of events occurs, i.e. a mallard duck is spotted on a lake, a rock is picked up and thrown at it, and it is hit. These events lead to the demise of the mallard duck, and is captured with resultant phrase, mii sa gaa-izhi-niiwana'waad 'she killed it' in (80b), accented by clitic $-s a$. While this series represents a cause and effect relationship, this is not a necessary requirement. The following example shows this where a grandmother volunteers herself and her granddaughter to go weed a garden for someone. The following morning, they pack a lunch, and leave for the garden.

(81) isa (Kegg 1991:58-59)

a) Mii dash a'aw nookomis, "Niin igo inga-o-bashkwashkibijige indaanis," DM but that my grandmother I EMPH I will go and weed my daughter

odinaan iniw ikwewan.

she tells her that woman

b) “Naawakamigookwe inga-wiijiiwaa," ikido.

Naawakamigookwe I go with her she says

c) Mii sa azhigwa gegizhebaawagadinig aapiji gaa-izhi-nawapwaaniked, DP DM now in the morning early and so she made a lunch

maagizhaa gaye bakwezhiganan gaa-maajiinaagwen miinawaa maybe also bread what she must have took along and

akikoonsan - maagizhaa gaye waa-aniibiishkikegwen imaa, little pail probably also what she wants to make tea with there

gaa-onji-maajiinaad iniw akikoonsan, akikoon, akikoonsan igowhy she took it along that little pail pail a little pail EMPH gaa-izhi-maajaayaang. and so we left

a) "'I'll go and weed her garden, my daughter," my grandmother told the woman.

b) "I'll go with Naawakamigookwe," she said.

c) Real [sa] early in the morning, she made a lunch, maybe she took bread along and a little pail - I guess she took along the little pail because she wanted to make tea in it - and then we left.' 
The initial event in (81a-b) is the grandmother's volunteering for the weeding. The resultant event in (81c) is them preparing a lunch the following morning and leaving for the garden. This resultant event is accented by clitic $-s a$. The initial volunteering is not the cause of their departure for the garden, but is the reason for it. The departure represents a natural consequence emanating from their initial act of volunteering, and it is this event which is marked by $-s a$.

\subsubsection{5 isa as a position strengthener}

Mystery particle isa is also used in situations where there is an incongruence between competing propositions, perspectives, dispositions, or expectations. Many times, this is an obvious incongruence, and the use of $i s a$ in such cases allows the speaker to project an attitude that their perspective (or propositional content put forth by the speaker) trumps, challenges, or corrects any challenging perspectives, positions, or dispositions, and that their position should be the prevailing one, and obviously so. This function has the effect of ultimately strengthening the speaker's position. An example of this is shown by the following example where an Ojibwe man is standing before a judge to be charged with assault and battery. He misinterprets the judge's indictment, however, and offers a defense against that misinterpreted indictment. His defense is accented by isa (in this case, clitic $-s a$ ). 
(82) Position strengthening feature of isa (Clark 1998:8, audio)

a) Miish ige wiindamaagod odigoon iniw dibaakonigewininiwan, and then also he tells him he says to him that judge

"You are charged to the salt and battery", inaa giiwenh. you are charged to the salt and battery he is told apparently

b) Ganawaabamaad iniw dibaakonigewininiwan, "Awenh, gaawiin-sa niin wiikaa looking at him that judge nuh uh not-DM I ever zhiiwitaagan gemaa-ge iw waasamoomakakoons ige ingimoodisiin," salt or also that battery also I did not steal it odinaan giiwenh mii ii gaa-initang. he tells him apparently DP that the way he heard it

a) 'And also the judge apparently tells him, "You are charged to the salt and battery.

b) Looking at the judge, he tells him apparently how he heard it, "Nuh uh, I [sa] never stole any salt or battery.",

Not having a good command of the English language, the Ojibwe man misinterprets the judge's indictment of assault and battery as being an indictment of stealing some salt and a battery. In (82b), the Ojibwe man accents his denial nuh uh, I never stole any salt or battery with is (in this case, clitic $-s a$ ). While the propositional content of his denial forms the basis of his defense, mystery particle is a allows him to make his case against a charge that he views as ridiculous. In other words, is a appears to allow him to express the attitude: I would never do such a silly thing, how dare you think that I would do such a thing, etc. Functionally speaking, isa allows the Ojibwe man to establish his position as the prevailing view, albeit under a false pretenses. 
Another example of this usage appears in the following example where a little girl was taking beads away from the adults. Instead of taking beads from them, she was urged to go around to all the wigwams to beg for beads instead. Here, while there is no charge of guilt or a defense against that charge, there is indeed a competition of dispositions: those of the adults, and that of the little child.

(83) isa (Kegg 1991:92-93)

a) “Naawakamigook," ikido bezhig a'aw ninoshenh, “aaniin nanda Naawakamigook she says one that my aunt why DM babaa-zaagidon ${ }^{57}$ imaa iniw wiigiwaaman!" go around begging there those wigwams

b) Ingikinoo'amaag-sh ge-ikidoyaan. she taught me what I will say

c) "Giga-miinigoo manidoominensag. you will be given beads

d) Mii mewinzha gaa-izhichigeng." DP long ago what was done

e) Inzhaagwenim isa. I am hesitant DM

f) Ingagiibaadiz. I am foolish

g) Indagaashiinh. I am small

h) Nimisawenimaag gaye ingiw manidoominensag, gaa-izhi-agwazhe'id moshwens. I want them also those beads so she covered me shawl

a) 'Naawakamigook," said one of my aunts, "why don't you go around and beg there at the wigwams."

b) She taught me what to say.

\footnotetext{
${ }^{57}$ My consultants are unfamiliar with the term zaagidon. It perhaps is a term which also has gone out of use for modern speakers.
} 
e) "You'll be given beads.

d) This is what they used to do long ago."

e) I was hesitant isa.

f) I was foolish.

g) I was small.

h) But I wanted the beads badly, so she covered me with a shawl.'

Here, a little girl, Naawakamigookwe, is urged to beg for beads and was even told what to say at the entrance of the wigwams. Reflecting upon this at the telling of this story, she reveals that she was hesitant at the time in (83e), and accents this statement with isa. In (83f-g), she even goes on to give justification for her hesitation, i.e. that she was foolish and small. Underlyingly, there are two dispositions at play in this story: that of her aunts who want her (a little girl) to go around to all the wigwams to beg for beads, and the little girl's hesitancy due to her childish nature and size. While the propositional content in (83e-g) forms the basis of her disposition, the use of $i s a$ allows her obvious difference in perspective, i.e. that a little girl would have the fortitude to go around begging for beads. It allows her to show that her disposition is contrary to their disposition, reinforcing her disposition against that of her aunts. In short, isa allows the speaker to project the attitude: I obviously could not do such a thing, contrary to what they think.

The proposition challenging feature of is a can be seen in the following exchange, found from a story in a related dialect, i.e. Nett Lake dialect. In this story, two brothers who are still in their mother's womb are fighting over who will be the first to be born. One says that he will be, and the other challenges him with a remark accented by isa. 
(84) isa (Jones 1917:4-5)

a) O'ow idash madwe-ikidowan: "Niin ninga-zaziikiz."

this but the other is heard saying I I will be the eldest

b) “Gaawiin,” madwe-ikido bezhig biinish igo ikido aw bezhig:

not he is heard saying one even EMPH he says that one

"Gaawiin gidaa-zaziikizisii.

not you could not be the eldest

c) Niin isa ninga-zaziikiz.

I DM I will be the eldest

a) "This was what one was heard to say: "I wish to be the first brought forth."

b) "No," one was heard saying, even did one say, "you cannot be the first-born.

c) I am [isa] the one to be the eldest.",

Sometimes isa is involved in propositional contrasts in such a manner that the propositional standing of the proposition containing isa is strengthened in relation to prior propositions. Like the example above where a speaker may exert their dominance over another by the use of $i s a$, speakers may also increase the illocutionary force of a proposition by the use of $i s a$. This can be seen in the following example where two ways of handling knowledge is being contrasted.

(85) isa (Clark 1998:56, audio)

a) A'aw dash Chi-mookomaan kina gegoo wiin gekendang mazina'iganing that but white people all thing him/her what he knows in a book

ogii-ozhitoon, mazina'iganing ogii-ozhibii'aan.

$\mathrm{s} /$ he makes it in a book s/he writes it

b) Miish igo akina awiiya noongom ge-nisidotanzig aanawi-go and the EMPH all someone today s/he would not understand it even though 
odaa-agindaan.

he could read it

c) Gaawiin-sh gegoo wiin imaa odaa-ondinanziin mazina'iganing

not thing him/her there s/he would not get it from there in a book

ji-agindang noongom.

if $\mathrm{s} /$ he reads it today

d) Aano-gikendaasod, gaawiin odaa-gashkitoosiin ji-gikendang i'iw

even though s/he is smart not s/he would be able to know it that

enamanji'od a'aw Anishinaabe.

what he means that Indian

e) Imaa isa wiin i-gaa-ina'oonind, ke gaawiin wiin ingoji

there $\mathrm{DM}$ him/her the thoughts s/he was given see not him/her somewhere

okanawisinzinini ogii-ozhibii'anziin i-gaa-pi-ina'oonind.

it is not written $\quad \mathrm{s} /$ he does not write it the thoughts that $\mathrm{s} / \mathrm{he}$ was given

a) 'But as for white people, they put everything they know into a book.

b) And no one today would understand it even though they could read it.

c) They wouldn't get anything out of it if they read it today.

d) Even though they are knowledgeable about it, Indians wouldn't be able to know the true meaning of it.

e) With [isa] the knowledge that he was given, you see, their knowledge wasn't written anywhere.'

In this story, the speaker was asked whether it would be possible to combine the Indian religion with the white man's religion into one. This query ultimately led the speaker to contrast the way in which white people handled their knowledge (they put it into books) with the way that Indian people handled their's (not written in anywhere). While there is a contrast being made between these propositions, this contrast is largely a pragmatic one due to the contrasting content inherent in the propositions themselves. The use of isa, therefore, is not marking contrast in the way that, say, idash does, but is used to strengthen the illocutionary force of the Indian way of handling knowledge. It allows the 
speaker to exert and validate the Indian way of handling knowledge. In other words, the nuance which isa allows to be displayed might be equivalent to the following: They have their way and we have our own. Let them do it their way, and we'll do it our way which is a perfectly legimate way of doing it.

\subsubsection{6 isa as a place holder}

Some minor uses of $s a$ appear to be as CONTINUERS, or as place holders, a function similar to the marker $u h$ in English. ${ }^{58}$ Used in this way, $s a$ functions to maintain the floor for the speaker, allowing the speaker to continue their story in preparation for upcoming talk. Many times, pauses or very slight pauses occur after sa (but not always) and do not exhibit sentence-final intonation. The evidence that these usages are narrative continuers is evinced by their high frequency in stories which are being made up on the spot, as opposed to narratives based upon real life events whose details are not being fabricated as the story goes on. For example, most of the stories I have collected for this thesis average zero to five occurrences of $s a$ per story. In one story which was completely made up on the spot, a total of eleven occurrences of $s a$ appeared. Also, in the Gilfillan letters (from the 1800s), Reverend Gilfillan usually glossed $s a$ as 'rest voice'. While this is not its only function (and this gloss may have been used over productively), it is a function that speakers are consciously aware of. A few examples of this usage should suffice. Commas in these examples represent significant pauses in the narrative by the speaker.

\footnotetext{
${ }^{58} \mathrm{I}$ am, of course, not suggesting that $s a$ and $u h$ are equivalent in every way. Uh in English has other functions too which $s a$ does not appear to parallel, e.g. Uh....yes. Here, with continuing tone on yes, uh signals that the answer provided should be obvious to the interlocutor, but for some reason isn't.
} 
(86) (Clark 2003:52, audio)

Mii imaa onzaam enigok-ko owiikwajitoonaawaa iw, $\boldsymbol{i}^{\prime} \boldsymbol{i} \boldsymbol{w}$-sa, that there overly try hard-customarily they try that-DM

anooj idi keyaa wiin enaabaji'aawaad anow asemaan... various there way him/her how they utilize this tobacco

'That's when they try too hard, that uh, in the various ways they are utilizing tobacco...'

(87) (Clark 2003:50, audio)

Endogwen igo gikendamogwen awegonen nendodang o'ow-sa, it is doubtful EMPH that he knows what what he's asking for this-DM

enwed gaa-ina'oonind wiin wayaabishki'iwed ge-wiin ji-inwed. language that was given to him him white person also-him to speak

'I don't know if he knows what he's asking for with this uh, language that was given to the White Man to speak.'

For this speaker, sa rarely showed up except in spots such as these, where there was some hesitation or pause before continuing on.

\subsubsection{7 sa go}

Mystery particle isa sometimes occurs with the emphatic marker igo to form the cluster sa go, and has the major function of allowing speakers to make interjections that are somehow connected to something that has just been mentioned within the discourse, or as a result of some event. Interjected content may be conclusory gist statements, elaboration, or just extra information whether it be relevant or irrelevant. It is almost like 
the speaker, once a topic or event has been brought up, remembers something significant about that topic or event and interjects it into the discourse. It is important to note that these so-called RESULTANT INTERJECTIONS always occur as a result or consequence of some aforementioned topic or event. Utterances with the cluster sa go never occur as the initial statement. The use of sa go in making resultant interjections can be seen in the following example where the speaker makes an interjection that is not relevant to the story at hand, but relevant to a topic just mentioned, i.e. playing on the shore.

(88) sa go (Kegg 1991:116-117)

a) Mii imaa jiibaakwewaad ingiw ikwewag, wii-sagaswe'iwewaad, DP there they are cooking those women when they want to have a feast izhiwidoowaad imaa niimi 'idiiwigamigong. they bring it there to the dance lodge

b) Babaa-dazhiitaayaan jiigibiig imaa neyaashing, giigoozensag I am playing around there shore there at the point minnows imbabaa-debibinaag. I am going around catching them

c) Anooj sa go imaa asiniinsan imaa. various DM DM there little rocks there

d) Baanimaa go imaa inaabiyaan agidaaki gaa-namadabid, mii a'aw suddenly EMPH there I look there on top of the hill he who was sitting DP that Gichi-jaagigaabaw gii-inaa. Gichi-jaagigaabaw he was called

e) Oo, yay, gichi-zegiziyaan. oh goodness I am really scared

a) 'The women cooked there for the feast and took it to the dance lodge.

b) I was playing around on the shore at the point catching minnows.

c) There were [sa go] all sorts of stones there.

d) Suddenly I looked up and there was Gichi-jaagigaabaw as he was called sitting on top of the hill.' 
In this excerpt, the speaker (the little girl) was playing around on the shore when she noticed an old man that really scared her sitting on top of the hill. This overall story is really about how the little girl stole fry bread in order to feed an old man that was always taunting her by saying things such as I'm gonna eat you, and I'm gonna marry you when you grow up. In her description of what she was doing when she noticed the old man sitting on the hill, she interjects the fact that there were all sorts of stones on the shore. Now, these stones make no further appearance in the story, showing that their mention is purely an interjection. Though the stones are irrelevant to the story as a whole, they are relevant to her prior mention of her playing on the shore catching minnows.

Another similar use shows up in the next excerpt from a story about the making of a bootaagan, a device used to dehusk wild rice. The speakers explains how they took care of the bootaagan to make sure it never gets wet, and that they would cover it with a birch bark roll when it rained. After this, she interjects the point that they do this also at night when they were using it.

(89) sa go (Kegg 1991:128-129)

Mii ezhi-wenda-ganawenimangid igo weweni gaye ji-nisaabaawesig DP then we really take care of him/her EPMH carefully also so that s/he does not get wet ezhi-badagwana'wangid, maagizhaa gaye wiigwaasabakway imaa gimiwang, then we cover him/her maybe also birch bark roll there when it rains

niibaa-dibik sa go gaye aabaji'aasiwangid.

at night DM DM also when we do not use him/her

'We took care of it properly so it didn't get wet, covering it, perhaps with a birch bark roll, when it rained or at night [sa go] when we weren't using it.' 
Though the English translation does not capture the function of sa go very well (due to the broad translations), it appears that the speaker was very deliberate about mentioning the fact that they used to cover the bootaagan when it rained (to prevent it from getting wet), but then apparently remembered that they also covered the bootaagan at night as well when they were not using it. This point is interjected and accented by sa go. The fact that the final utterance, accented by $s a$ go, is offset by a comma suggests that the speaker was indeed making an interjection here, i.e. a resultant interjection.

The final example of the use of $s a$ go occurs as a result of an event, being stumped. At one of our meetings, I asked a question that apparently stumped one of my consultants. After a long silence ensued, one of my consultants interjects the following utterance, accenting it with sa go.

(90) sa go (Mille Lacs Session)

Mii sa go wawaanimigooyaan. (after having been stumped) DP DM DM that I am stumped

'They stumped me.'

What all these examples show is that the core meaning of isa (or its clitic form $s a$ ) in marking finality or resultant content is still largely transparent within the cluster sa go. Though the cluster has an additional function in marking interjected content, it is content which occurs as a direct result of prior discourse. Recall also that sa go made its appearance in the closing of narratives as well. 
There are cases of sa go, however, where its function is as a continuer, similar to the use of the lone particle is $a$ as a place holder (as already described above). This usage appears to be purely stylistic, and quite individualized. For example, one speaker at Mille Lacs is well known for accenting his public discourses with a generous use of sa go as a way of continuing his narrative, or as a way to allow himself time to think of what to say next. I have only observed this stylistic use of sa go by him. At any rate, isa is a very prolific particle, and still has uses which remain unexplored. It is clear though that its many functions within discourse largely stem from its core function of marking finality or resultative action.

\subsubsection{2 sha}

Mystery particle sha is a marker of revealed information, or of DISCOURSE REVELATIONS. By revealed information or discourse revelations, I mean those general linguistic expressions which speakers use to inform or correct interlocutors in order to prevent them (i.e. the interlocutors) from pursuing their faulty logic or assumptions. For example, in English, it is quite common to tell someone no, you! (with an intonation rise and fall over you) in order to correct their referencing errors, i.e. referencing someone else when it is him/herself that is being referenced. It is perhaps quite unintuitive, however, for those unfamiliar with Ojibwe to speak of markers of revealed information, since many languages such as English do not make use of individual markers to mark such expressions. For example, in the example just cited, i.e. no, you!, there is no linguistic form or marker associated with this expression. Rather, it is intonation which 
accompanies the expression and provides its derisive nuance. ${ }^{59}$ In Ojibwe, however, markers such as sha, are common ways to mark revealed information (i.e. information that would set interlocutors straight) to interlocutors. In this function, sha usually has a derisive feel to it, since speakers commonly use sha to get after interlocutors (i.e. giving them hell) in order to show them the reality of the situation. There is usually some heightened emotional state as well. Also, when speakers use it to refer to themselves, they are, in effect, censuring themselves as a way of eliciting pity.

Its core function can be seen in the following example where one of my consultants was asking me whether I gave an explanation to a woman from the BBC (i.e. British Broadcasting Company) about how Ojibwes view dreams culturally. I had initially misunderstood her to be asking whether someone else had, to which she quickly corrected me using sha.

(91) sha

Giin sha (after being confused as to who she was referring to) you DM

'No, you!'

In this instance, I, the interlocutor, was in a state of confusion as I kept giving my consultant the wrong explanation due to my misunderstanding of who we were talking about. After a few unsuccessful attempts at an appropriate response, my consultant

\footnotetext{
${ }^{59}$ Recall that this is what we saw in regards to the use of mii as a discourse stressor. English uses stress and intonation for nuance effects within discourse, but Ojibwe does not. Rather, discourse markers are employed.
} 
finally corrected me with the expression in (91) above, accompanied by a hint of impatience and derision since I should have known who she was talking about. This is the function of sha in its simplest form, showing two major functions: 1) revealing to the interlocutor the truth or reality of the situation (thereby setting me straight); and 2) getting after them.

Sometimes the interlocutor does not need correcting per se, but needs an answer to something that has bewildered them. This results in a heightened state of emotion to which the speaker may use sha in order to counter-balance that heightened emotional state in revealing the answer. Therefore, the use of sha marks that the information revealed to interlocutors is either surprising, not obvious, unsuspected, or unexpected. The response, accented by sha, has the effect of eliminating the interlocutor's bewilderment. Therefore, while not correcting interlocutors per se, the use of sha allows the speaker to set them straight. For example, in the following interaction, I had brought a picture (at the request of an acquaintance) of an old Indian woman who had long since passed away. An acquaintance who had given me the picture had asked me if I would show the picture to the elders to see if they could identify her. One of my consultants, not knowing that I had brought the picture, asked one of the other elders present at the table how she got the picture. The response to this question is accented by sha.

(92) sha

a) Speaker A: Well, how'd you get that?

b) Speaker B: Awanigaabaw sha obiidoon.

a) Speaker A: 'Well, how'd you get that?

b) Speaker B: Awanigaabaw [sha] has brought it.' 
Not captured in (92a) is Speaker A's intonation which accompanied her query. Her query exhibited a heightened level of bewilderment, almost like saying: well, how in the world did you get that? That she was in a state of bewilderment or amazement is supported by the fact that the presentation of the photo of the old woman who had long since passed away was quite out of context and random for the purposes of our meeting. It was in this state that Speaker A made the query as to how Speaker B obtained the photo, to which Speaker B responds, accenting her response with sha: Awanigaabaw sha obiidoon 'Awanigaabaw [sha] has brought it'. The use of sha here appears to do two things. First, it counter-balances the heightened emotional state present in Speaker A's query. Second, sha supports the surprising or unexpected revelation that Awanigaabaw, i.e. me, who did not even know the old woman, nor would I be expected to have her picture, brought the picture. The use of sha in this example also appears to allow Speaker B to correct Speaker A's assumption (or perceived assumption) that Speaker B brought the photo. So, in effect, Speaker B's response is like saying: It was Awanigaabaw, not me, that has brought it.

In another situation, a speaker uses sha in regards to her own inadvertent behavior, as a way to admit her mistake, censure herself, and to elicit pity by interlocutors. In the following interaction between my consultants, one of my consultants ruins a surprise birthday gift by inadvertently telling the person for whom the gift was intended for about the surprise. Once she figures this out, she uses sha to accent her own statement that she has spilt the beans. 
(93) sha

a) Speaker A: Oda-waabandaan Pameda?

is she gonna see it Pameda (someone's name)

b) Speaker B: Baanimaa apii um michaatooyaan, niwii-agoodawaa dash um later on um when I make it big I want to give her a gift but um

mii azhigwa gegaa da-dibishkaad.

DP time almost to be her birthday

c) Speaker A: Dikinaagan na?

cradle board INTERR

d) Speaker C: I just got through calling her, ingii-wiindamawaa.

I just got through calling her I told her

e) Speaker B: Nooo!

no

f) Speaker C: Yeah I did. Told. (Everyone laughs.)

yes I did told

g) Speaker B: Chi-odoon.

$\mathrm{s} /$ he has a big mouth

h) Speaker C: I had no idea, oh! Nichi-odoon. (Laughing continues.)

I had no idea oh I have a big mouth

i) Speaker C: Ingii-wiindamawaa sha.

I told her DM

a) 'Is Pameda gonna see it?

b) Later on when I make it big, I want to give it to her as a present. It's almost her birthday.

c) Is it a cradle board?

d) I just got through calling her, I told her.

e) Nooo!

f) Yeah I did. Told.

g) She has a big mouth.

h) I had no idea! I have a big mouth.

i) I spilt the beans [sha]!' 
In (93d), Speaker C, not yet knowing her inadvertent error, reveals to the group that she had just called the very person that Speaker B wanted to give a cradle board to and told her of Speaker B's plan to give the cradle board away as a birthday gift. In (93e), the emotional state increases as the sentiment of Speaker B turns to disbelief, evident by her response to the news, i.e. nooo!. In (93h), Speaker C realizes her error, and then in (93i), makes the statement that she spilt the beans, accenting her statement with sha. The use of sha in this example has the feeling of self-reproach and self-pity. In short, the speaker is getting after herself for messing up the surprise.

As part of the general revealing feature of sha, there are occasions where speakers will use sha in order to reveal and confront interlocutors with their (the interlocutor's) faulty logic evinced by their (the interlocutor's) actions or utterances. In other words, speakers may use sha to throw the interlocutor's faulty logic in the face of interlocutors as a way of showing them where they have gone wrong. What the speaker is revealing with sha is the truth, or reality (as they see it), of a situation, which they view as not apparent to interlocutors. In these situations, sha usually (but not always) occurs within a second position cluster involving the emphatic marker igo (usually occurring as go), and occasionally with the mystery pleading particle naa (to be discussed in Section 3.2.2.7). This function is shown by the following interaction between my consultants. Once a month at our meetings, the tradition was to have a potluck. At one of these potlucks, one of my consultants noticed that there was fry bread, but no peanut butter. It was at this point that he mentioned that he was allergic to peanut butter, but his very next step was to call home to see if someone could bring some peanut butter to the meeting. After he got off the phone, one of the other elders queried him about the apparent contradiction, 
accenting her censure with sha and emphatic marker igo (appearing here as contracted form $g o)$.

(94) sha go

a) Speaker A: (Hangs up from asking someone to bring peanut butter.)

b) Speaker B: Mii na shago booch nandwewendaman?

DP INTER MP EMPH anyways that you are asking for it

'Are you [sha go] asking for it anyways?!'

In (94), Speaker B queries Speaker A as to why he would be asking for peanut butter when he just stated that he was allergic to it. Speaker B, recognizing the illogicality or unreasonableness of Speaker B's actions, uses the second position mystery particle cluster sha go to confront him about this, albeit in a teasing manner. In a way, Speaker B is getting after Speaker A, while also showing Speaker A his illogical actions.

This censuring feature can be seen also in the following examples as well, where an elder reveals and reproaches an assumption by interlocutors that he is really old. The response to this assumption is accented by the second position mystery particle cluster sha go naa.

(95) sha

Gaawiin sha go naa inde-apiitizisiin. not DM DM DM I am not old enough

'I'm not [sha go naa] that old!' (lit. I am not old enough.) 
Here, sha reveals the unreasonableness of the interlocutor's assumption, go is emphatic, and naa is the pleading particle. The combination allows the speaker to refute the interlocutor's faulty logic, this time, a wrong assumption about the age of the elder.

In short, sha allows speakers to set their interlocutors straight, whether it is just a simple correction in real-world deictic references, e.g. No, you!, providing bewildered interlocutors with an answer to a query, or in identifying and confronting interlocutors with their faulty assumptions or actions. In all cases, the use of sha helps to set interlocutors straight in some way by revealing the truth or reality of a situation, while also dealing them some level of derision.

\subsubsection{3 gosha}

Mystery particle gosha is similar to lone mystery particle $s h a$, in that, when speakers use it, they are making some type of revelation that is surprising, not obvious, unsuspected, or unexpected. The difference, however, seems to be that when gosha is used, there is relief that what was just revealed is not such a big deal as was initially thought before the revelation. In a way, this is polar opposite from sha, where the information revealed with sha was perceived as significant, the information revealed by gosha usually turns out not to be. This function has roughly the feeling of the English discourse marker actually, which serves the function in English of revealing the truth or perceived truth of a situation. This can be seen in the following example where a little girl had stolen and later ate some fine broken wild rice that flew out from the winnowing process. Later that night, she got bloated from eating the rice, and started throwing up. Her grandmother got really scared as there was no Indian doctor around. In the end, her 
grandmother figures out that she was just bloated, and accents her statement to this fact with gosha.

(96) gosha (Kegg 1991:132-133)

“Oonh, yay yay, baasinigo gosha wa'aw,” ikido. Mii gaa-izhi-ishkwaa-zegizid. oh goodness she is bloated DM this she said DP so she stopped being scared

“"Oh, goodness gracious, she's just bloated [gosha]," she said, and so she wasn't scared anymore.'

Here, the little girl's grandmother, not knowing what was wrong with her granddaughter, was really frightened at her granddaughter falling ill. It is only after finding out that it was because her granddaughter was bloated from eating winnowed wild rice, and not something else more serious, that her grandmother was relieved. Her eventual revelation, i.e. baasinigo 'she is bloated' is accented by gosha.

Another situation occurs when this same little girl is being following home by a big mysterious dog. Upon arriving home, she screamed and the ladies at her house heard her and ran to her to see what was wrong. Finding out that it was just a dog (which normally scares little kids), they make a statement to that fact, accenting it with the second position mystery particle cluster gosha naa. 
(97) gosha (Kegg 1991:104-105)

a) Miigo imaa aabanaabiyaan, geyaabi ko biminizha'od. DP EMPH there I look back still as usual following me

b) Gichi-aayaazhikweyaan, bimibatooyaan gichi-enigok.

I cry really loud I run really hard

c) Mii gaa-izhi-noondawiwaad ingiw ikwewag, biijiba'idiwaad. DP and they heard me those women running to me

d) “Aaniin," indig. what's wrong they tell me

e) “Awiiya imbiminizha'og," indinaag. someone s/he is following me I tell them

f) “Animosh gosha naa a'aw,” ikidowag. dog DM DM this they say

g) “Dibi naa wenjibaagwen," ikidowag. I wonder DM where s/he comes from they say

a) 'I looked back there and he was still following.

b) I screamed real loud and ran just hard.

c) The ladies heard me and came running.

d) "What's the matter," she said to me.

e) "Somebody is following me," I told them.

f) "Goodness, it's a dog [gosha naa]," they said.

g) 'I wonder where he came from," they said.'

Once the women find out that it was just a dog following her, they reveal this fact by the statement in (97f) goodness, it's a dog [gosha]. While the published translation itself does not make this explicit, one of my consultants suggests that the feeling here is one of relief, not excitement. While it is true, however, that the little girl is very frightened by the big dog following her home, the women appear to show that they are not very concerned as they give her a light reprimand later on in the same paragraph by saying $I$ told you to hurry, apparently meaning that this would not have happened had she hurried. 
What this appears to suggest is that it is the little girl who is scared, not the women.

Therefore, the use of gosha in the example, appears to signal the relieving revelation that it was only a dog following her home, and not something more serious.

Other examples of gosha show the relief revealing feature of gosha. For example, at one of our meetings, an elder showed up with some other visitors. When offered food by another elder, the visiting elder said the following utterance, accented with gosha.

(98) gosha

a) Imbaa-nanda-wiisin gosha.

I am looking around to eat DM

'I'm looking for some place to eat [gosha].'

In (98), what is implied here with gosha is that the visiting elder was actually hungry, but was reserved about helping herself to the potluck, possibly because she had not brought anything to contribute to the potluck. The feeling that gosha helps to establish in this response is best represented by the English phrase: Actually, I WAS hungry, and I'm glad you asked. Gosha, therefore, functioned in this example to reveal their true disposition, but only after the speaker was relieved to find out that it was okay to eat.

The emotional token of relief is not always a requirement for the use of gosha however, since sometimes, the speaker is simply revealing something significant to the situation at hand. In this way, gosha is similar to sha, but unlike sha in that it does not appear to assign blame, or is not used to censure anyone. Gosha merely strengthens the relevant revelation at hand. For example, in the following interaction, Speaker $\mathrm{C}$ makes 
an interjection (i.e. a discourse revelation), accented with gosha, as a way to inform the group of her disposition in regards to the situation at hand.

(99) gosha

a) Speaker A: Geyaabi na aniibiish awiiya?

still INTERR tea someone

b) Speaker B: uhm uhm

no.........

b) Speaker C: Indaano-gii-kagwejimaa gosha, “no!” indigoog. (laughing)

I tried to ask her DM no they tell me

a) Speaker A: 'Anyone what more tea?

b) Speaker B: uhm uhm (=no)

c) Speaker C: I tried to ask her [gosha], they told me "no!"” (laughing)

Here, Speaker A asks if anyone wants more tea, Speaker B responds with $u \mathrm{hm} u \mathrm{hm}$ (=no), and Speaker C immediately interjects with the comment that she already tried to ask those present if they wanted more tea, but they refused. She accents her comment $I$ tried to ask her with gosha. Seeing that Speaker A was unaware of Speaker C's previous attempt at offering tea, Speaker $\mathrm{C}$ seizes the opportunity, using gosha, to tease the group by revealing her previous failed attempt. The effect is that of a teasing or ribbing.

As already alluded to, gosha does not appear to be a censuring particle like sha, since when gosha is being used, speakers are generally not getting after or confronting interlocutors for their faulty logic. Rather, the core function appears to be involved in providing the truth of a situation, a truth known or recognized by the speaker, but somehow not to interlocutors. This fact can be shown in the following humorous story, 
where a grandmother and granddaughter visit a friend who speaks a different dialect of Ojibwe. This story centers around the practice of differing dialects of Ojibwe which make different distinctions of gender in regards to, among other things, articles of clothing, i.e. in this case, pants. Therefore, while some dialects may grammatically via morphological forms refer to pants as animate (i.e. living beings), others grammatically refer to them as inanimate (i.e. non-living). In the following story, the little girl entertains the thought that her grandmother's friend's pants would be living. Her grandmother responds to her comment, accenting her response with gosha.

(100) gosha (Nichols 1988:6-7) ${ }^{60}$

a) Ikwezens miinawaa ookomisan izhaawaad adaawewigamigong. little girl and her grandmother they go there to the store

b) Mii dash gaani-izhi-noogishkaawaad imaa owiijigamishkawaaganiwaan. and then and then stopped off there their neighbors

c) Ikwezens ookomisan ezhi-gagwejimaad, "Aaniin ezhichigeyan?" little girl her grandmother and asks him/her what are you doing

d) “Ingiboode'igwaazon indagonaa. my pants I am hanging him/her up

e) Eni-maajaawaad gomaapii gii-ikido ikwezens, "Bimaadiziwidogenan as they leave later on she said little girl s/he must be alive iniw ogiboode 'igwaazonan." that her pants

f) “Gaawiin, mii gosha omaa ezhi-giizhwewaad ongow Anishinaabeg." no DP DM here how they speak these Indians

\footnotetext{
${ }^{60}$ It is unclear who the author of this story is as the original publication list three people as the authors for a set of stories from whence this story came: Timothy Dunnigan, Rose Barstow, and Angeline Northbird. I have cited Nichols, who was the editor for this collection.
} 
a) 'A girl and her grandmother were going to the store.

b) On the way, they stopped off at a neighbor's house.

c) The girl's grandmother asked the neighbor, "What are you doing?"

d) I'm hanging up my pants."

e) Some time later after they had left there, the girl says, "Could it be that those pants of hers are alive?"

f) "No, that's [gosha] just the way that these Indians speak around here."'

Within the context of this story, the grandmother is not deriding her granddaughter for her faulty logic, but merely revealing the fact that the dialect spoken by her friend refers to pants (grammatically speaking) as being alive. In English, the revealing of such information is usually accomplished by the use of the word just accompanied by a special intonation contour which marks such revealed information, i.e. rising intonation over that's and speak within the phrase that's just the way that these Indians speak around here. As already noted earlier, Ojibwe does not use intonation contours in the way that English does. This becomes quickly evident when listening to an Ojibwe narration. The intonation contours within the narrative remain quite flat throughout the whole discourse, while English discourse shows a rich use of stress and intonation contours in order to produce a number of nuances. Given these facts, it is not surprising that Ojibwe would use discourse markers, such as gosha in this case, in order to mark such revealed information.

In short, gosha makes its appearances in situations where speakers want to make a revelation that is somehow significant or relevant in the situation at hand. The information that is revealed by speakers is usually information which, once revealed, makes the situation more clear to interlocutors. Another way of saying this is that gosha allows speakers to provide or interject the reality of a situation (as seen in the eyes of the 
speaker), a reality that the speaker perceives as not being visible to interlocutors. Many times, this revelation of reality has a relieving effect if the information that gosha is accenting is found out to be contextually benign in nature where it was once thought to be malignant. Also, while gosha is similar to sha in its revealing feature, it differs from sha in that speakers do not use gosha to in order to censure interlocutors.

\subsubsection{4 da}

Mystery particle $d a$ is nicknamed here as the "clarification particle", since it has a clarifying function. When speakers use this particle, they are asking for information that they missed in previous conversation. Its use is similar to the use of again in English for the same function, e.g. What is your name again? Though da in Ojibwe and the use of again in English have similar functions, their individual meanings are not the same, e.g. $d a$ does not mean again in Ojibwe. It is the exacting, or clarifying, nature of $d a$ which allows this reading. The clarifying function can be seen with these two examples. When I asked one of the elders a question, she initially did not know that I was speaking to her. Once she realized that I was, she uttered the question in (100b). The example in (100a) gives the common interrogative form for what.

(101) Clarification particle da

a) Wegonen?

INTER

'What?' 


\section{b) Wegonen da?}

INTER CP

'What now?' (asking for a repeat of the question)

Mystery particle $d a$ may be use with other interrogatives as well, having the same

function. This is shown below in the following examples provided by my consultants.

(102) da with interrogatives

a) Aaniin da ezhinikaazoyan?

how $\quad$ CP what you are named

'What is your name again?'

b) Awenen da gaa-ojiimad?

who CP who you kissed

'Who did you kiss again?'

Clarification particle $d a$ also functions as an attention-getter, having a function similar to that of hey in English. This function appears to stem from its clarifying or exacting nature. In other words, because $d a$ has a core function of honing in on things, it is no surprise that it also functions in getting the attention of others. This function is shown below from a story when a little girl's uncle wants her to go get a gun to shoot some ducks. 
(103) Attention-getter da (Kegg 1991:84-85)

Miish a'aw inzhishenh, 'Da, niiyawen', da, niiyawen' maajaan, and then that my uncle DM my namesake DM my namesake leave

naadin i'iw imbaashkizigan, ”...

get it that my gun

'My uncle said, "Hey, my namesake, hey, my namesake, go and get my gun...'

As do other mystery particles, clarification particle $d a$ also appears in discourse marker clusters. These discourse marker clusters will be discussed later, but an individual accounting of $d a$ here will help to understand their usage within clusters. This discussion is reserved for Section 3.2.2.7.3.1.

\subsubsection{5 bina}

Mystery particle bina has a core function of strengthening the illocutionary force of imperatives, having the force of the English damn it!, you had better do it!, etc. When used with imperatives (which appears to be its most common usage), the speaker is usually urging (almost berating) an interlocutor to do something that interlocutor knows s/he should do. The following example shows this type of usage.

(104) bina

a) Ojibwemotawishin bina!

speak Ojibwe to me DM

'Speak Ojibwe to me damn it!' (feeling: since you speak the language) 


\section{b) Ojibwemon bina naa! \\ speak Ojibwe to me DM DM \\ 'Speak Ojibwe damn it!'}

While the imperative form ojibwemotawishin in (104a) is quite direct in itself, its propositional content is strengthened even more by the use of bina. One of my consultants recounted to me once that he would use the imperative (with bina) in (104a) with other Ojibwe speakers when they would use English with him, rather than Ojibwe. I have personally heard one of my consultants use the imperative (with bina naa) in (104b) with another elder who complained that no one speaks Ojibwe anymore. ${ }^{61}$ For both of these examples, since it is well known among Ojibwe speakers that Ojibwe is an endangered language, the general expectation is that it should be used whenever possible, especially between native speakers. In essence, the speaker sees the interlocutor's actions as contradictory to general expectation (or at least, to the speaker's expectation) and tries to correct that action by an imperative expression, accenting it with bina.

When used with Ojibwe jussive expressions, bina has the same effect, increasing the illocutionary force of the jussive expression. A jussive, according to Trask, is like a "third-person imperative" in that it is an imperative expression such as the English Let them eat cake! where an imperative form is interpreted as being directed at someone other than the addressee (see Trask 1993:150). In Ojibwe, jussive constructions usually involve the use of maanoo 'let it be', as in the following examples.

${ }^{61}$ Discourse marker naa will be discussed in detail in Section 3.2.2.7.3.1. 
(105) Ojibwe jussives

a) (Mille Lacs Sessions)

Maanoo wiin da-wiisini.

let it be him/her he will eat

'Let her eat!'

b) (Mille Lacs Sessions)

Maanoo wiin oga-amwaan.

let it be him/her s/he will eat him/her

'Let him eat it (something animate)!'

c) (text communication)

Speaker A: Can I transcribe your story?

Speaker B: Maanoo.

Speaker A: Can I transcribe your story?

Speaker B: Go ahead.

On one occasion, one of my consultants used bina with the jussive maanoo. At the time of this utterance, my consultant was arguing with another elder at our meeting, and the elder angrily left the room. After that elder left, my consultant said the following statement with bina. 
(106) bina within jussive constructions

\section{Maanoo bina!}

let it be DM

'Let him (leave)!' (feeling of bina: I don't care, it's okay that he leaves.)

The statement in (106) was not uttered to the angry elder that left, but to us, the other interlocutors in the room at the time. Here, bina appears to signal to interlocutors that she does not care against the expectation that one would normally care in situations such as this. This particular elder was known to be a scrapper in her younger days and so it was no surprise that she would make such a comment. In short, the use of maanoo in her utterance tells us (the interlocutors) to let him (leave), and bina strengthens that imperative. It is important to note that the I don't care attitude emanating from this utterance is pragmatically inferred, since bina does not have any meaning in and of itself. It is bina's strengthening function which allows the pragmatically inferred attitude of $I$ don't care to be obtained. While my data is somewhat scanty for this particle, my observation has been that bina usually appears in these situations where there is some social norm or expectation that is not being observed.

While bina may strengthen the illocutionary force of imperatives (which are inherently confronting), bina may also strengthen, or reinforce, expressions which a speaker uses to quash any fears, hesitations, or unfounded expectations by interlocutors. For example, in the following example, my consultants suggest that the response to Speaker A's would be appropriate. Speaker A asks whether it would be okay to come and sing at a ceremony (something that someone might think is inappropriate to ask 
about, especially at ceremonial dances), the use of bina with aawaaw 'go ahead' shows that their presupposed fear or hesitation was unfounded. My consultants suggest that the following exchanges are common.

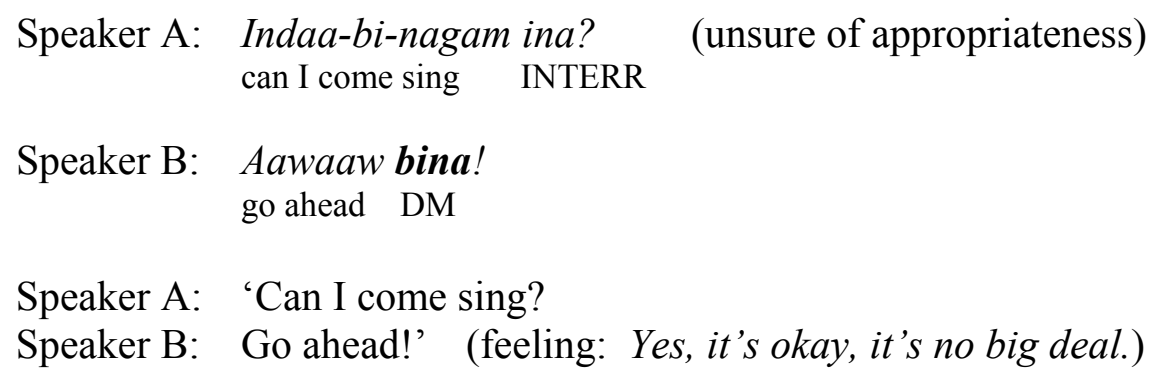

In (107), the particle aawaaw has the meaning 'go ahead' and is being used by the speaker to respond to Speaker B's question. Because bina strengthens the proposition 'go ahead' represented by aawaaw, the fear quashing attitude it's no big deal can be pragmatically inferred, and Speaker B's hesitations about asking are relieved.

Mystery particle bina is also seen within declarative type expressions as well where bina strengthens the propositional content of its containing utterance. This usage appears to be less common than its occurrence with imperatives, but its function remains the same, strengthening the illocutionary force of its containing proposition. The following example shows the use of bina with the particle ahaw 'okay, alright', which is commonly used to show receipt of information. 
(108) bina (text communication)

a) Consultant: Zoogipon omaa bangii.

it's snowing here a little

b) Me: Indaa-dibaabandaan the weather report.

I should check it the weather report

c) Me: Niwii-pi-izhaamin. (later)

we are coming

d) Consultant: Ahaw bina.

okay DM

a) 'It's snowing here a little.

b) I should check the weather report.

c) We're coming.

d) Okay go ahead and do it.'

In (108a), my consultant informs me that it was snowing a little up at Mille Lacs (the reservation where we had our meetings), thereby implying that it might be better not to come up. I then told her that I would check the weather report, and after doing so, I texted her back sometime later saying that we would be coming. To this, she responded with ahaw bina 'Okay go ahead and do it'. Ahaw shows a receipt of information, and bina strengthens that receipt. What the speaker appears to mean by this statement is that she is really indifferent and could go either way. In other words, the attitude that can be pragmatically inferred by the use of ahaw bina is: okay, whatever you want to do, it doesn't matter to me.

What all these examples have in common is the use of bina to strengthen the illocutionary force of its containing proposition. If bina is used with a confronting imperative, then that imperative is given more force. If bina is used with non-confronting 
imperatives, then a more positive result may be obtained. If bina occurs with an ambivalent proposition, then ambivalence is strengthened. The various resulting attitudes or attitudinal meanings are then pragmatically inferred depending on the proposition that it is strengthened.

\subsubsection{6 goda}

Mystery particle goda is like bina (above), since it too is used to accent imperatives. Its function is a little different, however. When used with imperative forms, goda has a function similar to the English temporal adverb then within the following English exchange.

(109) English temporal adverb then
a) Speaker A: I don't have any money.
b) Speaker B: Get a job then!

What is essentially going on here is that Speaker B is providing a temporal solution to Speaker A's problem of not having any money, and uses the temporal adverb then to suggest that the next step in time is to get a job. In Ojibwe, while goda is used for this same solution-giving function, it is not a temporal adverb, and does not have a temporal function elsewhere in the language that would parallel the English temporal adverb then, e.g. and then, she was a linguist then. Therefore, goda in Ojibwe is analyzed here as an option marker, since when it is used, possible options are always being offered without 
reference to time (although time is an inescapable inherent part of the solution). The point here is that the two languages handle this type of solution-giving exchange in different ways. English uses a temporal adverb, Ojibwe does not. This usage is illustrated below with the following example where one elder, who is notorious for complaining about people not using the language anymore, came into one of our meetings and said that we should meet more so that people can speak Ojibwe, all the while speaking English himself. One of the other elders present then said to him the following utterance.

(110) goda

\section{Ojibwemon goda! \\ speak Ojibwe DM \\ 'Speak Ojibwe then!'}

Here, using goda, the other elder provided the complaining elder with the obvious answer to his perceived problem, i.e. to speak Ojibwe himself.

Goda may appear within declarative statements as well where it appears to maintain its option marker feature. In the following example, I had asked one of my consultants via email to listen to some sound files. Later that day and after having not been able to listen to my audio files, she texted me the following bilingual statements, one occurring with goda (I kept my consultant's original orthography as it appear within the text message). 
'Sorry been a long day. I'll look at it tomorrow okay.'

After apologizing for having not been able to listen to my audio files, she offers up a plan (i.e. a resolution to the problem at hand) to look at them the next day. It is this phrase that is accented by goda.

\subsubsection{7 naa}

The mystery particle naa has various functions, as a HEDGE, as an EVIDENTIARY MARKER, and as an PLEADING MARKER. Each of these functions will be discussed in the following sections.

\subsubsection{1 naa as a hedge}

According to Trask, a hedge is an "expression added to an utterance which permits the speaker to reduce her/his commitment to what she/he is saying: I think, I suppose, I fancy, I would guess, I take it, it seems to me" (Trask 1993:128). In Ojibwe, one of the functions of the mystery particle naa is to serve as a hedge, and when used, allows speakers to generally distance themselves from a proposition. Distancing themselves may include situations where the speaker is either unsure of the correctness of a proposition, that they are unsure of the exact details or circumstances of a situation, or that they cannot explain how something has occurred. When speakers use mystery particle naa, they are essentially expressing the following rough glosses: I guess, I can't be sure, somehow, I don't how it happened, etc. In short, mystery particle naa allows 
speakers to speak about topics without totally committing to their correctness, or without having to explain how an event came to be. A good example of this is shown by the following utterance made by one of my consultants at one of our weekly meetings. After making a guess on how to spell a word, she immediately said the following utterance, accenting it with naa.

(112) naa as a hedge

\section{Ganabaj naa.}

probably DM

'Probably I guess.'

Because ganabaj 'probably' is somewhat of a hedge itself, it may be difficult to parse out the contribution that naa is making in this example. My consultants, however, feel that of the following two examples, the one with naa is the weaker statement, showing that the speaker is not fully committed or sure about the verity of the proposition of its containing clause.

(113) naa (Mille Lacs Sessions)

a) Ganabaj niimi. probably dance

'He's probably dancing.' 
b) Ganabaj naa niimi.

probably DM dance

'I think he's dancing.'

The basic proposition for both these statements in (113) above is essentially the same, he's probably dancing. While the English translations do not make the distinction clear, it is the use of naa in (113b) which allows the speaker to distance him/herself from the accuracy of the containing proposition. When naa appears with other words such as ganabaj 'probably', which are quite hedgy themselves, it is quite difficult to parse out naa's contribution to the proposition overall. For example, in the following example, naa may occur with the evidential adverb iidog 'must be, apparently'. In this story, a little girl steals some snuff from a birch bark box, puts it in her mouth, and then gets sick.

(114) naa with other hedging words (Kegg 1991:136-137)

a) Niwenda-minwaabandaan imaa ayi'ii atemagak, ayi'ii wiigwaasi-makakoons. I really like the look of it there thingy be put there thingy little birch bark box

b) Miigo naa iidog i'iw biindaakwaani-makakoons gaa-izhi-ayaayaan ${ }^{62}$, DP EMPH DM must be that snuff box then I got it giimaabamagiko ninoshenh, gidasiged, gaa-izhi-biindaakweyaan, I peek at her used to my aunt she is parching then I took a pinch of snuff gaa-izhi-agwanemwag, mii a'aw biindaakwaan, babaa-dazhitaayaan imaa then I put him/her in my mouth DP that snuff I play around there agwajiing babaa-zaziikoyaan.

outside I spit around

\footnotetext{
${ }^{62}$ My consultants suggest that the verbal complex gaa-izhi-ayaayaan should appear as the verbal complex gaa-izhi-ayaamaan instead.
} 
c) Baanimaa igo naa wenji-gizhibaabizoyaan indinendam, gizhibaabizoyaan suddenly EMPH DP I am spinning from it I think I am spinning

indinendam, zhishigagoweyaan, gaa-izhi-bwaanawitooyaan wii-pimoseyaan. I think I am throwing up then I am unable to walk

a) 'I admired the looks of that thing there, the little birch bark box.

b) I [naa] must have got the snuffbox, then I peeked at my aunt parching rice, took a pinch, put the snuff in my mouth, and went playing around outside, spitting all around.

c) All of a sudden [naa] I felt like I was spinning around, I felt like I was spinning, and I vomited, so I couldn't even walk.'

Here, the speaker is recounting a story from her youth, and uses mystery particle naa twice. Once with the evidential adverb iidog in (114b), and again in (114c) as the lone marker naa. As already noted, iidog is a hedge word itself, but it is quite easy to see its contribution in the (114b), as the gloss must have is a common gloss for iidog. It marks that the speaker, based upon the evidence, has gotten a hold of the snuff box. Now, what naa appears to be contributing in both instances is the speaker's fuzziness of the details. In (114b), naa appears to be expressing the feeling I don't know how, but I got a hold of that snuff box, or somehow I got of how she got the snuff box, but I don't know how exactly. In (114b), naa appears to support the ensuing confusion of spinning, vomiting, and not being able to walk by expressing the feeling, I don't know what happened exactly as I was dazed and confused, but I was spinning, vomiting, and wasn't able to walk. In other words, the little girl had no idea that a pinch of snuff could have the powerful effect that it did. Mystery particle naa captures the fact that the ensuing sickness was a mystery and a surprise, and that at the time, she did not know why she was getting so sick. The use of naa in this way is actually quite common where speakers are unable to account for an occurrence. For example in the next example, a little girl 
mistakenly plunges a deer hide into boiling water, shrinking and ruining the hide. She had no idea that boiling water would ruin the hide. Her recounting and her statements to her grandmother are littered with tokens of naa.

(115) naa as a hedge (Kegg 1991:160-163)

a) Gaawiin ingii-wiindamaagosiin, mii i'iw eta go gii-izhid ji-ningizwag not she didn't tell me DP that only EMPH she tells me to melt him/her

a'aw goon, ji-agonjimag a'aw waawaashkeshiwayaan. that snow to soak him/her that deer hide

b) Waa, mii azhigwa gegaa go ondeg nibi, miish imaa agonjimag. wow DP when almost EMPH it is boiling water then there I soak him/her

c) Mii go naa ezhi-odaapishkaad, ezhi-odaapishkaad. DP EMPH DM then s/he shrinks then s/he shrinks

d) Enda-agaashiinyi. $\mathrm{s} / \mathrm{he}$ is really small

e) “Gaawiin wiikaa, aaniin naa izhiwebizid," indinendam. not ever what DM is happening with him/her I think

f) “Nimaamaanaan," indinaa, “mii go naa gaa-izhi-odaapishkaad grandma I tell her DP EMPH DM then s/he shrank

a'aw waawaashkeshiwayaan.

that deerhide

a) 'She didn't tell me much about it; she just told me to melt the snow to soak the deerhide in it.

b) The water was about to boil and I put it in to soak.

c) It [naa] just shrank and shrank.

d) It got real small.

e) "Well, I never, what's [naa] happening to it," I thought.

f) "Grandma," I said to her, "the deerhide [naa] shrank.", 
The little girl in this story was told by her grandmother to melt some snow and soak a deer hide in it. Not ever having done this before, or ever having watched her grandmother do it, she melted the snow to a boil and threw the hide in, shrinking and ruining the hide. At the time, the little girl had no idea what was happening to the hide, and why it was shrinking. By accenting her utterances with naa, she distances herself from the event, as a way to avoid responsibility, as she did not know any better, nor was she instructed as to the correct manner in which to soak a hide. In (115c), the speaker uses naa to express the feeling I don't know how, but it shrank, or somehow it shrank. In (115e), naa expresses that the speaker cannot explain what is happening and is in effect saying I wonder what is happening. In (115f), the speaker uses naa to distance herself from the event when revealing to the incident to her grandmother. In a way, what the speaker appears to be saying when using naa is I don't know how, but the hide shrank.

As the example in (115e) suggests above, there are times when speakers are baffled about a situation, and are searching for an answer to what it is that is baffling them. This usage is still a hedge, since the speaker is still distancing themselves, not from the question or proposition, but from the answer. When used in this way, I sometimes like to call naa the WONDER PARTICLE, since this is what speakers are doing when they use naa in such cases. This can be seen in the following example where a little girl steals fry bread in order to give it to a man that she is quite afraid of (as he was always teasing her by saying that he was going to eat her up and that he will marry her when she grows up). The women cooking the bread realize that they are missing bread and say the following utterance, accenting it with naa. 
(116) naa as a wonder particle (Kegg 1991:118-119)

a) Miish ingiw ikwewag imaa jiibaakwewaad imaa, ginagaapiwaad igaye. and then those women there they are cooking there they are giggling also

b) "Gaawiin dash naa awiiya animosh ayaasiin?" not but DM someone dog nothere

c) "Animoshag dash wiin igo baatayiinowag." dogs but on the contrary EMPH they are plenty

d) "Gaawiin na omaa besho bi-onji-izhaasiin animosh? not INTERR here near s/he does not ever come dog

e) Oonh, ingii-metasinaa bakwezhigan." oh I am missing him/her bread

a) 'The women were still cooking, and also giggling.

b) There aren't [naa] any dogs here, are there?"

c) "But there's lots of dogs here."

d) "Did a dog ever come near here?

e) Oh, I'm missing some bread.",

In (116b), a little girl secretly stole a piece of fry bread in order to feed an old man that she was afraid of. Having noticed bread was missing, the women start wondering whether it was a dog that stole the bread. It is precisely when they are trying to figure this out that naa is used. The use of naa accentuates this baffled feeling expressed by the statement in (116b).

Now, there is another use of naa (to be discussed in Section 3.2.2.7.3.1) where naa is used within clusters da naa and sha naa (i.e. the damn it clusters) which are used to show strong speaker emotion or distress. It might be argued that naa within the example just discussed involving the dogs and fry bread that naa is not actually acting as a hedge (or wonder particle), but as a marker of strong emotional distress (i.e. when the speaker 
wants to express the equivalent of damn it). This could easily be the case since the women cooking fry bread do not want dogs taking their fry bread and could be saying, in effect: There aren't damn dogs here, are there? There is evidence, however, that naa in this case is indeed the wonder particle (i.e. a function as a hedge). In the following example, naa appears in an utterance where the speaker is baffled about something, and as a result is wondering what it going on. A young girl has acquired about twenty mud turtles that were taken off the lake for her. They were frozen and so she had piled them up outside. She took a kettle and put the frozen mud turtles in there to boil them. As a result of the warming water, the mud turtles begin to move. It is when she saw the mud turtles start to move that she made the following utterance, accenting it with naa.

(117) naa as a wonder particle (Kegg 1991:164-165)

a) Mashkawaakwajiwag. they are frozen

b) Gaawiin mamaajiisiiwag, biina'wagwaa miskwaadesiwag, mii imaa akikong. not they are not moving I put them in mud turtles DP there in the kettle

c) Mii go naa-sh mamaajiiwaad, ganawaabamagwaa. DP EMPH DM-DM they are moving I watch them

b) "Aaniin ezhiwebiziwaad?" what what is wrong with them

a) 'They were frozen.

b) Those turtles weren't moving when I put them in the kettle.

c) As I watched them, they started [naa] moving.

d) "What's happening to them?", 
Upon seeing the turtles start to move, the young girl is surprised, and wonders what is happening, apparently not realizing that the warm water had brought them out of their dormant state. The naa in this example, similar to the one occurring within the dog and fry bread example above, occur in situations where there is some confusion brought on by some surprising or unexpected event in which the speaker then tries to figure what is going on. Even though naa occurs within an interrogative sentence, rather than in an interrogative sentence as with the dog and fry bread example, naa shows the speaker's wonderment. In short, the turtles start moving, the young girl is surprised and cannot explain what is going on, and as a result expresses this bafflement (or wonderment) by the use of naa.

\subsubsection{2 naa as an evidential marker}

Another function of naa is as an evidential marker. When used in this way, the speaker is accenting an utterance that represents some type of prediction based upon visual evidence, past personal experience, or deduction. This evidential function of naa should be distinguished from the function of the well-known evidential adverbs giiwenh 'apparently, they say' and iidog 'must be' (see Valentine 2001:830-832 for more discussion about these evidential adverbs) whose major functions are to mark secondhand information, i.e. information that speakers cannot personally vouch for because the speaker was not personally present when the reported event occurred. In the case of naa, however, speakers are usually present during the occurrence of the event in question (and therefore able to directly report on it), or they have personally experienced or witnessed something that allows them to deductively report on an event. When used in this way, 
naa has the force of the English looks like. This evidentiary function can be seen in the following utterance made by one of my consultants about someone who looked really tired at the conclusion of one of our meetings.

(118) Evidentiary function of naa (Mille Lacs Sessions)

Gegapi naa da-nibaa.

finally looks like will sleep

'She’s finally [naa] gonna go to sleep.'

The person my consultant was referring to was leaned back in her chair, with her eyes closed, acting like she was tired and sleepy. There was visible relief on the part of that person that we had ended our meeting (as we usually ended late in the evening). Upon seeing this, one of my consultants makes the deduction in (118), accenting it with naa. This usage is not a hedge, since the speaker is not trying to distance herself from her proposition; rather, the speaker is making a deductive statement based upon visible evidence, i.e. leaning back in a chair, tired demeanor, etc.

This usage can also be seen in the following utterance made by a consultant's mother in regards to some kids she saw playing outside in the sun all day. She states that the kids are getting darker and darker from being out in the sun all day.

(119) Evidentiary function of naa

$\begin{array}{lll}\text { Genapii naa ani-makadewaasowag ongow. } & \text { and } \\ \text { as time goes by looks like they are getting dark these }\end{array}$

'They are getting darker as time goes by.' 
The speaker is relying on two types of evidence in making her deductive statement in (119). First, she can visibly see the kids getting darker. Second, it is her past personal experience that Ojibwe kids get darker when playing in the sun. Therefore, again, her use of naa in this example cannot be a hedge (as one might argue), but a statement deduced from both the visual evidence and personal experience. There is no doubt about the fact that the Ojibwe kids will become darker over time, and the use of naa here allows the speakers to express this deductive knowledge.

The following example shows that speakers may use naa in making deductive statements based upon residual evidence of an event, rather than from actually witnessing it. For example, in one story, some butchered snapping turtles were stolen from a barrel inside a cabin. Because the speaker did not actually see who or what took and ate the snapping turtles, he could only deduce what must have happened based upon the evidence, i.e. turtles are gone, big footsteps spotted around the cabin, and a broken window. He then makes the following assertions, all accented by naa.

(120) Evidentiary function of naa (Kegg 1991:90-91)
a) "Awegwenag naa.
I don't know who they are DM
b) Wenda-gichi-mamaangizidewag naa ingiw. they have very big feet DM those
c) Mii iidog naa gaa-izhi-niigoshkamowaad i'iw waasechigan, " ikido... that DUB DM then they broke it that window say
a) '“I don't know what they are [naa].
b) They [naa] have really big feet.
c) They must [naa] have broken the window," he said...' 
The first token of naa in (120a) appears to be the wonder particle, since the speaker appears to be wondering who could have taken the turtles from the cabin. The last two tokens in $(120 \mathrm{~b}, \mathrm{c})$ appear to be the evidentiary usage, since the speaker is making generalizations based upon the evidence left behind by the culprit. Again, it does not appear to be the hedge function, since the speaker does not appear to be hedging giving the circumstances; rather, he is reconstructing what happened based upon the visual evidence he saw at the cabin.

\subsubsection{3 naa as a pleading particle}

Discourse marker naa has another function as well. Within imperative expressions, naa has a strengthening effect, adding a feeling that the speaker is urging or pleading with interlocutors, and has the force of the English expression come on! Therefore, when speakers use naa to accent imperatives, mystery particle naa increases the overall illocutionary force of the imperative by increasing the emotional tug of the imperative. In the following elicited examples, my consultants suggest that the one with naa is the stronger imperative.

(121) Pleading particle naa

a) Daga bi-naazhishin!

please come get me

'Please come get me!' 


\section{b) Daga naa bi-naazhishin! \\ please DM come get me}

'Come on, please come get me!'

The basic imperative force of the carrier imperative expression in (121) is please come and get me!, but naa in (121b) contributes an emotional tug on the interlocutor. It increases the overall emotional urgency of the situation, allowing the speaker to increase the urgency of their pleading. In other words, naa amplifies the function of its surrounding content, here, an imperative expression. When used in this manner, mystery particle $n a a$ is a general amplifier marker, having the function of amplifying the functions of its containing clauses, the situational emotional statue, or other discourse markers. As we will see, when it occurs with other discourse markers within clusters, it amplifies the individual functions of those markers.

\subsection{Second position discourse clusters with naa}

The mystery particle naa appears frequently in various combinations of clusters, e.g. da naa, sha naa, bina naa, sa naa. In these clusters, naa always appears last in the combination, i.e. as the second or third particle in the cluster depending on whether there is an intervening emphatic particle, such as go. Therefore, the following combinations are unattested: *naa da, *naa sha, *naa sa, *naa bina, though each may appear individually within utterances.

Both da naa and sha naa have similar functions. They have a meaning similar to the English expression damn it or [what] the hell, but without the stigma of swear words. What this means is that though both combinations da naa and sha naa have the semantic 
weight of the English damn it, they can be appropriately used with children (or by them), since these words, or the combination thereof, are not considered to be profane. Though both share a common emotional functional load, the use of $d a$ or sha as the initial unit of these clusters changes the nuance of the cluster. As we have already seen, $d a$ is an information-seeker and sha is the getting-after marker. These individual functions contribute to the overall meaning in their use with naa. Therefore, da naa occurs in situations where the speaker is searching for information, but cannot find it; and sha is used when the speaker is directing their clarification or revelation to an individual or a group. Examine the examples below.

(122) "damn it" particle clusters da naa and sha naa

a) Wegonen da naa? (said to themselves while searching) what DM DM

'What the hell is it now?'

b) Biboon sha naa! (said to a group) winter DM DM 'It's winter damn it!'

One of my consultants uttered to herself the expression in (122a) when trying to recall a word from memory. It was uttered under her breath. The searching is indicated by the $d a$ particle, which is has been analyzed as an information-seeker or clarifier. The expression in (122b) shows the use of sha as the initial element, showing that her statement is directed toward either an individual or group in providing a revelation, rather 
than searching for information. Here, one of my consultants said the utterance in (122b) showing her disappointment that even though it was the dead of winter (i.e. January), it was too mild. In both cases, naa amplifies the respective functions of the individual markers $d a$ and sha in order to increase the overall emotional state of the situation.

Cluster sha naa also appears in a story about a little girl and her grandma who were traveling to go weed a garden for someone, further showing naa's emotional amplification function. On the way to their destination, they got hungry. They then saw a duck, killed it, plucked it, built a fire, and then singed it. After all this work and effort, they realize they had no knife to clean it with, to which the following phrase was uttered by her grandmother.

(123) sha naa (Kegg 1991:76-77)

$$
\begin{aligned}
& \text { “Oo, yay, gaawiin sha naa gegoo mookomaan gibimiwidoosiimin,” ikido. } \\
& \text { oh no not DM DM something knife we do not bring it along she says } \\
& \text { "“Oh no, we haven't [sha naa] even got a knife along," she said.' }
\end{aligned}
$$

Although the translation does not capture the discourse cluster usage, the interpretation is: Oh no, we didn't bring along a knife damn it. This interpretation is also supported by the fact that the situation was already in a heightened state of excitement, evinced by her grandmother's previous statement in regards to killing a duck: Oo, Naawakamigook, mii ji-wiisiniyang 'Oh, Naawakamigook, we're going to eat'. As noted in Fairbanks 2008 (forthcoming), the use of a mii-clause in statements such as this is not random. In other words, the Ojibwe speaker has two options in order to convey the proposition we're 
going to eat, as independent order inflection: giga-wiisinimin; or as conjunct order inflection within a mii-clause: mii ji-wiisiniyang. While the basic proposition is the same for both these statements, the mii-clause mii ji-wiisiniyang is the stronger statement of the two and carries heightened emotional load, having the interpretation 'now we're going to for sure!'. Given the amount of excitement that existed in killing the duck, and the amount of time and effort that was invested in preparing it for cleaning, the use of sha naa here is felicitous.

Recall also that sha also had a feeling of eliciting pity from interlocutors, e.g. ingiiwiindamawaa sha 'I told her' (getting after herself and eliciting pity from interlocutors). This sort of pity-invoking usage is also seen with sha naa as well, where speakers feel left out and want others to include them. The use of sha naa in the following examples provided by my consultants are equivalent to the use of rising tone in English over the first personal pronoun $I$ and the final word, i.e. English pity invoking tone.

(124) sha naa

(a) Niwii-odaabii'iwe sha naa. I want to drive DM DM

'I wanna drive.'

b) Niwii-namadab sha naa. I want to site DM DM 'I want to sit.' 
c) Nibakade sha naa.

I am hungry DM DM

'I'm hungry.'

In these examples, pity is invoked by the speaker's use of sha, and its illocutionary force is increased by naa.

One consultant suggested that sha naa can also be used in cutting people off midsentence. This is shown in the following example provided by one of my consultants.

\section{Niwii-o-ganawaab sha naa.}

I am gonna go watch DM DM

'Excuse me, but I'm gonna go watch.' (cutting them off)

This usage is quite forward and imposing. This meaning appears to derive its meaning from the getting-after particle sha.

The use of $d a$ naa, on the other hand, appears in situations where an alternative option is being offered up to interlocutors. In this usage, the cluster da naa may appear as the initial component of a sentence or clause (the only example of this in my data). This is shown in the following example provided by one of my consultants.

(126) Da naa giin gwaaba'amaadizon.

DM DM you scoop it out yourself

'Dish it up yourself damn it!' 
Here, the individual uses of both $d a$ and $n a a$ are clear. $D a$ allows the speaker to refuse the expectation that she dish up something for the interlocutor, and naa amplifies this action. The speaker also makes uses of a fronted second personal pronoun giin 'you', which has the effect of grammatically focusing on the referent. The combination of $d a$ and naa results in the damn it feeling, but without the stigma of having just cursed.

The last two clusters involving naa are bina naa and sa naa. As with the naa clusters just discussed, i.e. sha naa, da naa, pleading particle naa is the component which heightens the of emotional intensity, or which amplifies the function of the individual marker occurring with it. An example of this is given by some examples provided by my consultants.

(127) bina naa and sa naa (Mille Lacs Sessions)

a) Ojibwemon bina naa speak Ojibwe DM DM

'Speak Ojibwe!'

\section{b) Noongom bina naa} today DM DM

'Do it today!'

In both $(127 \mathrm{a}, \mathrm{b})$, bina naa signals a sharp reprimand to interlocutors to do something that they know should do, but do not. This function is typical of the lone particle bina. For example in (127a), given the urgency to preserve the Ojibwe language, the addressee is being strongly urged (more so than when just bina is used alone) to speak the language 
that they grew up with, as opposed to speaking English. In (127b), bina naa is used to express temporal urgency. In essence, the speaker is communicating to the interlocutor the urgency of being helped today. Mystery particle bina, again, functions as the reprimand, and naa amplifies that reprimand contributing the feeling that the interlocutor is being pleaded with.

The cluster $s a n a a$, is heard a lot in valedictions, i.e. saying goodbyes. Recall that mystery particle isa (or its clitic form $s a$ ) is commonly used in conclusory situations such as this, i.e. ending of stories, etc. In valedictions, naa functions as the pleading particle, allowing the speaker to increase the illocutionary force of his/her valediction.

(128) isa in valedictions

a) Agana sa naa

easy DM DM

'Take it easy!'

b) Weweni sa go naa carefully DM EMPH DM

'Take care!'

In these examples, the individual contributions of each mystery particle is clear. Marker $s a$ is conclusory, go is emphatic, and naa shows a wishing or urging function. Mystery particle $s a$ also may appear with the wonder particle naa as well in situations where something has happened, but the speaker cannot account for it. This was the case in the story about some turtles that were stolen from a cabin by some creature that had big feet. 
The uncle's initial utterance to his niece after finding out that the turtles were stolen is accented by the cluster sa naa.

(129) sa naa (Kegg 1991:90-91)

a) "Mii sa naa akina ingiw mikinaakwag, gaawiin awiiya," ikido, ikido DP DM DM all those turtles not someone he says he says

mii a'aw inzhishenh.

DP that my uncle

b) "Awegwenag naa.

I don't know who they are DM

c) Wenda-gichi-mamaangizidewag naa ingiw.

they have very big feet DM those

d) Mii iidog naa gaa-izhi-niigoshkamowaad i'iw waasechigan, " ikido... that DUB DM then they broke it that window say

a) “"All [sa naa] those turtles are gone," my uncle said.

b) "I don't know what they are [naa].

c) They [naa] have really big feet.

d) They must [naa] have broken the window," he said...'

The utterance in (129a) is a resultant expression shown by the speaker's use of $s a$. In essence, he appears to have given up trying to figure out who stole the turtles and finally states to his niece that they are now gone. The girl's uncle uses naa, apparently as a hedge, since he is unable to account for what happened, i.e. like saying somehow or another. In other words, with the use of sa naa in this example, the uncle is essentially saying to his niece after having done an inspection, but still not able to figure out who stole the turtles, all those turtles are finally gone. Note that the remaining three 
utterances are accented by naa as well, showing the overall bewilderment and deductive reasoning on the part of the uncle in reconstructing what happened, all functions of naa.

In sum, what these various clusters suggest is that when mystery particles cluster together, the resulting cluster is a product of the individual markers. The individual meanings of the individual markers remain largely transparent, allowing speakers to accomplish various functions within discourse. For example in valedictions, while $s a$ in the cluster sa naa signals that a visit has come to an end, the urging function of naa allows the speaker to increase the illocutionary force of their goodbyes. Ojibwe clusters also show that mystery markers may be used to accomplish a lot of the same work that intonation contours do in English. For example, in the phrase I'm not that old, an English speaker makes use of stress and an intonation rise over the demonstrative that in order to rebuke their interlocutors. Ojibwe, on the other hand, does not make productive use of stress and intonation in this way, but rather uses mystery particles to accomplish this same function, e.g. Gaawiin sha go naa inde-apiitizisiin. 'I'm not that old.' 


\subsection{Conjunct order as a discourse marking device}

It is well known for Ojibwe, as well as for other Algonquian languages, that there are three major verb orders (or sets of paradigms): INDEPENDENT, CONJUNCT, and IMPERATIVE. As their respective labels indicate, independent order verbs function as independent clauses or sentences, conjunct order verbs (or "plain conjuncts") ${ }^{63}$ function as dependent, subordinate, or embedded clauses, and the imperatives are the command forms. Examples of these orders are given below. Note that for independent verbs, agreement is accomplished by the utilization of both prefixes and suffixes, whereas the conjunct and imperative orders only utilize suffixes.

(130) Ojibwe verb orders

a) gi-maajaa-m $\boldsymbol{m}^{64}$

(independent order $\rightarrow$ independent clauses)

2-leave-2P

'You all are leaving.'

b) maajaa-yeg

leave-2P

(conjunct order $\rightarrow$ dependent clauses)

'When you all leave...'

c) maajaa-g

leave-IMP.2P

(imperative order $\rightarrow$ commands)

'Leave (all of you)!'

\footnotetext{
${ }^{63}$ More specifically, plain conjuncts are conjuncts which do not show INITIAL CHANGE, an ablaut process which changes the initial vowel of plain conjunct verbs. Those which do show initial change, are referred to as CHANGED CONJUNCTS, and may serve a variety of functions, i.e. showing completive aspect, or forming nominalized verbs.

${ }^{64}$ For independent order AI verbs, there is no personal prefix for third person singular, e.g. maajaa 's/he leaves'.
} 
A snag that this characterization runs into (i.e. that conjunct order function as dependent clauses), however, is the observation made by Rhodes for a related dialect of Ojibwe, OTTAWA (or ODAAWAA), that plain conjunct verbs may be used as independent clauses in certain contexts (Rhodes 1979:103, Rhodes 2006:6). These contexts include the use of plain conjunct verbs as independent verbs when those verbs are marking THEMATIC content (i.e. content which moves the plot forward) within a text, in marking what he calls "thematic futures", or in the consequent of 'if' constructions (Rhodes 1979:112113). An example of the use of plain conjunct verbs as independent, thematic verbs is given below.

(131) Plain conjunct as independent verbs (example from Rhodes 1979:110-111)

a) Gii-pagdosed iidig gaa-dbikak. that $\mathrm{s} / \mathrm{he}$ walked/CONJ must have after it got dark

b) Mkoon iidig gaa-zhi-nkweshkwaad. bear must have IC.and so met him/her/CONJ

c) "Aabii-sh ezhaayan?" wdigoon-sh ge. where are you going s/he tells him/her also

d) “Ann Arbor," odinaan ge. Ann Arbor s/he tells him/her also

e) “Gga-ni-waawiidsemi," kido giiwenh wa mko. we will walk together s/he says apparently this bear

f) Bbaamsewaad giiwenh nshaawi-dbik. that they walk around/CONJ apparently through the night

a) 'After it had gotten dark, he set out walking.

b) That's how he came to meet this bear.

c) "Where ya headed?" the bear asked him.

d) "Ann Arbor," he replied.

e) "Let's walk together," the bear suggested.

f) So they walked around through the night.' 
The verbs in bold type in (131a) and (131f) are plain conjunct verbs, evident by their exclusive use of suffixes (i.e. $-d$ 'third person', -waad 'third person plural') to mark agreement for number and person, and by the absence of initial change. As Rhodes points out, rather than acting as dependent clauses as the traditional rule would dictate, they instead carry thematic content, acting as independent clauses instead. ${ }^{65}$ It is precisely this behavior that leads Rhodes to say: "[t]his traditional characterization of verb forms as independent versus dependent can be quite misleading to a nonAlgonquianist syntactician because of the great variety of syntactic contexts in which dependently inflectioned verbs appear, some of which are not obviously subordinate" (Rhodes 2006:6, 110-113).

While early on it was known that plain conjunct verbs may sometimes pose as independent clauses within certain contexts, the question remains: Why? No work to date gives an explanation of the exact mechanism at work which makes such behavior possible. Rhodes (1979) only highlights this phenomenon with a few examples, devoting only one section to the phenomenon. Jones and Coleman (1979) provide a more detailed description of this phenomenon in Kickapoo where they show that the conjunct order in Kickapoo serves to mark eventline structures, but they do not account for it either. This is obvious in their conclusion where they state:

\footnotetext{
${ }^{65}$ The verb gaa-zhi-nkweshkwaad 'that's how he came to meet this bear' in (131b) appears to me to be thematic as well, since it too moves the plot forward. In fact, this verb is actually quite pivotal to this passage of the story. He does not include this, however, in his analysis. As we will see, however, syntactical factors come into play which may affect the shape of plain conjuncts within discourse, i.e. conjuncts which appear with initial change, etc. In short, this verb is underlyingly a plain conjunct, but must appear with initial change due to the presence of the relative root izhi. Therefore, verbs such as gaazhi-nkweshkwaad may carry the eventline of a narrative as well, acting as independent clauses.
} 
(Jones and Coleman 1979:91)

"In light of our analysis here, it seems strange (at least from the perspective of narrative) that the mode that carries the eventline material is called conjunct in Algonquian literature, whereas the mode that primarily serves to carry background material is called independent. Undoubtedly these labels, which have been longestablished in Algonquian studies are due to the fact that isolated sentences were the primary objects of study, where the conjunct was not so apt to occur except in its more idiomatic and rather subordinate uses, e.g., locative and temporal expressions. Conjunct was thus adopted as a term to indicate its supposedly subordinate nature. It is not surprising that the more important eventline use of the conjunct was not even apparent then, since such use would only be recognized in the context of an entire text."

It is this behavior, however, which is relevant to our discussion of discourse markers, since what is really going on, I argue, is that the conjunct order of inflection itself is being borrowed, or exploited, for work at the discourse level in much the same way that individual lexical or grammatical items are exploited for use within discourse. Therefore, based upon what we know about the behavior of discourse markers, there is no need to try to reconcile both uses into one category. In short, within sentence grammars, conjuncts are dependent clauses, but in discourse (as we will see), they may be used to mark eventline structure.

Now, it should also be noted here that the selection of the conjunct to carry eventline structure is not random, just as the selection of many lexical or grammatical items at the sentence level is not random. Recall that for many of the discourse connectives that it was their specific lexical or grammatical use at the sentence level that was exploited for work at the discourse level, e.g. coordinating conjunction miinawaa which functioned at the sentence level to conjoin similar grammatical categories, but also was shown to 
conjoin larger discourse units above the sentence level as well. In this way, the conjunct too, is being exploited as well, since, as we will see, that it is the conjunct's connective and temporal immediacy features which lend themselves to work at the discourse level.

In the following sections, both the sentence level and discourse functions of the conjunct will be discussed. This discussion will show that it is the plain conjunct verb which is borrowed to mark the eventline structure of a story or narrative within discourse. Ultimately, I will show that the same mechanism which allows individual sentence level grammatical/lexical forms to be exploited for discourse work, is also at work to allow the use of TAM forms, morphological forms such as the conjunct, to be exploited for discourse work as well.

\subsection{Sentence level use of conjuncts}

\subsubsection{Dependent clauses}

Within sentence grammars, plain conjunct verbs usually function as dependent clauses, or subordinate clauses. For example, plain conjuncts may serve as temporal subordinate clauses, serve as complements of predicative words, or as embedded clauses. The point here though is that the use of the conjunct is syntactically subordinate, and cannot act as the predicative meat of a clause or phrase within sentence grammars. The following examples show these uses. For clarity, the conjunct verbs in question have been glossed to show more morphological structure than the other words around them. 
(132) Various uses of the conjunct in sentence grammars

a) Conjuncts as temporal subordinate clauses (Benjamin 2006, unpublished story)

Mewinzha omaa gii-maajii-anokiiyaan gegaa nisimidana daso-biboonagad long ago here PAST-start-work.1/CONJ almost thirty be so many years

iw wapii, onzaam niibowagiziwag ingiw bakaan gegoo ezhichigejig.

that time too much they are a lot those different thing those who did things

'A long time ago when I started working here almost thirty years ago, there would be too many people who did things differently.'

b) Conjuncts as complements of predicative words (text communication)

Mii ji-bi-de-dagoshinaan oodi Waashtanong nidizhaa.

DP FUT-come-enough-arrive.1/CONJ there Washington D.C. I am going there

'I will be back by then as I'm going to Washington D.C.'

c) Conjuncts as embedded clauses (Mille Lacs Session)

Gego anaamimishiken maanaadiziyan.

don't don't blame me ugly.2/CONJ

'Don't blame me that you are ugly.'

In (132a), there is no temporal word meaning when. It is the use of the conjunct here which gives it this temporal meaning. In (132b), the conjunct verb dagoshinaan appears with the predicative element mii, which normally dictates the use of conjunct verbs. In (132c), the conjunct maanaadiziyan functions as an embedded clause. 
The subordinate nature of the conjunct allows for an array of adjunct clauses, some of which are cause-and-effect, benefactive, or just clausal elaborations. As a translation effect, the translation of such clauses vary widely. Examples provided by my consultants are given below (with the exception of the last example).

(133) Adjunct clauses

a) Nigii-makadewaas abaasandekeyaan. I got sunburned bask in the sun.1/CONJ

'I got black from basking in the sun.'

b) Onzaam ina gidaadawin nitaa-ojibwemoyaan. because INTERR I have you beat know how-speak Ojibwe.1/CONJ 'Just because I got you beat in speaking the language.'

c) Miigwech wiidokawiyan. thank you help.2>1/CONJ

'Thank you for helping me.'

d) (Kegg 1991:94-95)

Mii dash ezhi-gagwejimagwaa, "Aaniin dash i'iw ezhichigeyaan," and then and so I ask them why exactly that what I am doing

waabamaawaad iniw nimanidoominensiman. see- $3>4 /$ CONJ that my beads

'As they looked at my beads, I asked them, "Why am I doing this?"” 
Note that many of the grammatical relations displayed between the plain conjunct and the independent verb in these sentences are established by asyndetic connection. For example, in (133a), there is nothing in that sentence which means from or as a result of. Rather, it is the asyndetic connection between the plain conjunct verb and the independent verb within contexts which allows a resultative relation to be selected and displayed between clauses.

4.1.2 Temporal immediacy and the connective feature of the conjunct

Conjunct verbs may appear within sentences in conjunction with independent verbs to show TEMPORAL IMMEDIACY between actions (following Rhodes 1979). This means that the use of the conjunct indicates that the action denoted by the conjunct verb occurs immediately after the action denoted by the preceding independent verb. This is illustrated in the following example provided by my consultants.

(134) Temporal immediacy

Ingii-kanoonaa Sara, gii-pabanaazomag. 1.PAST-call.3.OBJ/INDEP Sara PAST-chew out.1>3/CONJ

'I called Sara and chewed her out.'

There are a few things to note in this example. First, the independent order inflected verb ingii-kanoonaa is juxtaposed with the conjunct order inflected verb gii-pabanaazomag. Second, there is no connective word conjoining the two Ojibwe clauses, such as the one conjoining the English clauses within the accompanying translation, i.e. and. The plain 
conjunct gii-pabanaazomag is not acting as a subordinate clause however (as we would expect), but as an independent clause, showing temporal immediacy. In other words, the juxtaposition of the plain conjunct gii-pabanaazomag 'I chewed her out' with the independent clause ingii-kanoonaa 'I called her' denotes that the chewing out occurs immediately upon calling Sara, not sometime after calling her. This behavior is perhaps demonstrated better in an example cited by Rhodes (1979:111) for a related dialect of Ojibwe. In the following example, there are two actions: going to bed at night, and getting up in the morning, actions which cannot occur immediately one after another.

(135) Rhodes' example (Rhodes 1979:111)

a) *Miin'waa dash nbaagning gii-gwishmo, ge ggizheb gii-nishkaad. and then in bed PAST-lay down/INDEP also morning PAST-get up-3/CONJ 'Next he went to bed, and got up the [next] morning.'

b) Miin'waa dash nbaagning gii-gwishmo, ge ggizheb gii-nishkaa. and then in bed PAST-lay down/INDEP also morning PAST-get up/INDEP 'Next he went to bed, and got up the [next] morning.'

These two examples are identical except that the verb in the second clause of (135a) is inflected as a conjunct, while its counterpart in (135b) is inflected as an independent verb. Note that the conjunct order inflected verb gii-nishkaad (evinced by its conjunct suffix - $d$ 'third person') in (135a) is pragmatically ungrammatical precisely because, as Rhodes explains, the act of getting up cannot be both "immediate and in the morning" (Rhodes 1979:111). According to my consultants, these facts are true at Mille Lacs as well. 
While the Rhodes example above occurred with a connective, ge 'also', the example in (135) suggests that such occurrence is optional. In fact, this connective feature of the conjunct may be demonstrated in the following excerpt from a story where a series of actions are conjoined, all without the use of a connective.

(136) Connective feature of the conjunct (Clark 2003:55, audio)

Shke, wa'aw nookomisiban mii-ko gaa-paa-izhi-mamood o-mashkiki look this my grandmother used to went around picking this medicine gekendaagwadinig ge-inikaagod a'aw anishinaabe, gii-agoodood endaad, known to be used for that Indian she hanged it up her house

gii-paasang, gii-na'inang.

she dried it she put it away

'You see, my grandmother used to pick medicine known to be good for people, and would hang it in her house, dry it, and put it away.'

In the passage in (136), we find a string of three conjunct verbs linked together without a connective word or coordinating conjunction, such as miinawaa 'and' or gaye 'also'. While the English gloss can tolerate some absence of a connector (except for the last verb), the Ojibwe sentence shows that it may tolerate a total absence of any connectors at all and still remain grammatical. This suggests, then, that the conjunct not only denotes the immediacy of actions in relation to one another, but that the conjunct also possesses a connective feature which allows the stringing together of the very verbs denoting those actions. 


\subsubsection{Situational immediacy}

There is a very restricted context in which plain conjunct verbs are uttered in isolation, without a predicating word or element, to show what I call SITUATIONAL IMMEDIACY. I use the term situational here because speakers usually make these comments or remarks in response to an event, action, or situation which has just occurred, either in real time, or within a conversation. The term immediacy is used here since the use of plain conjuncts within these contexts is usually only grammatical when said in the moment to describe or make reference to the event or situation at hand; otherwise, the use of conjunct becomes awkward. For lack of a better comparison, the use of plain conjuncts in this fashion appears to be akin to the English usage of lone adjectives in same type of situations. For example, in English, when one sees or hears something they perceive to be beautiful, they might say: "Beautiful!". In the moment, the lone utterance of the adjectival word beautiful is grammatical and appropriate, but once taken out of that moment (i.e. telling a friend later that you saw a beautiful portrait), its use becomes awkward if not support by other periphrastic content, i.e. it was

\section{beautiful.}

Also, these statements may be accompanied by a heightened sense of emotion, either in a dismissive, joking, or surprising manner. In a way, this is similar to temporal immediacy described above except that the preceding clause is not an independent clause, but a real world event or situation. The following examples were uttered by my consultants at one time or another in relation to in the moment events. 
(137) Situational immediacy

a) Chi-gagaandenimag. (after talking about someone who got hurt) very-take pleasure in his/her pain.1 $>3 / \mathrm{CONJ}$

*Ingichi-gagaandenimaa.

1.great-take pleasure in his/her pain.3.OBJ/INDEP

'It's well enough for him!'

'He got what he deserved!'

b) Gii-wawaanimigooyang.

PAST-stump him/her.0>21/CONJ

(after having been asked a hard question)

*Ingii-wawaanimigoomin.

1.PAST-stump him/her.0>21/INDEP

'They stumped us!'

The use of conjuncts in this way is striking, especially given the traditional view that conjunct order verbs function only as subordinate clauses. In these examples, however, conjunct verbs, not independent order verbs, are able to function as independent clauses, even without a predicating element, if said immediately upon the occurrence of the anteceding event or situation. Once the moment is lost, the use of plain conjuncts become awkward. This is also evinced by the fact that when some of these phrases were elicited out of context, independent forms where provided by my consultants rather than the conjunct forms. For example, when I elicited from my consultants the phrase he got what he deserved, I got the independent form nigagaandenimaa, rather than the attested conjunct form above (137a). In short, the use of the conjunct in these restricted situations appears to signal the immediacy of an event or situation, possibly allowing speakers to 
mark these events as being more salient or foregrounded. As we will see in the sections to come, this is one of the features makes it a prime target for work at the discourse level.

\subsection{Discourse use of conjuncts}

The conjunct has uses at the discourse level as well. Though conjuncts at the sentence level function largely as subordinate clauses or adjunct clauses (except for the limited cases of the situational immediacy examples), they also have connective and temporal immediacy features as well. It is perhaps no surprise then that the conjunct would be exploited for these features, since connectivity and immediacy are both features which are well suited to create cohesion within narratives. Though largely syntactically subordinate in nature at the sentence level, at the discourse level, conjuncts may function as independent clauses. This was also the case with the Rhodes example for a related dialect of Ojibwe. Given that independent order verbs already serve this function (at least at the sentence level), the question becomes then: If both independent order verbs and conjunct order verbs may function as independent clauses within discourse, what roles do they each play within discourse? As we will see, both the conjunct and independent order have distinct functions within discourse. In short, conjuncts carry the eventline structure of a narrative, while independent order verbs carry background and quotation phenomena. Background content is defined here as anything that gives contextualization to eventline structures. Eventline is defined her as content which moves the story along, and is the backbone of the story. What it is meant by "backbone" is that if you were to make a list of only the eventline verbs, you would get a basic, albeit rudimentary, summary of the story in general. Note that this is also true for many of the 
Amazonian languages as well which utilize individual lexical items to mark the eventline structure. For example, recall that for the Amazonian language Yagua, the individual lexical items jiíta or jií marked a progression through a discourse along a main eventline, or a progression from one thematic paragraph to the next (see Payne et al. 1990:427 already cited above). Ojibwe, rather than utilizing individual lexical items to mark eventline structures, utilizes the general morphological form of the conjunct order of inflection to mark them, leaving independent order verbs to perform other discourse functions.

A summary listing of the conjunct verbs in the following story show indeed that it is the conjunct which carries the eventline. In this story, a young boy and his friend were talking and laughing on the side of a road when a old man walks by and thinks that they are laughing at him. While a few conjuncts occur within the quotations as sentence level conjuncts, all the other conjuncts are otherwise eventline verbs. Note also that all discourse conjuncts are glossed more narrowly than their surrounding words. This is intended to give the reader who is unfamiliar with Ojibwe the ability to see the morphological make-up of each discourse conjunct.

(138) Conjunct marking eventline structure (Eagle 1998:16-18, audio)

a) Aabiding imaa naaniibawiyaang jiigikana. one time there standing around.1P/CONJ near the road

b) Gaa-izhi-bimosed aw Zhimaaganish. IC.PAST-RR-walks by.3/CONJ that Zhimaaganish

c) Bimosed akiwenzii. walks by.3/CONJ old man 
d) Chi-ayizhinoo'oyangid iw.

very-pointing. $3>21 / \mathrm{CONJ}$ that

e) Gaa-pi-zhi-maajiiba'iweyaan endaayaan gii-kiiweyaan.

IC.PAST-come-RR-flee.1/CONJ my house PAST-go home.1/CONJ

f) Gaa-izhi-wiindamawagwaa indedeyiban nimaamaa, "Wayaa, akiwenzii

IC.PAST-RR-tell.1>3P/CONJ my late dad my mother wow old man

niinawind a'aw Biindigegaabaw ingaagiigidomin di jiigikana

we that Biindigegaabaw we are talking over there near the road

imbaapi'idimin niinawind bimosed a'aw Zhimaaganish i'iw.

we are laughing we when he walks by that Zhimaaganish that

Ingii-inenimigonaan ji-baapi'angid gii-ikido."

he thought of us to be laughing at him he said

g) Gaa-izhi-wiindamawid nimaamaa, "Ambe wiib, wiib a'awasemaa oodi IC.PAST-RR-tell.3 $>1 / \mathrm{CONJ}$ my mother come on quickly quickly that tobacco over there

o-miizh akiwenzii, wiindamaw gaawiin baapi'aasiwad."

go give it to him old man tell him not that you are not laughing at him

h) Apane-go inaabamid wa'aw.

always looks. $1>3 / \mathrm{CONJ}$ this

i) Gaa-wiindamawag, "Hey, Zhimaaganish, gaawiin giin gigii-paapi'igoosiin

IC.PAST-tell.1>3/CONJ hey Zhimaaganish not you we were not laughing at you

oodi, indinaa.

over there I tell him

j) Mii akiwenzii gii-paapid i'iw, "Ho, ho, ho, ho noozis."

that old man PAST-laugh.3/CONJ that ho ho ho ho grandson

k) Ke-go miish gii-wiindamawid indedeyiban naa nimaamaayiban, "Gego you see and then PAST-tell.3>1/CONJ my late father and my late mother don't

wiikaa aapiji gego ji-niibawiyan baapi'aaken ingiw akiwenziinyag naa

ever very don't to be standing don't laugh at him/her those old men and

mindimooyenyag," gii-ikido.

old women he said 
a) 'One time we were standing around near the road.

b) And then Zhimaaganish walked by.

c) He walks by.

d) He was really pointing that thing [his cane] around at us.

e) And so I started running to my house and went home

f) And I told my dad and mom here where they were: "Me and Biindigegaabaw were laughing near the road, laughing it up, when Zhimaaganish walks by, he thought we were laughing at him he said."

g) And my mom told me, "Come, hurry, hurry and go over there and give him tobacco, tell him you weren't laughing at him.

h) He was constantly looking at me.

i) And then I told him, "Hey Zhimaaganish, we weren't laughing at you," I told him.

j) The old man laughed about that, "Ho, ho, ho grandson.

k) And my mom and dad told me, "Never ever stand around laughing at old men and old women," she said.'

When we include the portions of the story which give setting or background information that gives contextualization to the eventline, we find the use of independent verbs along with sentence level use of conjunct verbs. This is shown from the following excerpt of this same story. For easy visibility, the discourse conjunct verbs appear in bold type and the independent verbs are underlined. Note also that the independent verbs are glossed more narrowly than their surrounding words in order to show their independent order morphological structure in more detail.

(139) Independent verbs carrying background information (Eagle 1998:16, audio)

a) Bezhig oshki-inini gwiiwisens gaa-wiijiiwag apane, ingii-wiijiindimin, one young man little boy who I was with always 1.PAST-with each other-1P/INDEP ingii-gikinoo'amaa-goomin di. 1.PAST-be taught- $X>1 \mathrm{P} \quad$ over there

b) Aabiding imaa naaniibawiyaang jiigikana. one time there standing around-1P/CONJ near the road 
c) Haaw niinawind imbaapi'idimin gaagiigidoyaang imaa, imbaapi'idimin. okay we 1.laugh together-1P talking there 1.laugh together-1P/INDEP

d) Gaa-izhi-bimosed aw Zhimaaganish gii-izhinikaazo akiwenzii. IC.PAST-RR-walks by-3 that Zhimaaganish PAST-be named so/INDEP old man

e) Aaniish naa imbaapi'idimin niinawind imbaapi'idimin imaa anooj ikidoyaang. well ........ 1.laugh together.1P we 1.laugh together.1P there various us saying

f) Waa! Bimosed akiwenzii. man! walks by-4/CONJ old man

a) 'One young boy that I was always with, we were together, going to school over there.

b) One time we were standing around near the road.

c) We're just laughing and talking, laughing it up.

d) And then Zhimaaganish walked by, his name was Zhimaaganish.

e) Well, we were just laughing with each other there saying various things.

f) Man, he walks by.'

What this example shows very nicely is the distribution of independent verbs alongside conjunct verbs. Though both conjunct and independent verbs are acting as independent clauses, i.e. sentences, their functions in discourse are different. For example, in this excerpt, the independent verbs in (139a, c, d, e) all carry information about background which, in turn, provides contextualization for the eventline. The type of background information provided in (139a, c, e) is largely setting information, while the type of background information in (139d) is participant information, e.g. the name of the old man in the story. This distribution of independent and conjunct verbs continues in this manner throughout the story, and is a common distribution seen in all the stories examined for this thesis.

There are complications though. While showing a nice distribution of independent and conjunct verbs within discourse, the above excerpt also reveals that there are two 
types of conjuncts being utilized: Plain CONJUNCTS and CHANGED CONJUNCTS. The difference between these two types of conjuncts is the use of initial change, an ablaut process which changes, mutates, replaces, or alters the initial vowel of a conjunct verb (see Bloomfield 1958:23, Nichols 1980:146-148, Mithun 1999:41). By definition, plain conjuncts do not exhibit initial change, while changed conjuncts do (hence their names as changed conjuncts). Changed conjuncts have specific functions within sentence grammars: 1) showing completive aspect, and 2) functioning as nominalized verbs, or participles (Fairbanks 2008, forthcoming, see also Nichols 1980:200). The occurrences of changed conjuncts in the above story, however, are not serving these functions. Rather, their occurrence appear (at least on the surface) to be triggered by the mere presence of the relative root izhi. Recall that izhi (and other relative preverbal elements) has a peculiar syntax, in that, it may cause (or appear to cause) its containing verbs to undergo initial change, while verbs within the same syntactical environment without izhi do not. ${ }^{66}$ Therefore, the occurrences of the changed conjuncts within the example above are easily explained away, since the relative preverb izhi appears to trigger the presence of changed conjuncts (see also Valentine 2001:963, 969 for Odaawaa in regards to relative roots within mii-clauses). In other words, but for the appearance of the relative preverb $i z h i$, these verbs would appear as plain conjuncts. This can be shown from an excerpt of another story. When izhi appears within the verbal complex, initial change occurs on the verbal complex (or on izhi itself if no other element precedes it), but verbs

\footnotetext{
${ }^{66}$ To say that a plain conjunct verb undergoes initial change assumes that speakers start with a plain conjunct in their heads and then apply a rule of initial change to form (or derive) changed conjuncts. The label initial change, a common term in Algonquian linguistics to refer to ablaut forms, also appears to imply a derivational process. It is unclear, however, whether speakers are actually deriving anything. Speaking about the distribution of plain and changed conjuncts in this way, however, is only a matter of convenience, as it is sometimes helpful to talk about changed forms as being derived from unchanged forms.
} 
without izhi remain as plain conjuncts. The verbs involved with the event line occur in bold type.

(140) izhi invokes initial change (Kegg 1991:104-105)
a) Mii imaa ani-biminizha'oyangid.
DP there start-chase. $3>1 \mathrm{P} / \mathrm{CONJ}$
b) Wayiiba azhigwa imaa biindigeyaang. soon now there we come inside/CONJ
c) Aaniish naa zegiziyaan ezhi-mawiyaan imaa biminizha'od. well -------- I am scared/CONJ IC.then I cry/CONJ there that s/he is chasing me/CONJ
c) “Gidaano-inin ji-wewiibishkaayan,” indig. I tried to tell you to hurry up she tells me
e) Miigo imaa ba-izhi-biindiged a'awgichi-animosh, gaa-izhi-biindiged that EMPH there IC.come-RR-enter.3/CONJ that big dog IC.PAST-RR-enter.3/CONJ a'aw animosh. that $\operatorname{dog}$
a) 'It started following us.
b) In a little while we went inside.
c) Well, I was scared and crying at being followed there.
d) "I told you to hurry," she said to me.
e) That big dog came right in, that dog came right in.'

The mii-clauses, mii imaa ani-biminizha'oyangid in (140a) and mii go imaa ba-izhibiindiged in (140e) are particularly revealing, since they show similar syntactic environments from which to make a comparison. For example, in the mii-clause without $i z h i$ in (140a), the preverbal element ani- 'starts' is left intact, while the preverbal element $b i$ - 'come' housed within the mii-clause in (140b) undergoes initial change to $b a$-. In 
short, it is the mii-clause containing $i z h i$ which shows initial change on the verbal complex.

The fact that the conjunct verb carries the eventline structures of narratives may help to explain another syntactical snafu involving the mii-clauses themselves, since they too employ the use of both the conjunct order verbs and independent order verbs within discourse. Earlier work has characterized mii as primarily requiring the use of conjunct verbs, largely relegating cases involving independent verbs as rare cases or rare constructions (see Rhodes 1998:289). While it has been well known that mii may sometimes occur with independent verbs, especially with independent order negative clauses (Nichols 1980:118, Rhodes 1998:287), the use of mii dash, or its contracted form miish, with independent order verbs, as it turns out, is not so rare a phenomenon within discourse. ${ }^{67}$ In fact, these occurrences (especially those occurring with non-negative clauses) are quite consistent within discourse, even across speakers. Once such case occurs within the story from above about the old man who got mad because he thought a couple of kids were laughing at him.

(141) mii dash with independent verbs (Eagle 1998:16-18, audio)

a) Gaa-zhi-wiindamawagwaa indedeyiban nimaamaa omaa eyaawaad: IC.PAST-RR-tell.1>3P/CONJ my late dad my mom here where they are "Wayaa akiwenzii niinawind a'aw Biindigegaabaw ingaagiigidomin di wow old man we that Biindigegaabaw we are talking over there

\footnotetext{
${ }^{67}$ This use of mii dash or miish with independent order verbs can be found quite commonly in older texts such as the those originating from Bois Fort (a Minnesota reservation) within the 1919 William Jones collection of stories. These occurrences are not limited to the Bois Fort texts, however, as mii dash or miish can be found to occur with independent verbs quite frequently in modern texts as well. Many of these examples occur within this thesis.
} 
jiigikana imbaapi'idimin niinawind bimosed a'aw Zhimaaganish i'iw. near the road we are laughing we when he walks by that Zhimaaganish that

b) Ingii-inenimigonaan ji-baap'angid gii-ikido." he thought of us as that we were laughing at him he said

c) Ke gaawiin gidaa-baapi'aasiig chi-aya'aag. see not you should not laugh at them elders

d) Mii gaa-inendamaan iw. that what I thought that

e) Miish ingii-nishki'aanaan akiwenzii, mii izhinoo'oyangid i'iw omitigom. and then we made him mad old man DP him pointing at us that his stick

f) Gaa-zhi-wiindamawid nimaamaa, "Ambe wiib, wiib a'aw asemaa oodi IC.PAST-RR-tell.3>1 my mom come on quickly quickly that tobacco over there o-miizh akiwenzii, wiindamaw gaawiin baapi'aasiwad..." go give it to him old man tell him not that you were not laughing at him

a) 'And I told my dad and mom here where they were:

"Me and Biindigegaabaw were laughing near the road, laughing it up, when Zhimaaganish walks by,

b) He thought we were laughing at him he said."

c) You see, you shouldn't laugh at elders.

b) That's what I thought.

c) And then we went and made the old man angry, pointing his stick at us.

d) And my mom told me, "Come, hurry, hurry and go over there and give him tobacco, tell him you weren't laughing at him...",

The eventline verbs gaa-zhi-wiindamawagwaa 'and I told [dad and mom]' and gaa-zhiwiindamawid 'and [my mom] told me' occur in (141a,f), but nestled in between these events in (141c-e) is the narrator's commentary which gives contextualization to these events, i.e. that one should not laugh at elders, that he knew that, but that he and his friend made the old man mad anyways. Within the background commentary, miish occurs with independent order verb ingii-nishki'aanaan 'we made him mad', instead of conjunct order inflection. Note, however, that when miish is involved with verbs 
functioning within the eventline structure that the conjunct is triggered. This can been seen later on in this same story. Examine the following.

(142) miish with conjunct order verbs (Eagle 1998:18, audio)

a) Mii bijiinag gii-minwendamaan.

DP finally that I was happy

b) Ingii-ni-giiwe, wahaa, gii-ni-baapaapiyaan naa ni-nagamoyaan

I went home wow PAST-start-laugh.1/CONJ and start-sing.1/CONJ

dabwaa-ni-maajaayaan.

before I started to leave

c) Mii bijiinag gii-minwendamaan gii-miinag asemaan.

DP finally that I was happy that I gave him tobacco

d) Ke-go miish gii-wiindamawid indedeyiban naa nimaamaayiban, "Gego wiikaa see and then PAST-tell.3>1/CONJ my late dad and my late mom don't ever

aapiji gego ji-niibawiyan baapi'aaken ingiwakiwenziinyag naa

very don't be standing around don't laugh at him those old men and

mindimooyenyag" gii-ikido.

old women s/he said

a) 'I finally felt good about it.

b) I started home, man, and I started laughing and started singing before I left.

c) I finally was happy when I gave him tobacco.

d) And then my mom and dad told me, "Never ever stand around laughing at old men and old women," she said.'

What these examples involving miish show is that when the verbs connected to the miicomplex are carrying background information, the verb appears as an independent order 
verb. If carrying eventline information, the verb appears with conjunct order inflection. ${ }^{68}$ This same sort of process can be also seen with another mii-complex miish i'iw, which also has a similar narrative advancing function similar to miish (see also Fairbanks, forthcoming). This can be easily seen with the mii-complex miish i'iw as well. When the verb connected to miish i'iw is involved with the eventline, it occurs with conjunct inflection. When the verb occurs within background commentary, it occurs with independent order inflection. This is shown in the following excerpts from two stories. In the first excerpt in (143), the narrator lists the events which occurred during a trip to set a net for tullibees. In (144), the story is about the time the narrator met a "MooniyaaLady", but before recounting her encounter, the narrator provides a rather lengthy background about what a Mooniyaa-Lady is (only partially given here).

(143) miish i'iw within eventline structures (Kegg 1991:80-81)

a) Gaawiin igo gichi-gisinaasinoon, mii ezhi-gawishimoyaang imaa jiigibiig, not EMPH not very cold then RR-lay down-1P/CONJ there shore ezhi-gawishimoyaang imaa jiigibiig ganawenimaad iniw odasabiin, RR-lay down-1P/CONJ there shore as she watches him/her that her net

jiichiigawiganebinag imaa zhingishinaang, apane go ezhi-anoozhid scratch. $1>3 / \mathrm{CONJ}$ there as we lie there always EMPH has me do

ji-jiichiigawiganebinag. to scratch her back

b) Mish i’iw, miish i'iw maadaajimod. and then..... and then..... start telling stories.3/CONJ

\footnotetext{
${ }^{68}$ Lone mii occurs in (139a,c) and is connected to conjunct order verbs as well. These, however, are sentence level functions of the deictic particle mii (see Fairbanks, forthcoming, for a detailed discussion on the functions of mii).
} 
a) 'It wasn't very cold so we lay down there on the shore where she could watch the net and I scratched her back as we lay there; she always had me scratch her back.

b) Then she started to tell stories.'

(144) miish i'iw within background structures (Kegg 1991:142-145)

a) Mewinzha dashiwidi ayi'ing ingii-izhaamin, iwidi akeyaa long ago but over there that one place 1.PAST-go.1P/INDEP over there way

ayi'ing, waasago iwidi, amanj iidog ezhinikaadegwen that one place far EPMH over there I don't know DUBIT what it must be called

anishinaabewinikaadeg.

what it is called in Indian

b) Ingii-o-manoominikemin iwidi.

1.PAST-go and-rice-1P over there

c) Miish i'iw ingii-pi-waabamigonaanig iko ingiw anishinaabeg and then... 1.PAST-come-see.3P $>1 \mathrm{P} \quad$ used to those Indians

ini-onaagoshig, bi-mawadishiyangidwaa.

towards evening to come visit us

d) Bimishkaawag.

go by boat.3P/INDEP

e) Gaawiin gaye awiiya odaabaanan, gaawiin gegoo miikana. not also someone car not something road

f) Miish a'aw bezhig ikwe babaa-naaniibawid. and then that one woman around-stands.3/CONJ

g) Enda-onizhishi a'aw mindimooyenh. very-pretty/INDEP that old woman

h) Mii gaa-pi-izhi-nawadinid, “Awenen gidoodem, ” indig. DP IC.PAST-come-RR-grab.3>1/CONJ who your clan she tells me

a) 'Long ago we went over there, a long way, I don't know what it is called in Indian.

b) We went over there to rice.

c) The Indians came to see us for a visit in the evening. 
d) They got around in boats.

e) There were no cars and no road.

f) There was one lady standing around.

g) That old lady was nice-looking.

h) She came and grabbed me, asking me, "What is your totem?",

As expected, when the verb occurring with miish i'iw occurs within the eventline structure, the verb appears with conjunct order inflection; but when occurring within background structures, it appears with independent order inflection.

Overall, what these data show is that while the conjunct has very specific roles at the sentence level as marking subordinate clauses, it also has a very major role within discourse, to carry the eventline structure of a story or narrative. This is evident even where the use of the mii-complexes mii dash, miish, or miish i'iw are involved. With them too, the conjunct carries the eventline, while the independent carries background information. It is this elevation of the conjunct for work at the discourse level which shows that it is not only individual lexical or grammatical items which are targets for discourse work, but entire inflectional systems as well. 


\subsection{Conclusion}

I have accomplished two things in this thesis. First, I have identified and characterized many of the common discourse markers occurring in Ojibwe which heretofore have been largely unexplored. For example, while both linguists and second language learners have known about the existence of the Ojibwe marker isa, its exact function within discourse has largely been unknown. Many of the Ojibwe mystery particles like isa, such as sha, gosha, goda, naa, for example, share a similar fate. We know they exist, and that native speakers use them, but their functions as mystery particles have been exactly that, mysteries. As a result, many listings for mystery particles within dictionaries and pedagogical grammars have been labeled simply as 'emphatics', 'particles', 'fillers', or get no label at all. When a meaning is attributed to these elements, they are usually poorly defined. The Ojibwe discourse connectives such as inashke, though more transparent in their meaning, also have their fair share of mysteries. For example, if you were to ask an Ojibwe language teacher in our community what the word inashke ('see!, look!, hear!') meant, the answer you would normally hear is: "It means behold!" The immediate difficulty which arises from this definition is, of course, first figuring out what the meaning of the archaic word behold is, how it is used within English, and then how to correlate that use back into Ojibwe which may or may not coincide with its usage within English. In the end, such explanations based upon archaic English words are no explanation at all. Many Ojibwe discourse markers are just misunderstood, and this appears to be the reason why discourse markers do not appear much in second language speaker speech (at least from my point of view). Therefore, one of the objectives in writing this thesis was not only to document and 
describe these elements (which in itself is an important endeavor), but to begin to bring to light the various meanings and functions of these elusive elements so that they may start to become common knowledge among the second language speaker community. Once these markers become common knowledge and commonly taught, they then can start to make their way into the speech patterns of the second language speakers, who in turn may start to use them with their babies in the home. Otherwise, we risk losing (in a very short amount of time mind you) a whole array of markers that provide nuance and color to the language.

The second thing that I have accomplished is the expansion of Schiffrin's initial characterization of discourse markers to include the trends of discourse markers crosslinguistically. This has revealed that a variety of elements may function as discourse markers across languages, including: individual words, lexicalized phrases, clitics, affixes, and preverbs; and that markers may occur in a host of positions within an utterance or sentence: utterance initially, utterance internally, utterance finally, and in second position. Ojibwe has been especially instructive in regards to this cross-linguistic evidence since it not only employs the use of utterance initial words for discourse work (such as inashke, awenh, aaniish), but also second position clitics and particles (such as idash/-sh, isa, sha, gosha, naa), and a relative preverb (izhi). Other languages with rich morphological structures like Ojibwe also show a tendency toward the use of clitics and affixes as discourse markers. What this indicated to me was that speakers may use the linguistic/grammatical machinery available to them in the language in order to accomplish discourse work. This was also supported by the fact that some speakers of indigenous languages of the Americas, such as Tojolab'al and Yucatec Maya, have 
incorporated the use of markers from contact languages (such as Spanish) alongside the use of their own indigenous markers. Other machinery exploited for discourse use is the lexical or grammatical inventory existing in language itself. The cross-linguistic data have consistently shown that many lexical or grammatical items are exploited for their sentence level use for work at the discourse level. This sort of raiding of the inventory is not restricted to individual words, affixes, clitics, or preverbs, however, but also to entire inflectional systems. Recall that Ojibwe makes regular use of conjunct order verbs (verbs which are subordinate clauses at the sentence level, but have other 'connecting' features as well) to mark the eventline of narratives or stories. In other words, verbs which normally mark subordinate clauses at the sentence levels may act as independent clauses at the discourse level. This is a striking example of the exploitive nature of the discourse marking mechanism within languages.

While I have examined a wide range of elements that I have analyzed as discourse markers in Ojibwe, more research is necessary in order to determine the full range of uses for each marker described in this thesis. A whole paper could be devoted to the exposition of each one of these markers, and it is hoped that further research will either confirm, or provide further elaboration (or even corrections) on the various functions and meanings that I have described here. One of the difficulties that I encountered in describing the various functions of Ojibwe discourse markers is trying to reconcile the seemingly unrelated functions that some of them have. For example, I have characterized the particle mii as having various functions (e.g. deictic particle, aspectual marker, veridical marker, and command softener) which, on the surface, do not appear to emanate from a single underlying core function or meaning. Indeed, if such a core function 
existed (and it might), it would be a more accurate characterization to identify that underlying core meaning or function which then might account for mii's various surface functions. For mii, I have not been able to reconcile its various surface functions as emanating from a single underlying function. I suggest a few possible reasons for this. First, my descriptions might be inadequate, either because of a scarcity of data (which might not show the full picture of mii's distribution), or I just inaccurately described the data. Inadequate descriptions could mask the underlying core function. Second, there might be more than one mii, in which case, we are dealing with homophones - a situation which might result from two (or more) words which sound alike synchronically, but have different origins historically. This could also undermine an accurate description. Third, mii might have different surface functions which are not reconcilable with one single underlying function per se, but whose various surface functions might be typical for deictic particles like mii. In other words, our current linguistic knowledge of deictic particles might not be at a level sufficient enough to be able account for what seem to be unrelated functions. Future discourse marker research would need to try to reconcile seemingly unrelated functions that a single discourse marker might have, either by more accurate description based upon more language data, or by accounting for them with new available research.

There are still a great many elements in Ojibwe which I consider to be discourse markers that I did not describe in this thesis. Among these are the interjective type words which I am only beginning to grasp. These include: aapidekamig 'what in the world', wayaa hay 'oh my', and poh or poowaj 'gotcha', chaninge'e 'yuck, ew' (a female's terms), oy yooy 'there there (said to or about babies crying)', etc. While I have supplied 
some various translations for these interjectives, they need more exploration to get a better idea of their general use and meaning. I also did not include the description of the temporal discourse marker azhigwa 'now, and then', which has various sentence and discourse level uses. This is another marker which is still largely unexplored. The exposition of these various markers (as well as others not mentioned here) will have to await further research. 


\section{REFERENCES}

Abraham, Werner. 1991. Discourse particles: descriptive and theoretical investigations on the logical, syntactic and pragmatic properties of discourse particles in German. Amsterdam: Benjamins.

Agbayani Brian, and Chris Golston. In press. Second-position is first position. Festchrift for Raimo Anttila, ed. by Sheila Embleton, Giorgios Giannakis and Konrad Koerner. Amsterdam: John Benjamins.

Aijmer, Karin, and Anne-Marie Simon-Vandenbergen. 2006. Introduction. Pragmatic markers in contrast, ed. by Karin Aijmer and Anne-Marie Simon-Vandenbergen, 110. Boston: Elsevier.

Altenberg, Bengt. 2006. The Function of adverbial connectors in second initial position in English and Swedish. Pragmatics in Contrast, ed. by Karin Aijmer and AnneMarie Simon-Vandenbergen, 11-37. Boston: Elsevier.

Andersen, Gisle. 1998. The pragmatic marker like from a relevance-theoretic perspective. Discourse markers: descriptions and theory, ed. by Andreas Jucker and Yael Ziv, 147-170. Philadelphia: Benjamins.

Anderson, Marge. 1999. The Circle of great conversation. Unpublished translation of Mille Lacs 1999 State of the Band Address.

Ariel, Mira. 1998. Discourse markers and form-function correlations. Discourse markers: descriptions and theory, ed. by Andreas Jucker and Yael Ziv, 223-260. Philadelphia: Benjamins.

Aubid, David. 2008. Email communication.

Author unknown (Jim Clark?). 2006. Mii giitagoshing ziigwanike. Ojibwe Inaajimowin 8(3).13 Onamia: Mille Lacs Band of Ojibwe.

Baraga, Frederic. 1992 [1878, 1880]. A dictionary of the Ojibway language. Reprint. St. Paul: Minnesota Historical Society Press.

Bazzanella, Carla. 1990. Phatic connectives as interactional cues in contemporary spoken Italian. Journal of Pragmatics 14, 629-647.

Benjamin, Millie. Date unknown. Ikido nimaamaanaan indizhitwaawininaan. Unpublished document.

Benjamin, Millie. 2006. Elderly Advisory Council. Unpublished story. 
Bible. 1875. Iu otoshki-kikindiuin au Tebeniminung gaie Bemajiinung Jesus Christ: ima Ojibue inueuining giizhitong [The new testament of Our Lord and Saviour Jesus Christ translated into the language of the Ojibwa Indians. New York: American Bible Society.

Biq, Yung. 1990. Conversation, continuation, and connectives. Text 10(3), 187-208

Bishop, Ruth G. 1979. Tense-aspect in Totonac narrative discourse. Discourse studies in Mesoamerican languages 1: Discussion, ed. by Linda K. Jones, 31-68. Summer Institute of Linguistics Publications in Linguistics, 58. Dallas: Summer Institute of Linguistics and the University of Texas at Arlington.

Blakemore, Diane. 1987. Semantic constraints on relevance. Blackwell, Oxford

Blakemore, Diane. 2004. Discourse markers. The handbook of pragmatics, ed. by Laurence R. Horn and Gregory Ward, 221-240. Malden: Blackwell Publishing.

Bloomfield, Leonard. 1958. Eastern Ojibwa: grammatical sketch, texts and word list, ed. by Charles F. Hockett. Ann Arbor: University of Michigan Press.

Brinton, Laurel J. 1996. Pragmatic markers in English: grammaticalization and discourse functions. Berlin: Mouton de Gruyter.

Brinton, Laurel J. 2003. Historical discourse analysis. The handbook of discourse analysis, ed. by Deborah Schiffrin, Deborah Tannen \& Heidi E. Hamilton, 138-160. Malden: Blackwell Publishing.

Brody, Jill. 1987. Particles borrowed from Spanish as discourse markers in Maya languages. Anthropological Linguistics 29(4), 507-521.

Brody, Jill. 1989. Discourse markers in Tojolabal Maya. Papers from the annual regional meeting of the Chicago Linguistic Society, 15-29.

Brody, Jill. 1995. Lending the 'unborrowable': Spanish discourse markers in indigenous American languages. Spanish in four continents: studies in language contact and bilingualism, ed. by C. Silva-Corvalán, 132-148. Washington, DC: Georgetown University Press.

Bruti, Silvia. 1999. In fact and infatti: the same, similar or different. Pragmatics 9(4), 519-533.

Cadiot, A., O. Ducrot, B. Fraden, and T. Nguyen. 1985. Enfin, marqueur métalinguistique. Journal of Pragmatics 2(3), 199-239. 
Clark, James. 1998. Oshkaabewis Native Journal 5(2), 8-9. Bemidji: Bemidji State University.

Clark, James. 2003. Oshkaabewis Native Journal 6(1-2), 50-63. Bemidji: Bemidji State University.

Clark, James. 2008. Personal communication.

Cook, J. 1990. An indexical account of the Japanese sentence-final particle ne. Discourse Processes 13(4), 507-539.

Cook, Haruko. 1992. Meanings of non-referential indexes: a case study of the Japanese sentence-final particle $n e$. Text 12(4), 507-539.

Davidsen-Nielsen. 1996. Discourse particles in Danish. Pre-Publications of the English Department of Odense University, Denmark, No. 69, August.

Eagle, Melvin. 1998. Oshkaabewis Native Journal 5(1).8-85. Bemidji: Bemidji State University.

Fairbanks, Brendan. 2008. In press. All about mii. Papers of the Thirty-ninth Algonquian Conference, ed. by Karl Hele, London: University of Western Ontario.

Fleischman, Suzanne. 1985. Discourse functions of tense-aspect oppositions in narrative: toward a theory of grounding. Linguistics 2, 851-882

Fleischman, Suzanne. 1986. Evaluation in narrative: the present tense in medieval "performed stories." Yale French Studies 70, 199-251.

Fraser, Bruce. 1990. An approach to discourse markers. Journal of Pragmatics 14, 383395.

Fraser, Bruce. 1996. Pragmatic markers. Pragmatics 6(2), 167-190.

Fraser, Bruce. 1998. Contrastive discourse markers in English. Discourse markers: descriptions and theory, ed. by Andreas Jucker and Yael Ziv, 301-326. Philadelphia: Benjamins.

Fraser, Bruce. 1999. What are discourse markers? Journal of Pragmatics 31, 931-952.

Fuji, S. 2000. Incipient decategorization of mono and grammaticalization of speaker attitude in Japanese discourse. Pragmatic markers and propositional attitude, ed. by G. Andersen and T. Fretheim, 85-118. 
Goddard, Ives. 1978. Central Algonquian languages. Handbook of North American Indians, ed. by Bruce G. Trigger, 583-587. Washington: Smithsonian Institution

Goddard, Ives. 1996. Languages. Handbook of North American Indians, ed. by Ives Goddard. Washington: Smithsonian Institution

Goldberg, Julia. 1980. Discourse particles: an analysis of the role of $y^{\prime} k n o w$, I mean, well, and actually in conversation. PhD Dissertation, Cambridge University.

Grimes, Joseph E. 1975. The thread of discourse. The Hague: Mouton.

Hakulinen, Auli, and Eeva-Leena Seppänen. 1992. Finnish kato: from verb to particle. Journal of Pragmatics 18, 527-549

Hakulinen, Auli. 1998. The use of Finnish nyt as a discourse particle. Discourse markers: descriptions and theory, ed. by Andreas Jucker and Yael Ziv, 83-97. Philadelphia: Benjamins.

Hansen, Mosegaard. 1998. The function of discourse particles. A study with special reference to spoken French. Amsterdam: Benjamins.

Hayes, Bruce. 1995. Metrical stress theory. Chicago: The University of Chicago Press.

Jones, Linda Kay and Ned R. Coleman. 1979. Towards a discourse perspective of modes and tenses in Kickapoo narratives. Linda Kay Jones (ed.), Discourse studies in Mesoamerican languages, 1: Discussion, 69-95. Summer Institute of Linguistics Publications in Linguistics, 58. Dallas: Summer Institute of Linguistics.

Jones, William. 1917. “The birth of Nänabushu.” Ojibwe texts, Volume VII, Part 1, ed. by Truman Michelson, 2-7, New York: American Ethnological Society.

Jones, William. 1919. Ojibwe texts, Volume VII, Part 2, ed. by Truman Michelson. New York: American Ethnological Society.

Jones, Linda Kay and Ned R. Coleman. 1979. Towards a discourse perspective of modes and tenses in Kickapoo narratives. Discourse studies in Mesoamerican languages, 1: Discussion, ed. by Linda Kay Jones, 69-95. Summer Institute of Linguistics Publications in Linguistics, 58. Dallas: Summer Institute of Linguistics and the University of Texas at Arlington..

Jucker, Andreas H. 1993. The discourse marker well: a relevance theoretic account. Journal of Pragmatics 19, 433-452. 
Jucker, Andreas H. and Sara W. Smith. 1998. And people like just you know like 'wow': discourse markers as negotiating strategies. Discourse markers: descriptions and theory, ed. Andreas H. Jucker and Yael Ziv, 171-201. Philadelphia: Benjamins.

Jucker, Andreas H. and Yael Ziv. 1998. Discourse markers: introduction. Discourse markers: descriptions and theory, ed. Andreas H. Jucker and Yael Ziv, 1-12. Philadelphia: Benjamins.

Kegg, Maude. 1991. Portage Lake: memories of an Ojibwe childhood, ed. by John D. Nichols. Minneapolis: University of Minnesota Press.

Koike, Dale. A. 1996. Functions of the adverbial ya in Spanish narrative discourse. Journal of Pragmatics 25(2), 267-279

Kroon, Caroline. 1998. A framework for the description of Latin discourse markers. Journal of Pragmatics 20(2), 205-223.

Kwong, Luke 1989. The Cantonese utterance particle la the accomplishment of common understandings in conversation. Papers in Pragmatics 3(1), 39-87.

Longacre, Robert E. 1976. 'Mystery particles' and affixes. Papers from the twelfth regional meeting of the Chicago Linguistic Society, 468-475. Chicago: Chicago Linguistic Society.

Maschler, Y. 1997. Discourse markers at frame shifts in Israeli Hebrew talk-ininteraction. Pragmatics 7(2), 183-211.

Maschler, Y. 1998. Rotse lishmoa keta? Wanna hear something weird/funny? Segmenting Israeli Hebrew talk-in-interaction. Discourse Markers: descriptions and theory, ed. by A. Jucker and Y. Ziv, 13-60. Philadelphia: Benjamins.

Massam, Diane, and Donna Starks, and Ofania Ikiua. 2006. On the edge of grammar: discourse particles in Niuean. Oceanic Linguistics 45(1), 191-206.

Matsumoto, Y. 1988. From bound grammatical markers to free discourse markers: history of some Japanese connectives. Proceedings of the $14^{\text {th }}$ annual meeting of the Berkeley Linguistics Society, ed. by S. Axmaker, A. Jaisser, and H. Singmaster, 340-51.

Mille Lacs Band of Ojibwe Official Website. 2008. www.millelacsojibwe.org.

Mille Lacs Band of Ojibwe. 1998. Baswewe "echo." Nay Ah Shing Schools Mille Lacs Band of Ojibwe. 
Mithun, Marianne. 1999. The languages of native North America. New York: Cambridge University Press.

Na-gan-i-gwun-eb. 1893. Letter to Reverend Gilfillan. Gilfillan letters, 1883-1913. Minnesota Historical Society.

Nakao 1995. Japanese-English English-Japanese dictionary. New York: Ballantine Books.

Nichols, John D. 1980. Ojibwe morphology. PhD dissertation, Harvard University.

Nichols, John D. and Nyholm, Earl. 1995. A concise dictionary of Minnesota Ojibwe. Minneapolis: University of Minnesota Press.

Nichols, John D (editor). 1988. An Ojibwe text anthology. London, Ontario: Centre for Research and Teaching of Canadian Native Languages, University of Western Ontario.

Nichols, John D. 1995. "Weak of heart - strong of heart: approaching the narrative art of Dedaakam of Mille Lacs." Oshkaabewis Native Journal 2(1), 49-68.

Ningewance, Patricia M. 2004. Talking gookom's language: learning Ojibwe. Lac Seul, Ontario: Mazinaate Press.

Onodera, Noriko Okada. 1994. Pragmatic change in Japanese: conjunctions and interjections as discourse markers. Georgetown PhD dissertation in linguistics.

Onodera, Noriko Okada. 1995. Diachronic analysis of Japanese discourse markers. Historical Pragmatics, ed. by A. Jucker, 393-437.

Or, W. 1997. Chinese temporal adverbs of succession and overlap. Paper presented at the annual convention of the Midwest Modern Language Association, Chicago.

Park, Yong-Yae. 1999. The Korean connective nuntey in conversational discourse. Journal of Pragmatics 31(2), 191-218.

Payne, Doris L., and Thomas E. 1990. Yagua. Handbook of Amazonian languages, ed. by Desmond C. Derbyshire and Geofrey K. Pullum, (2).249-474. Berlin: Mouton de Gruyter.

Payne, Thomas E. 1997. Describing morphosyntax: a guide for field linguists. Cambridge: Cambridge University Press.

Redeker, Gisela. 1990. Ideational and pragmatic markers of discourse structure. Journal of Pragmatics 14(3), 367-381. 
Rhodes, Richard 1979. Some aspects of Ojibwa discourse. Papers of the Tenth Algonquian Conference, ed. by William Cowan, 102-117. Ottawa: Carleton University.

Rhodes, Richard. 1998. The syntax and pragmatics of Ojibwe mii. Papers of the $29^{\text {th }}$ Algonquian Conference, ed. by David H. Pentland, pp. 286-294. Winnipeg: University of Manitoba.

Rhodes, Richard. 2006. Clause structure, core arguments and the Algonquian relative root construction. The Belcourt Lecture. Paper originally delivered before the University of Manitoba on 20 March 1998. Winnipeg: Voices of Rupert's Land.

Richardson, Peter. 1991. Tense, discourse, style: the historical present in "Sir Gawain and the Green Knight.” Neuphilologische Mitteilungen 92, 343-349.

Richardson, Peter. 1995. Tense, structure, and reception in Porsteins Páttr stangarholggs. Arkiv för nordisk filologi 110, 41-55.

Sadler, Misumi. 2006. A blurring of categorization: the Japanese connective de in spontaneous conversation. Discourse Studies 8(2), 303-323.

Salser, J.K. and Neva. 1976. Some features of Cubeo discourse and sentence structure. Discourse grammar: studies in indigenous languages of Colombia, Panama, and Ecuador (2), 253-272. Summer Institute of Linguistics Publications in Linguistics and Related Fields, 52(2). Dallas: Summer Institute of Linguistics.

Solomon, Julie. 1995. Local and global functions of a borrowed native pair of discourse markers in a Yucatan Maya narrative. Proceedings of the $21^{\text {st }}$ annual meeting of the Berkeley Linguistic Society, Feb. 17-20. General session and parasession on historical issues in sociolinguistics, ed. by J. Ahlers, 287-298. Berkeley: Berkeley Linguistics Society.

Schiffrin, Deborah. 1987a. Discourse markers. Cambridge: Cambridge University Press.

Schiffrin, Deborah. 1987b. Discovering the context of an utterance. Linguistics 25(1).1132.

Schiffrin, Deborah. 2003. Discourse markers: language, meaning, and context. The handbook of discourse analysis, ed. by Deborah Schiffrin, Deborah Tannen \& Heidi E. Hamilton, 54-75. Malden: Blackwell Publishing.

Schourup, Lawrence. 1985. Common discourse particles in English conversation. $\mathrm{PhD}$ Dissertation. New York: Garland. 
Schwenter, Scott. 1996. Some reflections on o sea: a discourse marker in Spanish. Journal of Pragmatics 25, 855-874.

Shemesh, Rivka. 2006. Direct discourse markers in Mishnaic Hebrew. Journal of Semitic Studies 51(1), 45-58.

Shloush, Shelley. 1998. A unified account of Hebrew bekicur 'in short': relevance theory and discourse structure considerations. Discourse Markers: Descriptions and Theory, ed. Andreas H. Jucker and Yael Ziv, 61-82. Philadelphia: Benjamins.

Silva, Giselle, and Alzira de Macedo. 1992. Discourse markers in the spoken Portuguese of Rio de Janeiro. Language Variation and Change 4, 235-249.

Smits, Aletta. 2002. How writers begin their sentences. Complex beginnings in native and learner English. LOT, Utrecht.

Staples, Lee. 2007. Miigwanens. Unpublished story.

Tchizmarova, Ivelina K. 2005. Hedging functions of the Bulgarian discourse marker xajde. Journal of Pragmatics 37, 1143-1163.

Torres, Lourdes. 2006. Bilingual discourse markers in indigenous languages. The International Journal of Bilingual Education and Bilingualism, 615-625.

Trask, R. L. 1993. A dictionary of grammatical term in linguistics. Routledge: New York.

Treuer, Anton. 1997. The importance of language: a closer look. Oshkaabewis Native Journal, 3-11. Bemidji: Indian Studies Publications, Bemidji State University.

Treuer, Anton (editor). 2000. Omaa akiing. Princeton, New Jersey: Western Americana Press.

Treuer, Anton(editor). 2001. Living our language. St. Paul: Minnesota Historical Society Press.

Valentine, J. Randolph. 2001. Nishnaabemwin reference grammar. Toronto: University of Toronto Press.

Vasco, Ildiko. 2000. The interplay of Hungarian de (but) and is (too, either). Pragmatic Markers and Propositional Attitude, ed. by G. Andersen and T. Fretheim, 255-264. Amsterdam: Benjamins.

Vincent, Diane. 1993. Les ponctuants de la langue et autres mots du discours. Quebec: Nuit blanche. 
Wilson, Deirdre. 1994. Discourse markers: social and cognitive approaches. Paper delivered at conference on Linguistic Processes in Communication, University of Wales, Bangor.

Wilson, Deirdre and Dan Sperber. 1993. Linguistic form and relevance. Lingua 90, 1-25.

Wilson, Deirdre and Dan Sperber. 2004. Relevance theory. The Handbook of Pragmatics, ed. by Laurence R. Horn and Gregory Ward, 607-632. Malden: Blackwell Publishing.

Wouk, Fay. 1998. Solidarity in Indonesian conversation: the discourse marker kan. Multilingua 17(4), 379-406.

Zavala, Virginia. 2001. Borrowing evidential functions from Quechua: the role of pues as a discourse marker in Andean Spanish. Journal of Pragmatics 33, 999-1023.

Ziv, Yael. 1998. Hebrew kaze as discourse marker and lexical hedge: conceptual and procedural properties. Discourse markers: Descriptions and Theory, ed. by Andreas H. Jucker and Yael Ziv, 203-222. 